\title{
Estimating Brand Equity from Aggregate Data
}

\author{
by \\ Sudhir Voleti \\ Submitted in Partial Fulfillment \\ of the \\ Requirement for the Degree \\ Doctor of Philosophy
}

Supervised by

Professor Paul Nelson

William E. Simon Graduate School of Business

University of Rochester

Rochester, NY

2009 


\section{Curriculum Vitae}

The author was born in Narsapur, India, on March 5, 1977. He attended the Birla Institute of Technology, Ranchi from 1994 to 1998 and graduated with a Bachelor of Engineering degree in Mechanical Engineering. He joined Cognizant Technology Solutions as a Programmer Analyst in 1998 and worked there up to mid 1999. He attended the Indian Institute of Management, Calcutta from 1999 to 2001 and graduated with a Post Graduate Diploma in Management (M.B.A. equivalent). He worked as an analyst for the management consulting practice of Accenture Ltd, Mumbai in 2001-02 and as a lecturer of Marketing at the ICFAI Business School, Hyderabad in 2002-03. He came to the University of Rochester in 2003 to pursue graduate studies in Marketing. He received a Master of Management Science Degree in 2006. He pursued his doctoral research in the areas of Brand Equity Management and Measurement under the guidance of Professor Paul Nelson, Professor Sanjog Misra and Professor Dan Horsky. 


\section{Acknowledgements}

I would like to thank my faculty advisors Prof. Paul Nelson, and Prof. Sanjog Misra for their time, patience, guidance and support in my research endeavors. I express thanks to the head of the Marketing Department at Simon and a member of my thesis committee, Prof. Dan Horsky for his encouragement and support. I also thank other marketing faculty, in particular Dr. Paulo Albuquerque, and the Ph.D. students at the Simon School with whom I have interacted and exchanged ideas. I thank seminar participants at the INFORMS Marketing Science Conference, 2006 for their questions and comments.

I remain thankful to my parents, Lt. Col. Voleti Panduranga Vithal and Smt. Voleti Lalitha. This dissertation would not have been possible without the support of my wife, Archana Rai Voleti. Last but not least, I dedicate this work to my little girl, Annapurna Voleti. 


\section{Abstract}

Brands are now widely recognized as among a firm's most valuable assets. Hence the assessment of the value or equity of brand assets has attracted a lot of academic and practitioner attention in recent years. Various Brand Equity (henceforth, BE) measurement schemes have been proposed and utilized. These methods rely either on surveys or experimental approaches that require costly or complex data collection at the individual level, on valuation approaches requiring firm financial data, or on aggregate level product-market outcomes often utilizing fixed effects approaches that interpret brand intercepts as BE.

In this dissertation, I propose and estimate a model of BE measurement based on a random effects approach that uses readily available data sources. In contrast to current methods based on aggregate data that model BE as a fixed unknown constant for each brand, I posit that realized BE values in any market are outcomes of a complex process that is difficult to specify completely, but which can be modeled as draws from an underlying distribution. The model is data-driven in that it does not explicitly specify how $\mathrm{BE}$ is generated from the underlying complex system. Rather, it makes identifying assumptions on the shape and domain of the unknown distribution based on the profit maximizing actions of rational economic agents. I develop the general conceptual framework for the model and adapt this framework to three different applications in the course of three essays: (1) Brand Equity as a Revenue Multiplier, an application based on

a national dataset; (2) The Brand Equity of Private Labels, an application based on a multi-retailer dataset; and (3) Spatial Patterns in Brand Equity, based on a multi-market dataset. 
The random effects approach presents a simple, single-stage BE estimation and inference procedure that yields six distinct advantages: (i) an implicit baseline product for reference, (ii) easily interpretable results because $\mathrm{BE}$ is now a residual measure, (iii) useful downstream BE measures such as a BE dollar metric, which aids in assessing the financial value of brand assets, (iv) the use of a reduced form specification that does not make assumptions about the nature of the game and behavior of the players involved, (v) the incorporation of SKU based competitive effects modeled in product-attribute space, and all this (vi) in the presence of complex product structures and branding hierarchies. The tradeoff is that parametric assumptions on the underlying BE distribution need to be made.

The first essay introduces the BE measurement problem, develops the modeling approach, tests the model empirically on national data in the beer category, and seeks to validate the analysis results using independent, external sources. I find that the results bear face and external validity, and parsimoniously account for inter-product competition. The second essay is an application of the proposed model to BE estimation of Private Labels in addition to those of National Brands. The conceptual model is adapted to a multi-retailer setting in which the Private Labels are all Store Brands, and response heterogeneity across retailers is incorporated using a random coefficients specification. I find that there is considerable heterogeneity in BE across brands and retailers, that some but not all Private Labels have BE and thereby are 'brands', and that Private Label BE estimates present evidence favoring an 'economic benefits and costs' value proposition. 
The third essay examines whether the demographic characteristics of U.S. metropolitan markets in conjunction with geospatial location information aid in understanding the level and distribution of $\mathrm{BE}$ across these markets. Unlike traditional spatial analyses that assume a multivariate normal error covariance structure, in this study I develop a distribution-free approach based on generalized least squares. I find heterogeneity in BE levels across brands and markets, substantial spatial correlation between the BEs of beer brands across geographic markets for many of the brands sampled, and a distinct regional pattern in the BE distribution. I find that the demographic composition of markets are related to the BE for many of the brands in the sample and further, that the parameter estimates of the demographic BE antecedents are substantially improved by the incorporation of spatial information into the model. 


\section{Contents}

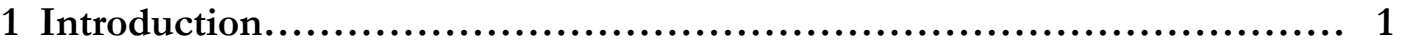

1.1 Overview of the Research Problem............................. 1

1.1.1 Conceptual Model...................................... 6

1.1.2 Restrictions on the Brand Equity term................ 13

1.1.3 Modeling Competition............................. 15

2 Literature Review................................................... 20

2.1 Brand Equity Measurement................................ 20

2.2 Brand Equity Measurement in Private Labels..................... 23

2.3 Spatial Association in Marketing Outcomes......................... 24

3 Brand Equity as a Revenue Multiplier............................... 27

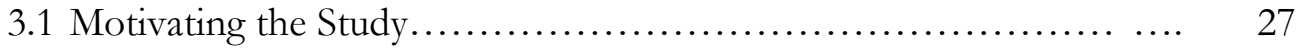

3.2 Empirical Investigation.................................... 28

3.2.1 Data and Variables................................. 28

3.2.2 Estimated Model................................. 34

3.2.3 Discussion of Results................................ 36

3.2.4 External Validation...................................... 43

3.2.5 Managerial Implications and Summary $\ldots \ldots \ldots \ldots \ldots \ldots \ldots . \quad 46$

4 The Brand Equity of Private Labels................................ 49

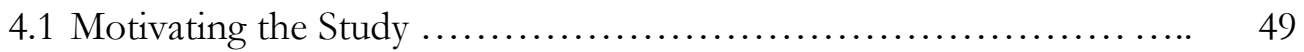

4.2 Empirical Investigation...................................... 50

4.2.1 Data and Variables.................................. 50 
4.2.2 Estimated Model................................ 53

4.2.3 Discussion of Results............................ 56

4.3 Managerial Implications and Summary.......................... 62

5 Spatial Patterns in Brand Equity.................................. 65

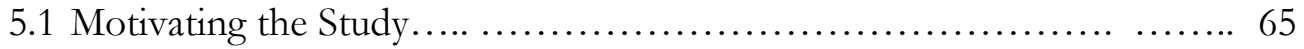

5.2 Data and Variables............................................... 66

5.3 Model Development.......................................... 68

5.3.1 Brand Equity Estimation............................. 68

5.3.2 Spatial BEM Analysis................................ 70

5.4 Discussion of Results.......................................... 76

5.4.1 Spatial Effects Discussion......................... 83

5.5 Managerial Implications and Summary........................... 88

6 Conclusion........................................................ 92

6.1 Brand Equity as a Revenue Multiplier.............................93

6.2 The Brand Equity of Private Labels............................. 94

6.3 Spatial Patterns in Brand Equity............................. 95

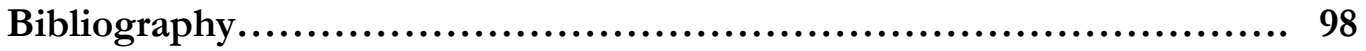

Appendix A: Data Sources....................................... 108

Appendix B: Estimation Details for the General Model................... 109

Appendix C: On Model Identification ................................114 


\section{List of Tables}

1. U.S. Beer Market Summary of Variables (Essay 1)................... 128

2. U.S. Beer Market Summary Statistics by Brand (Essay 1)................ 129

3. Main Effects of the Revenue Regression (Essay 1)................... 130

4. Illustration of Competition Effects............................ 131

5. $\quad$ BEM Estimates (Essay 1) ................................... 132

6. Brand Valuation of Budweiser and Miller (Essay 1) $\ldots \ldots \ldots \ldots \ldots \ldots \ldots$

7. Multi-Retailer CSD Data, Summary of Variables (Essay 2).............. 134

8. Summary of Retailer Characteristics (Essay 2) $\quad$.

9. Main Effects of the Revenue Regressions (Essay 2).................. 136

10. Random Coefficients in Main Effects (Essay 2).................... 137

11. BEM Estimates and 95\% HPD Interval by Retailer (Essay 2)........... 138

12. Ex Post Variable Correlations (Essay 2)............................ 139

13. Summary of Analysis Variables (Essay 3)....................... 140

14. U.S. Multi-Market Data, Brand Characteristics (Essay 3)............... 141

15. U.S. Metropolitan Markets - Characteristics (Essay 3)................... 142

16. Main Effects Summary (Essay 3) ............................... 143 


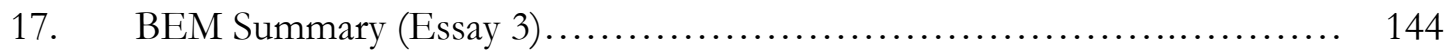

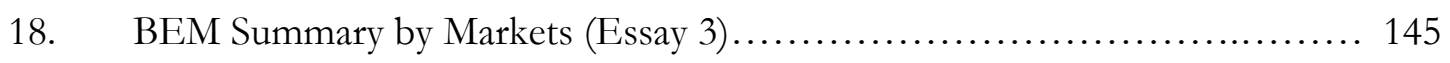

19. OLS Analysis of Pooled BEMs (Essay 3).......................... 146

20. Spatial Association Test Results (Essay 3) .......................... 147

21. BEM OLS Spatial Results Summary (Essay 3)........................ 148

22. BEM GLS Spatial Results Summary (Essay 3)..........................149

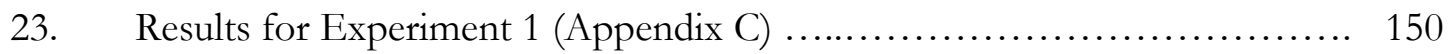

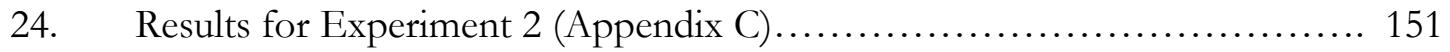

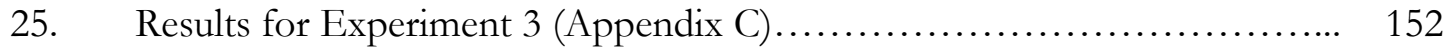

26. Results for Experiment 4 (Appendix C) .......................... 153 


\section{List of Figures}

1. Price-BEM Relation for National and Private Labels......................... 154

2. Box-Plots of the Coefficients of Packaging Variables..................... 155

3. Box-Plots of the Coefficients of the Promotion and Distribution

Variables........................................................... 156

4. BEMs Box-Plots for Six U.S. Regions.............................. 157

5. BEMs Box-Plots for Six Brands.................................. 158

6. BEM Distribution for the 4 Largest Brands by Market Share.............. 159

7. BEM Distribution for the Next 4 Largest Brands by Market Share.......... 160

8. BEM Distribution for the 4 Smallest Brands by Market Share ............. 161

9. Variation in Model Fit against the Level of $Z$........................ 162

10. Variation in Model Fit against the Dispersion in $Z \ldots \ldots \ldots \ldots \ldots \ldots \ldots \ldots . \ldots \ldots$

11. Recovery of Z Values under Different Distributional Assumptions............164 


\section{Chapter 1}

\section{Introduction}

\subsection{Overview of the Research Problem}

Brands have long been recognized as being one of the most valuable assets owned by a firm. The term brand equity encompasses the notion of the value of the brand asset. Federal Reserve Board data from the fourth quarter of 2004 show that intangible assets comprise $52 \%$ of the total assets of non-farm, non-financial businesses, up from $33 \%$ in 1985. For consumer packaged goods (CPG) firms, these intangible assets are primarily Brand Equity (henceforth, BE). Hence, it is no surprise that managers and academics alike show a strong interest in measuring and managing BE. Ailawadi, Lehmann and Neslin (2003) summarize the consensus definition of BE in the marketing community as "the marketing effects or outcomes that accrue to a product with its brand name compared to those that would accrue if the product did not have its brand name".

In an increasingly competitive marketplace, many CPG firms compete in portfolios of brand and product offerings. This has led to product proliferation and given rise to complex branding structures involving master brands, sub-brands, umbrella brands, variants, branded differentiators, endorsements, etc. (Aaker, 1994). The advent of complex branding structures and product proliferation presents challenges for the clean and consistent measurement of BE.

In the Marketing literature, extant BE measurement schemes broadly fall into one of three classes (Ailawadi et al, 2003; Keller and Lehmann, 2006) - those based on 
primary data collected from consumers, those based on product-market outcomes, and those based on firm financial data.

The first class of measurement methods takes the consumer perspective and uses tools such as experiments, conjoint studies and surveys to collect individual level data on brand preferences, attitudes, willingness to pay, etc. and then seeks to transform these data into a BE construct. The difficulties with this approach are that data collection is costly because it is at the individual level, analysis involves subjective responses and a well-documented mismatch exists between stated preference and revealed preference (Park and Srinivasan, 1994).

The second class of measurement schemes uses aggregate data on revealed product-market outcomes. It often adopts a fixed effects approach wherein the data are analyzed in a regression framework and brand intercepts are interpreted as BE. In fixed effects models, one brand (called the reference brand) is normalized ex ante to a fixed value of $\mathrm{BE}$ (typically zero) and the $\mathrm{BE}$ of all the other brands is measured relative to this fixed baseline value. A concern with using a fixed effects approach is that in situations involving complex branding structures, brand intercepts are often multicollinear with product attributes at the supra- or sub- brand level (for instance, dummy variables for whether the brand is 'Imported' or 'Regional') and with other levels in the brand-product hierarchy (such as stock-keeping unit or 'SKU', and sub-brand or 'variant'). Redefining the reference baseline to include more than one brand could break the multi-collinearity, but it jeopardizes BE interpretation. Another fix would be to use multiple stages of regressions wherein the collinear attributes and brand-product levels are filtered out in successive stages such that finally, only BE remains. The concern here 
is that estimation efficiency is adversely affected in a multiple stage setting compared to a single stage one (see, e.g., Ainslie and Rossi, 1998). There are also non-regression methods that utilize aggregate product-market outcome data such as simple revenue differences from Ailawadi et al (2003) but these methods necessarily fix the BE of some baseline brand a priori.

The third class of BE measurement schemes relies on financial and stock market data at the firm level. The issue here is that most firms in the CPG space are multi-brand firms and so inferring the $\mathrm{BE}$ of individual brands within the firm is difficult, if not impossible (Keller and Lehman, 2006).

In each of the three essays in this dissertation, I use models based on aggregate data but propose a random effects rather than a fixed effects approach to estimating BE. A random effects specification implies that for any market or set of markets under study, there exists an underlying $\mathrm{BE}$ distribution from which the BEs of particular brands are drawn. In contrast to current approaches that model BE as a fixed, unknown constant for each brand, I posit that realized BE values in a market are the outcomes of a complex system and can be viewed as draws from some unknown, underlying probability distribution ${ }^{1}$. The complex system assumption follows through because a large number of market participants - firms, retailers, other channel partners and consumers - each maximize their own unique objective functions and operate under their own, unique sets of constraints amidst a variety of random shocks and events. Attempts to structurally

\footnotetext{
${ }^{1}$ Such an assumption is not unreasonable in that the outcomes of many complex phenomena in the natural sciences such as the intensity of earth quakes, of volcanic eruptions, etc. and in the social sciences such as the distribution of wealth in a society, city sizes in a country, firm sizes in an industry, membership sizes in social networks, etc. appear to follow empirical regularities that obey power law relationships. Studies of such power law regularities are part of active research in a variety of fields. The posited BE pattern can similarly be viewed as a complex-system outcome regularity expressed as a distribution.
} 
model such complex systems run a high misspecification risk, and hence making relatively fewer assumptions on the nature of the complex system is advantageous.

Having proposed the existence of an underlying BE distribution, I impose two conditions on it - (1) a restriction on the domain of the distribution based on the profit maximization imperative of rational economic agents, and (2) a parametric form for the distribution that facilitates identification and inference. To guard against the risk that it is a particular parametric form rather than BE that is driving the results, I check for model sensitivity to different distributional forms which satisfy condition (1). The proposed model estimates $\mathrm{BE}$ as the brand-specific component of revenue shorn of the impact of both observed and unobserved non-brand product attributes as well as other marketing mix and category factors. Thus, in adherence to the BE definition, the model creates, for each particular brand, a unique reference baseline that has identical marketing mix investments including product features but no brand name and then compares the estimated product-market outcome for this "unbranded equivalent" with that of the branded entity. The ratio of these constructed values is what I term the BE Multiplier (BEM).

I endeavor to demonstrate that given complex branding structures for the products under study and syndicated secondary data, the random effects approach has some advantages over alternative product-market outcome specifications such as simple revenue differences (Ailawadi, Lehman and Neslin, 2003), fixed effects approaches (e.g., Kamakura and Russell, 1993) and structural modeling in equilibrium frameworks (Goldfarb, Lu and Moorthy, 2008). The advantages include the separation of brands from non-brand attributes (in contrast to the revenue differences specification), the 
separation of brands from other elements in the branding structure and an implicit reference brand normalization instead of an a priori one (in contrast to fixed effects based approaches), an intuitive interpretation of results as residual BE after all other effects have been accounted for, obtaining a BE measure that is directly monetizable into a dollar metric, the modeling of competition levels with an intuitive interpretation of cross-product substitution effects, and all this within a simple reduced form specification. The tradeoff is that a distributional assumption on BE is made.

In the first essay, titled 'Brand Equity as a Revenue Multiplier', I estimate the proposed model on aggregate beer data at the monthly stock-keeping unit (SKU) level from supermarket stores nationwide. Results from the empirical implementation of the model are validated by comparing main effects to those in the extant literature, and brand asset values from BEM to valuations from external sources.

In the second essay, titled 'The Brand Equity of Private Labels', I apply the model to a multi-retailer setting using aggregate data for carbonated soft drinks from five regional retailers to estimate the $\mathrm{BE}$ of Private Labels in those retailers. One adaption made is the incorporation of random coefficients to account for response heterogeneity across retailers. Traditional approaches using fixed effects models typically use a Private Label as the reference brand and a priori normalize its BE to zero. In the proposed random effects approach on the other hand, the reference baseline is implicitly chosen during the estimation process. I leverage the proposed model's ability to implicitly generate a baseline for the brands in the data, and estimate Private Label BEs.

The third essay, titled 'Spatial Patterns in Brand Equity', brings in a spatial dimension to BE. I posit that the BE of a brand in a market is likely to be influenced by 
that in nearby markets on account of both demand side effects (influence on and of consumer brand preferences) and supply side effects (regional logistics and distribution effects due to relationships with channel partners). The model is applied to multi-market aggregate beer data in 49 U.S. metropolitan markets and BEs are estimated in each of these markets. Thereafter, I investigate the existence of spatial patterns in the level of BE across regional clusters of neighboring U.S. metropolitan markets, and also examine the role of market demographics in conjunction with geospatial location information in determining the level of brand equity.

The rest of this chapter is structured thus: Section 1.2 develops a conceptual framework for the random effects BE model. In subsection 1.2.1, I propose restrictions on the $\mathrm{BE}$ distribution, discuss their rationale and finally develop an econometrically implementable model. In subsection 1.2.2, I develop a model of attribute based competition effects at the SKU level.

\subsection{Conceptual Model}

In developing a conceptual framework for BE, I distinguish the market response to the brand name of a product from that to all other (non-brand) characteristics of the product. The implication that $\mathrm{BE}$ in a product is distinct and separable from the rest of the product follows from the BE definition itself. 'Market response' above refers to product-market outcomes that result from the interactions of brands and consumers with one another in the market, and 'product characteristics' refer to not just the physical features or attributes of a product but also to characteristics such as price, promotion and distribution. In effect, 
Market Response $=f\left(\begin{array}{lll}\text { Category } & \text { Marketing Mix } & \text { Brand } \\ \text { Charateristics } & \text { Actions } & \text { Equity }\end{array}\right)$.

The aim is to identify the impacts that category characteristics and a product's marketing mix actions have on the product-market outcome of interest and, in effect, remove them from the observed product-market outcome measure, thereby, leaving a more accurate estimate of $\mathrm{BE}$ (the effect of brand name on that outcome). The combined impact of the first two factors described in equation (1.1) provides an estimate of the product-market outcome that would result for an unbranded product that has identical product characteristics to those of the branded product. Once the estimated outcome for this "unbranded equivalent" (henceforth, UE) is removed from the branded product's observed outcome, what is left is the impact of the brand name itself - the proposed BE measure.

I choose revenue as my metric of market response for a variety of reasons. A major reason is that revenue is the product of price and quantity and both price and quantity are likely to be functions of both the marketing mix and BE. Thus, by modeling revenue as the dependent variable, I circumvent the need to have either price or quantity as an explanatory variable, greatly simplifying the analysis. Another reason is that whether firms choose to 'buy' market share for their brands by lowering prices or attempt a 'demand-pull' for their brands while maintaining prices, the brand's revenue earned captures either effect well (Ailwadi, Lehmann and Neslin, 2003). In addition, revenue is recorded in scanner data at every level of product aggregation, has previously been used as a BE metric (e.g., Ailawadi, Lehmann and Neslin, 2003), and is amenable to the economic rationale underlying the proposed parametric restrictions. 
I also utilize a general multiplicative formulation that accommodates various response shapes and rates including both diminishing and increasing returns (Lilien, Kotler and Moorthy, 1992). Thus, I now have:

$$
\underset{\text { Revenue }}{\text { Product }}=\left[\begin{array}{c}
\text { Revenue of the } \\
\text { Unbranded Equivalent }
\end{array}\right] *\left[\begin{array}{l}
\text { Brand Equity } \\
\text { Multiplier }
\end{array}\right] .
$$

Thus, the Brand Equity Multiplier (BEM) for a particular branded product is simply a multiplier of the product-market outcome that would accrue to its UE (i.e., an unbranded product with exactly the same product attributes, promotion, price and distribution). Further, the multiplicative functional form finds supporting evidence in both the experimental and empirical literatures. Experimental studies (e.g., Bousch et al, 1987), find that brand associations raise or lower the perceived evaluation of other product characteristics suggesting that the brand in some sense scales up or down the perceived value derived from product attributes. In empirical studies, Sullivan (1998) analyzes the prices of 'twin automobiles' (manufactured in the same plant with the same set of features but selling under different brand names) using a multiplicative model and shows that twin automobiles command different prices in the used-car marketplace because of differences in perceived quality attributable to brand name.

Equation (1.2) implies that the accuracy of the BEM measure depends on how well one estimates the revenue that would accrue to the UE. For each branded product analyzed, this requires a reasonably complete description of its marketing mix as well as general category conditions so that their impacts on revenue can be accurately estimated and used to derive the revenue particular to each branded product's unique UE. To spell this notion out further, I identify the revenue of the UE of each brand as a multiplicative 
function of the marketing mix decisions of the brand, general category level sales drivers, and a random error term (non-systematic revenue shocks that can be interpreted as measurement error). This results in a more detailed expression for product revenue.

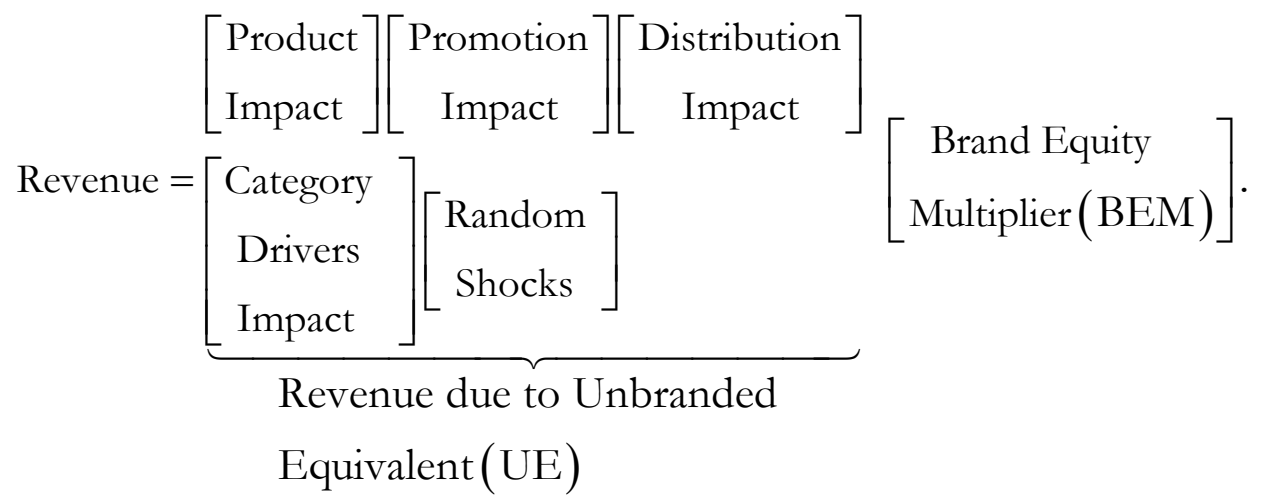

In equation (1.3), I decompose revenue into broad determinants of product demand, labeled "Revenue Components", and use observable measures (detailed in the data sections) to capture the effect of each Revenue Component. In addition, since a brand typically encompasses numerous SKUs, each with different marketing mix characteristics, an analysis of SKU rather than brand level revenues allows for more accurate estimation. Each SKU associated with each particular brand, thus, has its own unique UE. The transition from equation (1.2) to equation (1.3) implies that the nonbrand part (the UE), now yields the revenue response due to every product characteristic unrelated to brand name.

The implicit assumption above is that non-brand characteristics are free of all brand influences. This assumption if violated would lead to an endogeneity problem. The endogeneity of marketing mix and $\mathrm{BE}$ is a concern common in all $\mathrm{BE}$ measurement methods. In the proposed approach, the endogeneity of marketing mix elements with $\mathrm{BE}$ is driven mainly by a simultaneity problem in that marketing mix elements influence 
$\mathrm{BE}$ and vice versa. One solution is the use of an instrumental variables, but it is difficult to find any instrument (if such exists) that is correlated with marketing mix but is independent of BE. The alternative would be track BE and marketing mix levels from the moment of brand introduction forward but such data are hard to obtain. Thus, the endogeneity problem has not been addressed in BE measurement studies and it remains an acknowledged limitation in this dissertation as well.

Coming back to equation (1.3), the Revenue Components include factors such as category level drivers (e.g., market size and seasonality), product attributes (both search attributes and experience attributes can be included and survey data can easily be integrated into the framework), promotion and distribution factors and random shocks that represent measurement error. Together, I assume that these constitute the revenue that would accrue to the UE SKU because these characteristics are defined at the SKU level. The brand part of the SKU's market response aggregates all brand level influences and manifests as a multiplier of the revenue of the UE SKU for every focal branded SKU in the data. These considerations give rise to a more explicitly defined revenue expression detailed in Equation (1.4).

$$
\begin{aligned}
\text { Revenue }_{j t} & =e^{\beta_{0}} \prod_{a=1}^{A}\left(\text { Product }_{a, j}\right)^{\beta_{1, a}} \prod_{c=1}^{C}\left(\text { Promotion }_{c, j t}\right)^{\beta_{2, c}} \\
& \prod_{d=1}^{D}\left(\text { Distribution }_{d, j t}\right)^{\beta_{3, d}} \prod_{p=1}^{P}\left(\begin{array}{l}
\text { Category } \\
\text { Drivers }_{p, t}
\end{array}\right)^{\beta_{4, p}} e^{u_{j t}} \mathrm{BEM}_{b(j)},
\end{aligned}
$$

where $j$ refers to a particular SKU, $b$ to a particular brand, $b(j)$ to the brand $b$ that contains $\operatorname{SKU} j$, and $t$ to each particular time period. The various measures outlined 
below for the UE Revenue Components are referred to generically. $u_{j t}$ is the random error.

$\mathrm{BE}$ manifests as a multiplier of the UE's revenue. It summarizes the systematic revenue response due to unexplained brand level influences. As mentioned previously, I posit that realized $\mathrm{BE}$ values are random effects drawn identically and independently (IID) from some underlying unknown distribution, say $F(\lambda)$ with parameters $\lambda$.

Observed SKU level variables (such as size and packaging attributes) are likely to only partially capture variation in SKU revenue because the complete list of variables would typically not be available. To illustrate, consider a scenario where SKU $A_{0}$ of brand A has more attractive packaging than does SKU $A_{1}$ of the same brand and consistently outsells the latter. In the absence of a measure for the 'attractiveness of packaging' (and other such variables not captured in the data), a general term to capture SKU-specific aggregate effects that are unobserved by the researcher could possess significant explanatory power. I denote this SKU specific latent factor $\eta_{j}$. A similar argument applies at the variant level. Consequently, I define a variant-specific latent factor $\xi_{v}$. Thus, I now have four error terms as variance components in the model at the brand, variant, SKU and SKU-period levels. More could be added depending on the branding structure. To facilitate econometric analysis, I follow standard procedure and linearize equation (1.4) by taking logs on both sides. Thus, I arrive at a general, conceptual model for the proposed random effects approach: 


$$
\begin{aligned}
\left.\operatorname{Ln}_{\left(\text {Revenue }_{j t}\right.}\right)=\beta_{0}+\left[\sum_{a=1}^{A} \beta_{1, a} \operatorname{Ln}\left(\text { Product }_{a, j}\right)+\xi_{v}+\eta_{j}\right] \\
+\sum_{c=1}^{C} \beta_{2, c} \operatorname{Ln}\left(\text { Promotion }_{c, j t}\right)+\sum_{d=1}^{D} \beta_{3, d} \operatorname{Ln}\left(\text { Distribution }_{d, j t}\right) \\
+\sum_{p=1}^{P} \beta_{4, p} \operatorname{Ln}\left(\text { Category Drivers }_{p, t}\right)+\operatorname{Ln}\left(\mathrm{BEM}_{b(j)}\right)+u_{j t} .
\end{aligned}
$$

Here, $\operatorname{Ln}\left(\right.$ Revenue $\left._{j t}\right)$ is the $\log$ of revenue for SKU $j$ in period $t$, $\operatorname{Ln}\left(\right.$ Product $\left._{a, j}\right)$ is a set of A variables denoting observable product attributes, (likewise for variables describing the Promotion, Distribution and Category Drivers Revenue Components). $\boldsymbol{\beta}$ is the $(1+A+C+D+P) \times 1$ vector of coefficients. Further, I include an inter-product competition term Competition ${ }_{j t}$ that measures the level of attributebased competition. I include it as a variable in the $\operatorname{Ln}\left(\right.$ Promotion $\left._{j t}\right)$ group because it is a function of the promotional activity of competing SKUs. The modeling of the Competition $_{j t}$ term is described in Section 1.2.2. For the dummy variables in equation (1.5), the formulation $x^{\beta}$ is replaced by $e^{\beta x}$, which upon taking logs becomes $\beta x$ rather than $\beta \ln x$. This is done to avoid the $\log$ of zero problem.

As described previously, the terms $\left\{\operatorname{Ln}\left(\mathrm{BEM}_{b(j)}\right), \xi_{v}, \eta_{j}\right\}$ aggregate the revenue effect of latent factors, and unobserved or otherwise unaccounted for product attributes at the brand, variant and SKU levels respectively. They manifest as IID components in a variance decomposition of a composite error term $\varepsilon_{j t}$. The number of IID variance components depends on the branding structure prevalent in the category under study. 
Hence, in this case there are four variance components - one each for brand

$$
\begin{array}{r}
\left(\operatorname{Ln}\left(\operatorname{BEM}_{b(j)}\right)\right), \operatorname{Variant}\left(\xi_{v}\right), \operatorname{SKU}\left(\eta_{j}\right) \text { and SKU-period }\left(u_{j t}\right): \\
\varepsilon_{j t}=\operatorname{Ln}\left(\operatorname{BEM}_{b(j)}\right)+\xi_{v}+\eta_{j}+u_{j t} .
\end{array}
$$

I make assumptions on the distributions of each of these variance components according to the application context. Following Allenby and Ginter (1995), I assume that the variance components at the variant, SKU and SKU-period level are symmetric in shape and are distributed mean zero normal ${ }^{2}$. Thus:

$$
\begin{aligned}
\xi_{v} & \sim \operatorname{IIDN}\left(0, \sigma_{\xi}^{2}\right) ; \\
\eta_{j} & \sim \operatorname{IID} N\left(0, \sigma_{\eta}{ }^{2}\right) ; \\
u_{j t} & \sim \operatorname{IID} N\left(0, \sigma_{u}^{2}\right) .
\end{aligned}
$$

I detail the restrictions surrounding the remaining variance component $\operatorname{Ln}\left(\mathrm{BEM}_{b(j)}\right)$ in the next subsection.

\subsubsection{Restrictions on the Brand Equity Term}

The BEM is estimated through the use of a random variable $\operatorname{Ln}\left(\mathrm{BEM}_{b(j)}\right)$ defined at the brand level. I argue that a brand must provide added value to the product or its producer would not utilize the brand name and would rather sell it as its unbranded equivalent. That is, given the multiplier formulation, BEM must be greater than or equal to one (i.e.,

2 To check whether the normal distribution is appropriate, I observe the pattern formed in a histogram of residuals of a simple OLS regression of $\mathrm{Ln}$ (Revenue) on the explanatory variables (including brand intercepts) in each instance of model application. I find that the distribution has a single mode at the mean and appears fairly bell-shaped. 
$\operatorname{Ln}\left(\operatorname{BEM}_{b(j)}\right) \geq 0$ ). If a particular brand's BEM were less than one, then its unbranded equivalent would earn more revenue than it does. Since the only difference is in the two scenarios is the brand name, it must be that the brand name actively destroys product value. Correspondingly, the firm would be better off withdrawing the brand name from the product. $^{3}$ In sum, the BEM measure for each brand is modeled as an asymmetric random effect constrained to lie on $[1, \infty)$ due to the firm's rational, profit maximizing behavior. For $\operatorname{Ln}(\mathrm{BEM})$, this restriction translates into a "positive" support [0,infinity).

The positive support for the parametric distribution of $\operatorname{Ln}\left(\operatorname{BEM}_{b(j)}\right)$, the implicit assumption that every brand's BEM comes from this parametric distribution, and the fact that the four "error" terms $\left(\operatorname{Ln}\left(\mathrm{BEM}_{b(j)}\right), \xi_{v}, \eta_{j}\right.$ and $\left.u_{j t}\right)$ are distributed independently of one another and defined at different levels of aggregation (brand, variant, SKU and SKU-period, respectively) allow the parameters to be identified. The independence assumption enables the density of the overall non-normal error term $\varepsilon_{j t}$ to be expressed as the product of the densities of its four error components. The symmetrically distributed error components are distinguished from each other because they are defined at different levels of data aggregation. Both the skew and level of aggregation in the $\mathrm{BE}$ error term distinguish it from the symmetric error components. The identification of the BEM (and implicitly the relaxation of the "base brand"

3 With new brands it is possible that not yet enough market data are available to weed out underperforming brands (with $\mathrm{BEM}<1$ ). However, this is unlikely to be the case with long-standing brands in a mature category such as beer. Furthermore, grocery brand withdrawals are numerous (Haig, 2005), which suggests that firms withdraw failed brands and products fairly quickly. 
problem) comes directly from the assumption of a parametric functional form for the one-sided distribution of $\operatorname{Ln}\left(\mathrm{BEM}_{b(j)}\right)$.

Clearly, the more flexible or nonparametric the density of $\operatorname{Ln}\left(\mathrm{BEM}_{b(j)}\right)$, the less it would be empirically separable from the normal error components. The question thus becomes one of selecting an appropriate parametric distribution in the positive domain that captures the behavior of $\operatorname{Ln}\left(\mathrm{BEM}_{b(j)}\right)$ well. Stochastic frontier models in production economics are methodologically similar to the proposed model in that they use a nonnormal composed error term that includes a one-sided error component, which can be modeled using standard distributions such as the gamma, exponential, half- or truncated normal, and the log-normal. Given a parametric functional for the $\operatorname{Ln}\left(\mathrm{BEM}_{b(j)}\right)$ term, the likelihood of the model can be written down.

I apply Markov Chain Monte Carlo (MCMC) methods to obtain estimates of the parameter values in the proposed framework. The results from the MCMC routine give samples from the joint posterior distribution of the parameters of interest. Once I have these posterior samples of the parameters, brand specific BEM estimates are obtained by straightforward computation. Similarly, estimates of any other metrics based on the parameters and data are also easily constructed.

\subsubsection{Modeling Competition}

It is well known that the intensity of competition affects product sales, mainly through inter-product substitution effects. Whereas in the Logit formulation, purchase probability or market share relate to the marketing mix of all the products in the sample and thereby implicitly account for competition effects, in a traditional regression 
framework parsimoniously modeling competition remains a challenge. In this section, I develop a model of inter-product competition that accounts for substitution effects based on attribute similarities as well as the promotional intensity and distributional reach of rival products.

Product competition occurs in many ways - (i) through the set of product attributes chosen by manufacturers, (ii) through the number and scope of items available at different levels of product aggregation such as brand, variant and SKU, and (iii) through marketing activities such as advertising, couponing, in-store promotions, price discounts and choice of distribution channels. As an example of the modeling of oligopolistic competition, Villas Boas (1993) shows that firms in oligopoly have an incentive to advertise as well as price-promote out of phase. In this section, I model the competitive intensity on an item $j$ 's sales due to a rival item $i$ in period $t$, termed Competition $(j t, i t)$, as proportional to the degree of similarity in attributes between the $i$ and $j$, how widespread the availability of the rival item $i$ is and how much promotional activity rival item $i$ undergoes, thus:

$$
\text { Competition }(j t, i t) \propto\left(\begin{array}{l}
\text { Degree of } \\
\text { similarity } \\
\text { between } i \text { and } j
\end{array}\right) *\left(\begin{array}{l}
\text { Availaility } \\
\text { of rival } i
\end{array}\right) *\left(\begin{array}{l}
\text { Promotion } \\
\text { intensity of } \\
\text { rival } i
\end{array}\right) \text {. }
$$

I measure the degree of similarity in attributes simply as the number of observable attributes shared by the two items. Let $l=1,2, \ldots L$ be the set of observable binary attributes along which products compete, and $D_{l}(j t)$ be the set of items (excluding item $j$ ) that share attribute $l$ with item $j$ during period $t$. Then the degree of similarity in attributes between $i$ and $j$ can be expressed as: 


$$
\left(\begin{array}{l}
\text { Degree of } \\
\text { similarity } \\
\text { between } i \text { and } j
\end{array}\right)=\frac{1}{L} \sum_{l=1}^{L} I\left(i t \in D_{l}(j t)\right),
$$

where $I($.$) is an indicator function, defined as:$

$$
I\left(i t \in D_{l}(j t)\right)=\left\{\begin{array}{l}
1 \text { if SKU it } \in D_{l}(j t) \\
0 \quad \text { otherwise }
\end{array} .\right.
$$

Thus, the competition level affecting the sales of item $j$ in time $t$ due to all the other rival products in the market in time $t$ (Competition $(j t,)$.$) can be written as:$

$$
\text { Competition }(j t, .)=\sum_{\substack{i=1 \\
i \neq j}}^{J}\left\{\begin{array}{r}
{\left[\frac{1}{L} \sum_{l=1}^{L} I\left(i t \in D_{l}(j t)\right)\right] *\left(\begin{array}{l}
\text { Availaility of } \\
\text { rival item } i \text { in period } t
\end{array}\right)} \\
*\left(\begin{array}{l}
\text { Promotion intensity of } \\
\text { rival item } i \text { in period } t
\end{array}\right)
\end{array}\right\} .
$$

Thus equations (1.8) to (1.10) imply that for any item $j$, Competition $(j t, i t)$ measures the competitive impact of a competing SKU $i$ on $\operatorname{SKU~} j$ as depending on its attribute similarity to $j$, the availability of $i$, and the promotional activity of $i$. Brand name is also included as an attribute and hence, cannibalization by other SKUs within the same brand is also captured. And as equation (1.11) implies, the sum of Competition $(j t,$.$) across all$ items $i$ in time $t$ yields the inter-product competition level on $\mathrm{SKU} j$ in period $t$. For convenience, I term this inter-product competition level Competition ${ }_{j t}$ and use it as a variable in the $\mathrm{BE}$ model in equation (1.5). The variables constituting the distributional reach and promotional intensity of rival items are described in the data sections of each essay. 
How well the competition effects have been modeled can be seen from how realistic the substitution patterns implied by the model are. For instance, one motivation for the random coefficients Logit model is that the Independence of Irrelevant Alternatives characteristic implied by simple Logit is seen as unrealistic (see, e.g., Train 2003; Nevo, 2000). In the proposed framework, the revenue elasticity of $j$ with any change in the promotion level of $i$ can be written as:

$$
\begin{aligned}
\text { Elasticity }_{\mathrm{PROMO}}^{\mathrm{REV}} & =\frac{\partial \operatorname{Ln~REVENUE}_{j t}}{\partial \operatorname{Ln}_{\text {PROMOTION }} t} \\
& =\beta_{2, \text { Comptition }} *\left[\frac{1}{L} \sum_{l=1}^{L} I\left(i t \in D_{l}(j t)\right)\right] *\left(\begin{array}{l}
\text { Availaility of } \\
\text { rival } i \text { in time } t
\end{array}\right) .
\end{aligned}
$$

In summary, the Comptetition $_{j t}$ term is proportional to (i) the number of attributes shared between the rival items and the focal $\mathrm{SKU}_{j}$, (ii) the distributional reach of the rival items, and (iii) the intensity of promotions by the rival items, in a time period t. Clearly, the competition effect of item $i$ on item $j$ need not be the same as that of $j$ on $i$. My competition model accounts for this asymmetry because

$$
\text { Competition }(j t, i t) \neq \text { Competition }(i t, j t) \text {, }
$$

if the promotion or distribution levels of the two items $i$ an $j$ differ. Further, the competition model is a parsimonious specification in that it requires only parameter $\beta_{2, \text { Comptition }}$ to be estimated for the entire dataset, but which thereafter allows the competition effects for any pair of SKUs to be computed. The model thereby yields intuitive substitution patterns.

In concluding this chapter, I layout a roadmap for the rest of the dissertation: Chapter 2 surveys research on topics touched upon at various points in the three essays 
and serves to position the dissertation in the literature. The research topics include brand equity measurement, Private Labels, and models of spatial association. Chapters 3, 4 and 5 contain the major portion of the body of the first, second and third essays, respectively. These chapters also contain variations of the general model (1.5) adapted to particular situations. Chapter 6 concludes the dissertation by drawing upon insights from each of the three essays. 


\section{Chapter 2}

\section{Literature Review}

\subsection{Brand Equity Measurement}

Essentially three perspectives emerge in the literature on BE measurement consumer-based (e.g., Keller, 1993), financial valuation based (Aaker and Jacobson, 1994), and product-market based (Ailawadi, Lehmann and Neslin, 2003). In the consumer perspective researchers attempt to measure a consumer perception construct such as attitude, awareness, liking, or credibility as information content in brand signals (Erdem and Swait, 1998) and translate it into brand affect (Bousch et al 1987) or brand specific associations (Chakravarti, MacInnis and Nakamoto, 1990). Transforming these perceptual constructs into figures more directly relevant to managers (such as monetary values, for instance) is typically not a straightforward exercise. Another strand of this literature uses conjoint analysis to measure BE (e.g., Srinivasan, 1979; Green and Srinivasan, 1990 for full-profile conjoint analysis; Park and Srinivasan, 1994 for perceptual BE using a survey method). While sound in theory, the practical difficulties with this approach are well known. The advantages are that the value contribution of individual attributes can be isolated and determined, which is useful in new product development situations. Also, the baseline for comparison can be fine tuned to a degree not available to other methods. The drawbacks however are a mismatch between stated preference and observed behavior, the ability of consumers to accurately articulate preferences (Park and Srinivasan, 1994 note this in their study), in an artificial questioning environment and expensive collection of individual level data. 
$\mathrm{BE}$ from the financial perspective is defined as the incremental cash flow accruing to a product with the brand name as compared to that without (Leuthesser, 1998). Financial measures (e.g., Bartov et al, 2002) such as purchase price in acquisitions (Mahajan, Rao and Srivastava, 1994), discounted cash flow as observed in license fees and royalties, market value of equity (e.g. Kallapur and Kwan, 2004), Tobin's q ratio (Lindenberg and Ross, 1981) and residual market value (Simon and Sullivan, 1993) have been used to yield estimates of BE. The issue here is that financial measures use highly aggregated data (at the level of the firm) and hence estimating individual brand values in multi-brand firms becomes problematic (Aaker and Jacobson, 1994). Since a variety of factors impact the market valuations of firms, financial BE measures do yield noisy estimates that obtain more of a brand's total earnings potential than of its current BE. They are likely to be of limited diagnostic value to a brand manager.

Product-market outcome measures summarize marketplace results that contain information about BE. Various product-market outcome measures such as additional consumer willingness-to-pay for a branded product compared to an unbranded one (Aaker, 1991, 1996; Sethuraman, 2000), brand constants in multi-attribute settings (Holbrook, 1992), market-share and relative prices (Chaudhari and Holbrook, 2001), segment wise brand preferences (Kamakura and Russell, 1993), revenue premiums (Ailawadi, Lehmann and Neslin, 2003), and profit differentials (Dubin, 1998) have been used to estimate BE. The approach proposed in this paper also relies on product-market outcomes.

There is wide variation in how different product-market outcome based studies define and measure BE. For example, the brand value measure of Kamakura and Russell 
(1993) and the 'equalization price' measure of Swait et al (1993) both overestimate BE by measuring the value of the brand-product combination and not the value of the brand alone. Kamakura and Russell (1993) define a "brand intangible value" measure that removes the effect of product attributes but their method requires consumer panel data. Ailawadi et al (2003) define BE as the simple revenue difference between the set of all products (SKUs, variants, flavors, sizes, etc.) in a category under one brand name and that under the baseline brand name. Hence, they effectively compare not just two brands but two portfolios of product attributes. Goldfarb, Lu and Murthy (2008) use structural demand estimates to compute a counterfactual set of profits for unbranded products and measure $\mathrm{BE}$ as the profit difference between the estimated branded and the counterfactual unbranded equilibriums. To keep the model simple and the estimation tractable, they use a "representative SKU" from each brand in the Cereal category thereby ignoring information contained in the portfolio of products under each brand name and the complex branding structures present in the category.

Except for revenue differences, all the above product-market outcome based methods rely on a fixed effects approach. Correspondingly, identification restrictions in both cross-sectional and panel data require that at least one brand (the baseline brand) have an a priori fixed BE. The revenue differences method too relies on the a priori selection of a baseline brand. Typically, a Private Label is chosen as the baseline brand and it's BE is set to zero. Ideally, the baseline brand determines the particular productmarket outcome of interest of each brand in the sample given its attribute set but without its brand name. Since attribute sets differ across products even within a brand name (e.g., across different SKUs) let alone across brand names, no single brand can be 
an ideal baseline. I contend that a BE measurement method based on a random effects approach circumvents some of the limitations of the BE approaches discussed above. Under the random effects assumption, I posit that the BE for a brand in any market is the outcome of a complex system and I use a reduced form approach (in the sense that it is a data-driven, statistical model that does not explicitly specify how BE is generated from the underlying complex system) to estimate BE values. The model's data requirements are modest in that easily available, syndicated scanner data are used and it implicitly defines an appropriate baseline.

\subsection{Brand Equity Measurement in Private Labels}

The literature on Private Labels has primarily focused on explanations for their introduction (e.g., Narsimhan and Wilcox, 1998 about bargaining power with channels; Cotterill, Putsis and Dhar, 1998 about category expansion; and Hoch, 1996 about segmenting consumers), the antecedents of Private Label performance in terms of quality (e.g., Seturaman, 1997; Apelbaum et al, 2003), price differential (e.g., Sethuraman, 1992), Private Label market share (Dhar and Hoch, 1997), or the impact of Private Label introduction on store differentiation and loyalty (e.g., Corstjens and Lal, 2000). Though these studies do not directly address BE estimation, BE measures can be derived from some of them by interpreting Private Label intercepts as equity. No study has directly measured Private Label or Private Label equity using aggregate data.

Extending extant methods to Private Label BE estimation encounters many of the same problems that were described in the previous subsection such as the need for complex data collection (e.g., survey data on perceptual measures used by Sethuraman, 1997). Alternately, choosing price premiums or Private Label market-shares as BE 
measures runs the risk of inaccuracy because a high market share is not necessarily indicative of high BE or vice versa (e.g., Keller and Lehmann, 2006). A brand can always 'buy' share in the short run by lowering prices but such an action would not imply any increase in BE (e.g., Ailawadi et al, 2003). My proposed technique offers a BE measure that overcomes these problems and directly estimates Private Label equity after separating the confounding sales effects related to non-brand sources. It lends itself naturally to estimating Private Label BE on account of its implicit baseline selection property.

I will also examine how National Brand and Private Label BE relate to retailer characteristics. The literature on this subject has seen studies on store and category characteristics (Raju, Sethuraman and Dhar, 1995), consumer characteristics (e.g., Hansen, Singh and Chintagunta, 2006; Ailawadi, Neslin and Gedenk, 2001), and the positioning of Private Labels vis-à-vis National Brands (Sayman, Hoch and Raju, 2002). In particular, I investigate if Private Label BE is consistent with an "economic benefits and costs" value proposition seen in the literature (Ailawadi, Neslin and Gedenk, 2001).

\subsection{Spatial Association in Marketing Outcomes}

There is some support in the literature for the conjecture that markets located near one another are likely to have related product-market outcomes. For instance, Bronnenberg, Dhar and Dube (2005) track historical market shares in the coffee category and find a strong spatial component to the growth of brands in new markets. Bronnenberg and Mahajan (2001) show the presence of significant spatial dependence in the market shares and promotions of brands. 
I use spatial analysis techniques to test the assumption of spatial association in BEs across neighboring markets. Spatial models in general, have found wide use in natural sciences such as biology and geology, for applications ranging from disease mapping to ore kriging (Cressie, 1993). Broadly speaking, a spatial model specifies relations between outcomes and covariates based on their similarity in location. The location map is typically treated as exogenously given and a distance metric of some sort is used to measure distances between the locations. Spatial models specify a particular type of interdependence across cross-sectional observations which is two (or more) dimensional and bi-directional. This makes calibration in spatial models considerably more complex than in traditional models which assume statistical independence across units, or even time-series models which assume uni-directional relations between time dependent variables (Cressie, 1993; Anselin, 2001; Bradlow et al, 2005).

Spatial econometricians (Anselin, 1988; 2001) have brought spatial models into the realm of economic modeling. Whereas the natural sciences primarily use geographic maps for spatial location and Euclidean distance for the distance metric, marketing studies have tended to generalize the notion of a map to include demographic and psychometric representations (Bradlow et al, 2005). For instance, Yang and Allenby (2003) use both postal codes and demographics in defining a social network of consumers, Moon and Russell (2004) use a latent map of consumer ideal points ignoring geographic location entirely, and Bell and Song (2004) use a contiguity matrix of purely geographical postal codes.

Few studies have examined the spatial dispersion of brand effects. Bronnenberg, Dhar and Dube (2005) explore the effect of order of entry, regional advertising 
expenditures and the geographical dispersion of markets on brand shares in various CPG categories. They use Euclidean distance as their distance metric, and a kernel based method to estimate spatial dependence in marketshares. Bronnenberg and Sismeiro (2002) include price as the sole demand covariate. Bronnenberg and Mahajan (2001) use the presence of spatial dependence in the marketshares and promotions of brands to mitigate price and promotion endogeneity effects.

Broadly, I will develop a spatial model to understand the level of and variation in BE across 49 U.S. metropolitan markets as a function of the demographic characteristics and geospatial location information of the markets. In particular, in contrast to typical spatial analyses, my model estimates spatial dependencies in BEMs across markets without making any distributional assumptions on the error term. 


\section{Chapter 3}

\section{Brand Equity as a Revenue Multiplier}

\subsection{Motivating the Study}

Chapters 1 and 2 present a brief introduction to the general research problem and to a survey of the related literature. In this section, I motivate the research objectives of Essay 1. The rest of the chapter presents the body of Essay 1.

Section 1.2 in Chapter 1 presents a general, conceptual framework for estimating $\mathrm{BE}$ under random effects. I argue that $\mathrm{BE}$ as a random effect affords the advantages of simple, single-stage BE estimation and inference, easily interpretable results, downstream measures such as a BE dollar metric and the incorporation of inter-product competition effects even in the presence of complex branding structures. In this essay, (i) I demonstrate the econometric implementation of the proposed model on real data, and (ii) assess its advantages over alternative methods based on the analysis results.

Because $\mathrm{BE}$ is a complex, multi-dimensional construct, different $\mathrm{BE}$ measurement methods yield vastly different results and interpretations. The proposed approach yields BE estimates based on aggregate data available readily from syndicated data sources. To check whether the results from the analysis are realistic, (iii) I undertake a series of reality checks and validate the analysis results using metrics from independent, external sources. Finally, (iv) I discuss the insights that emerge from the results.

Subsequent sections detail the variables used in the analysis, the estimated model, a discussion of the results and their managerial implications. 


\subsection{Empirical Investigation}

\subsubsection{Data and Variables}

Beer data collected from a variety of readily available sources are used to illustrate the methodology. The U.S. beer market is a well defined and mature product category with characteristically little change in the total quantity of beer sold during the sample period 2002 - 2005. As with sales, distribution, promotion and price levels differ widely across brands and SKUs. Distribution is a major determinant of sales, and promotions - especially advertising ( $\$ 1.175$ billion in 2005$)$ and retail merchandising (features, displays, and temporary price reductions) are utilized heavily. However, while the category is dominated by a handful of big brands and manufacturers with extensive distribution and large promotional programs (Anheuser-Busch, SAB Miller, MolsonCoors and Pabst account for over $81 \%$ of U.S. sales), smaller, more regionally distributed brands compete quite effectively. Indeed, the collective share of the top 25 beer brands I analyze is slowly falling. I note also that even these major brands have numerous SKUs that receive limited distribution and promotion.

In order to achieve a reasonably accurate partitioning of SKU level revenues into those related to brand equity and those that would accrue to the SKU's unbranded equivalent (UE), it is necessary to identify and use a variety of measures to reflect the impact of the UE Revenue Components outlined in equation (1.4). These data are outlined in Table 1 and detailed forthwith. The data sources are listed in Appendix A. Table 2 briefly profiles the 25 top selling beer brands. 
Revenue

For the revenue measure, Revenue, I use monthly AC Nielsen national revenue data pertaining to the various SKUs that constitute the top 25 beer brands sold in food stores for the years 2002 to $2005 .{ }^{4}$ I define "brand" as the identifier for any group of products which share a nominal label, "variant" as a subset of the brand that differs from other variants of the same brand by some identifier or descriptor in the label, and "SKU" as any packaging or size of the product that differs from other products of the same variant. For example, Budweiser is a brand, Bud Light and Bud Ice are two variants of Budweiser, and a six pack of 12 ounce Bud Light longneck bottles is a different SKU from a six pack of Bud Light 12 ounce cans.

Note that a SKU level analysis allows each branded SKU to be compared to its own unique UE. Any higher level product (i.e., variant or brand) analysis will necessarily utilize a less comparable UE (i.e., the marketing mix description of a variant is less accurate since it must be represented as averages or sums over the SKUs that share the variant name). For example, outside of a few high sales "star" SKUs, most SKUs do not sell nearly as well and are not distributed as widely. Furthermore, each SKU has at least one product attribute difference from its other similarly branded SKUs. If the data were aggregated to the brand level, then these large SKU level marketing mix differences that do exist and strongly influence revenues would be ignored and their impact likely attributed either positively or negatively to brand equity. Furthermore, SKU level analysis

\footnotetext{
${ }^{4}$ Each 4-week period is referred to as a month. The beer category is defined as lagers and light beers since they constitute the vast majority of all malt beverages sold (i.e., malt liquors, stouts, ales and flavored malt beverages are not included in the analysis).
} 
has merit since most consumer, retailer and manufacturer decisions are made at the SKU level (Fader and Hardie, 1996).

In order to keep the number of SKUs analyzed to a reasonable level, I removed SKUs that were not sold over at least half the sample time span, had sales totaling less than $\$ 10$ million over the four year period or had a distributional reach of less than $10 \% \mathrm{ACV}$ (i.e., $10 \%$ of food stores, weighted by store revenue, sold at least one unit of the product). Consequently, the dataset contains 13,777 observations pertaining to 278 SKUs which constitute 25 brands. These SKUs account for over 90\% of category revenue in U.S. food stores. In turn, food stores as defined by AC Nielsen account for about $88 \%$ of total beer sales at all food, drug and mass merchant outlets.

Product

The multi-attribute model literature (Lancaster 1966; Horsky and Nelson, 1992) highlights the importance of product attributes in the consumer choice decision. These product attributes can be tangible and objective (such as weight in ounces) or intangible and subjective (such as expert or consumer ratings of taste) but must be relevant to consumers (Keller, 1998), not be unique to a brand ${ }^{5}$, and show enough variation across the SKUs to allow identification of their impact on choice. Beverage Industry trade publications (e.g., Adams Beer Handbook) and the AC Nielsen scanner data SKU descriptions provide easily observed objective attributes that differentiate SKUs by beer type, beer color, packaging and country of origin. In particular, five types of beer are identified (Regular, Dry, Lite (low calorie), Ice and Craft). Correspondingly, four binary

\footnotetext{
5 Both figuratively and econometrically, attributes unique to a brand cannot be identified as separate from the brand and, thus, form part of BE.
} 
dummy variables are used to represent whether or not a particular SKU is a Dry, Lite, Ice or Craft beer rather than Regular. Similarly, three dummy variables identify whether a SKU's color is Amber, Light, or Golden rather than Dark. A number of packaging related dummy variables also are utilized. In such, a dummy variable Can represents whether the container is a can as opposed to a bottle. Five dummy variables correspond to various pack sizes. These are $\mathbf{6}$ Pack 12 oz (for a 6 pack of 12 ounce containers), 6 Pack Other oz (for a 6 pack of non-12 ounce containers), 12 Pack (for a 12 pack of containers), SmallPack for either single units or packs with less than 6 containers and Case (for 18, 20, 24 and 30 pack sizes). Lastly, the dummy variable Imported is used for beers originating outside the U.S.

These objective SKU level attributes are coarse and not likely to fully capture SKU level objective attribute differences. In addition, subjective attributes that are not easily observable to the researcher such as "taste" or "attractiveness of packaging" may differ between two objectively identical SKUs. To specifically account for subjective taste differences across products, for each variant (and, thus, for each of its SKUs) I use an overall beer rating on a 0-5 scale provided by a panel of experts and beer aficionados at two online data sources (www.beerpal.com and www.ratebeer.com). Since it is likely that these beer ratings partially depend on the measured objective product attributes, I regressed the beer ratings on the objective attributes $\left(\mathrm{R}^{2}=0.64\right)$ and use the residuals Resid $_{v}$, which I term Subjective Taste, as a measure of taste that is not explained by the objective attributes. Thus:

$$
\text { Ratings }_{v}=\alpha_{0}+\sum_{a=1}^{A} \alpha_{a} \text { Product }_{v, a}+\operatorname{Resid}_{v} \text {. }
$$


To avoid any further confounding of the unobserved variant and SKU level product attribute impacts with $\mathrm{BE}$ due to omitted objective and subjective product attributes (such as attractiveness of packaging), I include latent variant and SKU level random effects $\xi_{v}$ and $\eta_{j}$. To illustrate the $\eta_{j}$, consider that the Modelo Especial 12 pack of 12 ounce cans SKU outsells the 24 pack of 12 ounce cans SKU of the same brand and variant by over a hundred to one on average. If the former SKU sells better because of, say, more attractive packaging or more convenient transport and storage, then the observed product elements would not entirely capture this. Furthermore, this effect is unrelated to $\mathrm{BE}$ and might collect in the $\mathrm{BE}$ term if unaccounted for.

Promotion

The key promotional drivers behind grocery product sales are typically advertising and retail merchandising (displays, features and temporary price reductions). Consequently, from the Leading National Advertisers database, I acquired the annual advertising expenditure (AdSpend) of each variant in each year studied. Each SKU within a variant is assigned its variant's advertising spend and this annual amount is used as a proxy for the monthly advertising spends. Standard scanner data provides numerous measures of retail merchandising. I utilize \%ACV Merchandizing which denotes the percentage of food stores, weighted by store revenue, in which the SKU underwent some form of retail merchandising during each month.

As seen in the competition model in section 1.2.2, the inter-product competition level on a focal product is a function of the promotional activity of rival products. Therefore I categorize Competition within the Promotion Revenue Component. 


\section{Distribution}

How much distribution (consumer access) a SKU has is obviously a huge determinant of its sales. To this end, a standard scanner data measure - the monthly percentage of stores, weighted by store revenue, which carried each particular SKU (\%ACV Distribution) is utilized. Shelf presence also is a key determinant of sales (Little 1979; Guadagni and Little, 1983; Hoch et al., 1995). While data concerning the number of facings a SKU receives or its location on the shelf are not easily found, standard scanner data does provide a variable, Vt SKUNUM which denotes on a monthly basis the average number of different SKUs for each variant carried by a store that sold that particular variant. The more SKUs of a particular variant on the shelf, typically the more shelf space and, thus, shelf presence it has. Correspondingly, the more likely each of its particular SKUs is to be noticed.

\section{Category Drivers}

Various economic and demographic factors are likely to impact industry-wide revenues (and hence, the sales of the particular SKUs). The monthly number people in the U.S. over age 21 (AdultPop), obtained from the U.S. Census Bureau, provides a nice proxy for changes in total market size. Input prices are likely to impact retail prices and, hence, revenues. So, from the Bureau of Labor Statistics database, the producer price index for long haul trucking in the U.S. (FreightPPI) serves as an input cost measure. Since imported beer prices are affected by foreign exchange rates (ExchgRate), a monthly averaged index of the Canadian Dollar, Mexican Peso and Euro exchange rates per U.S. dollar (obtained from the Federal Reserve website) acts as an additional cost 
measure for the imported brands. Seasonality also is prevalent in this industry, so three simple quarterly dummies (Fall, Winter and Spring) are utilized. To proxy for additional unobserved factors that that may influence market level demand, three yearly time dummies (Year2002, Year2003 and Year2004) also are instituted.

\subsubsection{Estimated Model}

The estimated model is based upon the conceptual model described in Equation (1.5) and is written as:

$$
\begin{aligned}
\operatorname{Ln}\left(\text { Revenue }_{j t}\right)=\beta_{0}+\left[\sum_{a=1}^{A} \beta_{1, a} \operatorname{Ln}\left(\text { Product }_{a, j}\right)+\xi_{v}+\eta_{j}\right] \\
+\sum_{c=1}^{C} \beta_{2, c} \operatorname{Ln}\left(\text { Promotion }_{c, j t}\right)+\sum_{d=1}^{D} \beta_{3, d} \operatorname{Ln}\left(\text { Distribution }_{d, j t}\right) \\
+\sum_{p=1}^{P} \beta_{4, p} \operatorname{Ln}\left(\text { Category Drivers }_{p, t}\right)+\operatorname{Ln}\left(\operatorname{BEM}_{b(j)}\right)+u_{j t} .
\end{aligned}
$$

Here, the covariates are as described in the data section. The Competition ${ }_{j t}$ term included in the Promotion Revenue Component is detailed in terms of observed distribution and promotion measures for every competing product $i$ to every focal product $j$. From equation (1.11), while the term (Promotion intensity of rival item $i$ in period $t$ ) could include marketing and promotional activities such as advertising and couponing, my dissertation data includes only Merchandizing by SKU recorded for every period. Advertising spend data are annual and at the variant level, and couponing data are not available. Hence, consistent with the log-log model in equation (1.5), I use the natural log of the Merchandizing variable to measure the promotion intensity, thus:

$$
\left(\begin{array}{l}
\text { Promotion intensity of } \\
\text { rival item } i \text { in period } t
\end{array}\right)=\mathrm{Ln} \% \mathrm{ACV} \text { Merchandizing }{ }_{i t} \text {. }
$$


And for distribution, from equation (1.11), I use:

$$
\left(\begin{array}{l}
\text { Availaility of } \\
\text { rival item } i \text { in period } t
\end{array}\right)=\operatorname{Ln} \% \text { ACV Distribution }{ }_{i t} .
$$

Following equation (1.6), I decompose the error term $\varepsilon_{j t}$ into four IID variance components - at the brand, variant, SKU and SKU-period levels, thus:

$$
\varepsilon_{j t}=\operatorname{Ln}\left(\mathrm{BEM}_{b(j)}\right)+\xi_{v}+\eta_{j}+u_{j t} .
$$

Of these, three are modeled as mean zero normal, following equation (1.7). $\xi_{v}$ and $\eta_{j}$ model revenue heterogeneity due to variant and SKU level unobserved factors through a random effects specification (e.g., Allenby and Ginter, 1995) and $u_{j t}$ is a nonsystematic random shock.

$$
\begin{aligned}
& \xi_{v} \sim \operatorname{IIDN}\left(0, \sigma_{\xi}^{2}\right) ; \\
& \eta_{j} \sim \operatorname{IID} N\left(0, \sigma_{\eta}{ }^{2}\right) ; \\
& u_{j t} \sim \operatorname{IID} N\left(0, \sigma_{u}^{2}\right) .
\end{aligned}
$$

As explained in Chapter 1, the brand level variance component $\operatorname{Ln}\left(\mathrm{BEM}_{b(j)}\right)$ is assumed distributed in only the non-negative domain. I now make particular functional form assumptions on the distribution of $\operatorname{Ln}\left(\mathrm{BEM}_{b(j)}\right)$. Following van den Broek et al. 
(1994), I define $\operatorname{Ln}\left(\operatorname{BEM}_{b(j)}\right)$ as distributed exponential with parameter $\lambda$, where $\lambda$ is distributed gamma with hyper-parameters $\alpha$ and $\gamma^{6}$. That is:

$$
\begin{aligned}
& \operatorname{Ln}\left(\operatorname{BEM}_{b(j)}\right) \sim \operatorname{IID} \text { Exponential }(\lambda) ; \\
& \lambda \sim f_{\text {Gamma }}(\alpha, \gamma) .
\end{aligned}
$$

This can be alternatively interpreted as an assumption that the BEM density has a modal value of one and assigns small probability to very large values of BEM.

Appendix B details the derivation of the full conditional likelihood for a more general model than that in (3.2) and details the MCMC sampling scheme used. The model in (3.2) is nested in the general model of equation (B.1). The analysis results consist of the mean and the 95\% Highest Probability Density (HPD) interval of 10,000 draws from the stable, joint posterior density of each of the main effects parameters $(\boldsymbol{\beta})$ and of the variance component $\operatorname{LnBEM}_{b(j)}$ for every brand in the sample. These draws are made after a burn-in of 50,000 MCMC cycles, with a 'thinning' of 3 (i.e., every third iteration is selected) to mitigate correlations between selected draws. The software packaged used to estimate the model is WinBUGS 14.

Further, Appendix C details the identification of the model using a simpler model template and illustrates the results with the aid of simulation experiments.

\subsubsection{Discussion of Results}

Two sets of results emerge from the analysis - the main effects for Equation (3.2) and the individual BEM estimates by brand. In this section, I present the analysis results,

6 Other positive distributions for $\operatorname{Ln}\left(\mathrm{BEM}_{b(j)}\right)$ provide very similar fit and parameter estimates. Van den Broeck et al (1994) choose Exponential because they find this distribution to be least sensitive to the choice of prior values. 
discuss the intuition behind them, assess the relative advantages of the proposed method, and perform reality checks and result validation. In particular, I check whether the parameter estimates for the Revenue Components and the BEM estimates agree with theory and intuition, and compare previous brand equity valuations for particular brands with those derived using the BEM measure.

\section{Revenue Component Parameter Estimates}

Table 3 shows the MCMC estimates and related statistics for the estimated model. Overall, the parameter estimates are intuitive. The parameters of the product attributes which make up the Product Revenue Component are reasonable and many are significantly different from zero. American tastes are well supported in that, all else being equal, Craft and Lite beers are preferred to other beer types. Similarly, preferences run toward Cans and Light colored beers. Case and 12 Pack SKUs generate higher revenues than smaller package sizes. Interestingly, Subjective Taste has a negative impact on revenues indicating that beers that are rated high on taste tend to have lower revenues. This is intuitive since highly rated beers typically are specialty brews or super premium ${ }^{7}$ beers which have smaller target markets. Note also that the unobserved variant and SKU attribute differences $\xi_{v}$ and $\eta_{j}$ capture a significant amount of revenue variation. Indeed, the variance of these two random effects $\left(\sigma_{\xi}^{2}+\sigma_{\eta}^{2}\right)$ is over ten times the size of the unexplained error variance in each observation $\sigma_{u}^{2}$, which suggests (i) the clear presence of latent variant and SKU level attributes, (i.e., not all relevant variant and SKU level attributes are modeled) and (ii) that the bulk of the unexplained variation in

\footnotetext{
${ }^{7}$ Beers are commonly classified into Super Premium, Premium and Popular classes based on their positioning and price (Adams Beer Handbook).
} 
revenues is attributable to this systematic latent variant and SKU level factors. The relative sizes of $\sigma_{\eta}^{2}$ and $\sigma_{\xi}^{2}$ clearly indicate that SKU level unobserved factors carry more explanatory power than the variant level ones.

The revenue impacts of the variables in the Promotion Revenue Component are significant in magnitude and bear the expected signs. Higher levels of merchandising and advertising spend relate positively to revenue whereas the intensity of competition relates negatively to revenue. The competition effect result in particular implies that item revenues drop with the wider availability and higher promotion intensity of similar products due to a pronounced substitution effect. I illustrate the substitution patterns implied by the competition model in greater detail.

Table 4 presents the competition effects for 8 different SKUs with different observable attributes, across 6 brands. Each cell $(j, i)$ in Table 4 displays the competition level on the SKU in row $j$ due to the SKU in column $i$. The number of attributes shared between $i$ and $j$ is noted in brackets. Following equations (1.11), (3.3) and (3.4), this competition level in cell $(j, i)$ can be written as:

$\begin{aligned} \text { Competition }(j t, i t)=\left[\frac{1}{L} \sum_{l=1}^{L} I\left(\begin{array}{l}\# \text { Attributes } \\ \text { shared between } \\ i \text { and } j\end{array}\right)\right. & *\left(\text { Ln \%ACV Distribution }{ }_{i t}\right) \\ & *\left(\text { Ln \%ACV Merchandizing } \text { it }_{i t}\right)\end{aligned}$

From equation (3.8), it is clear that the more negative the value of Competition $(j t, i t)$, the more negative is SKU is impact on SKU js sales in period $t$. I use bold font in Table 4 to highlight some particular pairs of interest. Miller and Budweiser compete head on, as do Samuel Adams and Corona. Brands that compete head-on at a particular price- 
point, in a particular positioning niche or in a set of product attributes are likely to have roughly similar levels of distribution and promotion than do brands that do not (Lal and Padmanabhan, 1995). In Table 4, this translates into similar beer types among competing brands having comparable marketing mix elements and thereby appearing to exert a larger influence on competition effects than similar packaging types. For instance, although both Bud Ice and Miller SKUs are 6 pack 12 oz bottles, Miller is more affected by the distributional reach and promotional intensity of the Budweiser 6 pack 12 oz cans SKU. The Milwaukee's Best 24 pack $12 \mathrm{oz}$ bottles SKU is the only popular price-class beer in the Table and it shows the asymmetric nature of the competition effect. Whereas Milwaukee Best's competition effect on the other SKUs in the Table (Column (7)) is rather small (the average is -11.13), that of the other brands on Milwaukee's Best is relatively large (averaging -47.14), in absolute terms. This is consistent with results in the literature (e.g., Kamakura and Russell (1989) talk about "clout" and "vulnerability" of products to affect of be affected by consumer switching behavior).

For variables in the Distribution Revenue Component, the results show that the revenue elasticity (i.e., the parameter value) of distribution is very close to one. This suggests that increases in distribution raise revenues in almost the same proportion. Further, the fact that the entire 95\% Highest Probability Density (HPD) interval falls below one indicates there are decreasing returns to scale for incremental distribution. As expected, the more shelf presence (i.e., the greater the number of SKUs) a variant has, the larger are the sales of its various SKUs.

The Category Driver variables also show strong significance and intuitive appeal. The time dummies decrease from year to year, reflecting the slight downward trend in 
the revenue total of the top 25 beer brands. As for the seasonal dummies, beer consumption, unsurprisingly, rises along with outdoor temperatures. The size of the U.S. adult population also positively impacts sales revenue. The exchange rate parameter is also positive indicating that the cheaper imports become in U.S. dollars, the higher is their sales revenue. This is consistent with a price elasticity of greater than one in absolute terms for these beers. ${ }^{8}$ Similarly consistent with beer price elasticities exceeding one, increases in the cost of long haul freight raise prices and lower revenue.

\section{Discussion of BEM Revenue Multiplier Estimates}

Column (2) of Table 5 displays the estimated BEM for each of the 25 brands in the sample. The mean BEM of 1.26 implies that the brand represents about $20.6 \%{ }^{9}$ of the average beer brand's revenues. This percentage ranges from $51.7 \%$ for Heineken to $3.8 \%$ for Coors (which has the lowest BEM of 1.04). The top five brands by BEM are Heineken, Corona, Pacifico Clara, Budweiser and Samuel Adams. Of these, the niche brand Pacifco Clara is the lone surprise but its position can be justified on the basis of its narrow focus in distribution (availability limited to the Southern West Coast), consumer targeting (the Hispanic community) and merchandising. High revenue but low BEM brands such as Miller, Michelob and, especially, Coors rely on their high levels of distribution, appealing observable product attributes (their SKUs are largely Light colored and Lite type beers that are the most popular), heavy advertising and retail merchandising to earn revenue (Table 2 has details on these market mix factors). Miller and Michelob also are the only brands that have variants with significant differences in

\footnotetext{
${ }^{8}$ A regression of the log of beer volume sold against the observed marketing mix variables and price per unit volume over the sample data results in a price elasticity estimate of approximately -3 .

9 The percent contribution of BE to revenue is computed as [(BEM-1)/BEM].
} 
their product and price characteristics. Michelob spans the super premium (Michelob Amber Bock and Michelob Ultra Light) and premium (Michelob and Michelob Light) classes, while Miller spans the popular (Miller High Life) and premium (Miller Lite, Miller Genuine Draft) classes. This implies that brands must be wary when extending their brand lines. When new variants and their SKUs differ strongly from the original brand line, brand equity is diluted. ${ }^{10}$

To highlight the importance of accounting for the impact of marketing mix and brand name separately, I compare these BEM estimates with those from the revenue premium methodology proposed by Ailawadi, Lehmann and Neslin (2003; henceforth, ALN). Since their brand equity measure is a dollar metric, I introduce a dollar metric measure derived from the BEM measure - the Revenue Dollar Premium. I utilize this value because BEM does not measure the absolute monetary size difference between the revenues of a brand and its particular unbranded equivalent (UE). Rather, a brand's BEM is a percentage mark-up of its UE's revenues. Thus, two brands can have the same BEM but quite disparate revenues if their observed marketing mix (including product attributes) differs greatly.

In plain terms, the Revenue Dollar Premium is the dollar difference between the observed revenue earned by the brand and the estimated revenue of its UE. Conceptually,

$$
{\underset{\text { Dollar }}{\text { Remenue }}}_{\text {Premium }_{b}}=\sum_{j \in b} \sum_{t=1}^{T}\left\{\left[\begin{array}{l}
\text { Revenue from } \\
\text { Branded SKU } j
\end{array}\right]-\left[\begin{array}{c}
\text { Revenue from Unbranded } \\
\text { Equivalent of SKU } j
\end{array}\right]\right\} \text {. }
$$

\footnotetext{
10 It is likely that the variant names assume the driver's role and not the parent or family brand name (Aaker, 1996).
} 
Since the focus of this study is equity at the brand level, I aggregate Revenue Dollar Premiums to the brand level in equation (3.9) by summing across all time periods and all SKUs that share a brand name.

Column (3) in Table 5 shows the Revenue Dollar Premium estimates. Column (4) shows the actual total revenue figures, while Column (5) provides the revenue premium estimates using ALN's technique. Since the latter method computes the revenue premium of a brand as the difference in revenue earned by all the SKUs under that brand name with the revenue sum of all the SKUs under a predefined baseline brand name, it confounds the marketing mix and BE effects of each brand. Furthermore, additional bias is added since the market mix of the baseline brand (Molson, a low sales brand) is not the same as that of the other brands and the brand equity of Molson is unlikely to be zero as it is assumed. These BE measurement biases show clearly in that the high revenue brands (which also typically have much greater promotion and distribution levels) are estimated to have ALN premiums that generally account for well over half of their total revenues. Similarly, the lesser distributed and promoted brands typically have much smaller absolute and relative ALN premiums. The proposed Revenue Dollar Premium measure, on the other hand, takes these market mix influences into account and provides brand equity estimates that are generally much smaller, and more likely to be realistic because marketing mix differences are accounted for. The average Revenue Dollar Premium is $\$ 46.3$ million per annum - much lower than the ALN average of $\$ 192.8$ million.

Since $\mathrm{BE}$ is a relatively stable quantity that is not likely to change drastically within a short span of 1-2 years (Keller, 1998), I apply a simple reality check and ask if 
the BEM estimates are stable over time. To test temporal stability, I estimated the model separately for three two year time span subsets (2002-03, 2003-04 and 2004-05) and compared these BEM estimates with those of the four year estimation. The correlation with the full sample BEM estimates in all three cases exceeds 0.8. Furthermore, for all three time sub-intervals, the BEM estimates for all 25 brands are within the 95\% Highest Probability Density (HPD) interval of their full sample BEM. Thus, I infer that the BEM estimates are indeed stable over time.

\subsubsection{External Validation}

I next present evidence from independent, external sources about whether the BEM estimates obtained are realistic and bear validity. Three compelling examples of the external validity for the proposed approach come from comparisons with brand valuations based on financial data.

The first comparison is between the value added by BE relative to the UE generic product and the $\mathrm{BE}$ contribution relative to firms' replacement values from Simon and Sullivan (1993). They use firm-level financial data from the late 1980's to value brand assets for a number of industries and firms. They find that the size of BE in Anheuser-Busch is $35 \%$ of the firm's replacement value. In this study, the four Anheuser-Busch brands in the sample (Budweiser, Natural, Michelob and Busch) have a share-weighted BEM of 1.363. Since the UE of the brands as defined for this study is a close approximation for the firm's replacement value as defined by Simon and Sullivan, the BEM estimates show Anheuser-Busch brands with a BE equal to $36.3 \%$ of firm replacement value. This compares very favorably with the 35\% figure that Simon and 
Sullivan find. Despite the different time periods for the two analyses, a reasonable degree of agreement occurs which lends validity to the BEM measure.

The second and third comparisons pit discounted cash flow based financial brand valuations derived from the BEM measure for the two largest selling brands in the sample - Budweiser and Miller - against Interbrand Inc's brand valuation for Budweiser and the actual acquisition price paid for Miller's brand assets. A brand valuation estimates the net present value of a firm's or brand's equity and represents the dollar returns to brand assets. Using the Revenue Dollar Premium measure for the Miller and Budweiser brands, I calculate a simple, rough-cut net present value BE valuation and compare these with previous financial brand equity values generated for the Budweiser brand and the Miller brands portfolio.

South African Breweries (SAB) merged with the Miller Brewing Company in 2001 to create the world's second largest brewing company (behind Anheuser-Busch). At that time, SAB Miller listed the goodwill of its Miller assets at $\$ 4.25$ billion. This goodwill principally represents the net present value of the various Miller brands' brand equities. In Table 6, I use the sum of the annual BEM Revenue Dollar Premiums for the Miller Brewing Company’s brands (Miller, Milwaukee’s Best and Icehouse) which total $\$ 93.2$ million per year from Table 5 as the yearly value of the brand at retail grocery outlets and then adjust this figure to account for retail mark-ups, retail sales through non-grocery channels, on-premise (bar and pub) sales and non-US sales. The resulting annual brand equity figure of $\$ 274.6$ million when discounted in perpetuity using a discount rate of $7.3 \%$ (the rate used by SAB Miller in their calculations) provides a net present value 
estimate for the brand equity of the Miller brand portfolio of $\$ 3.76$ billion, which is quite close to the reported value of $\$ 4.25$ billion.

The brand consultancy InterBrand estimated the brand value of Budweiser at $\$ 11.93$ billion in 2005. In Table 6, I again use the BEM annual Revenue Dollar Premium for the Budweiser brand ( $\$ 493.8$ million from Table 5) as the yearly value of the brand at retail grocery outlets, and adjust the figure to account for other factors not in my analysis data similar to that done for Miller. Assuming a discount factor of $10.7 \%{ }^{11}$, I arrive at a global brand value for Budweiser of $\$ 11.34$ billion. Once again, despite using rough cut calculations, broad assumptions and entirely different methods and data sources, this computed brand value is quite similar to that estimated by InterBrand. I believe this is a powerful vote of confidence for the proposed methodology and BEM measure.

In sum, the proposed $\mathrm{BE}$ revenue multiplier methodology reasonably captures the influence of marketing mix (promotion, distribution and both observed and unobserved product attributes) and category factors that previous methodologies have typically included as part of their brand equity estimates. Correspondingly, a more accurate measure of brand equity is identified which, in fact, agrees rather well with equity measures derived from alternative financial data sources. Further, the proposed BEM measure is also intuitive and credible, objective, grounded in theory, based on readily available data, a single-number measure (which facilitates easier tracking and communication), robust and stable, reasonably complete (in that it captures facets of BE not captured by summary measures), and able to assess the potential of future brand line extensions. In such, it meets nine of the ten ideal criteria for a BE measure as

${ }^{11} \mathrm{I}$ arrive at a discount rate of $10.7 \%$ for Anheuser-Busch by using (i) a risk-free rate of $5 \%$ (close to the historical average), (ii) Anheuser-Busch's stock beta of 0.62 (Yahoo company profiles) as a proxy for risk, and (iii) a long term market risk premium of 9.2\% (Bowman, 2001). 
enumerated by the Marketing Science Institute (1999). As for the tenth criterion, akin to other product-market measures, the BEM is diagnostic only to the extent that it can identify changes in BE over time or differences across brands.

\subsection{Managerial Implications and Summary}

Managers have long felt the need for a reliable brand equity measurement system (Keller 1998) and the proposed approach represents a step forward in constructing a BE measurement system that overcomes two key problems in extant measurement schemes. Primarily, the model is demonstrated on the beer category that has a complex branding structure. The model thus accommodates various levels in the brand-product hierarchy such as time-invariant supra-brand characteristics (e.g., the Imported dummy), brand level effects (the BEM itself), variant level characteristics (e.g., color), and SKU level characteristics (e.g., packaging). In traditional approaches, accommodating the complex product structure would entail multiple stages of regressions to disentangle brand effects from those of other levels in the branding structure. Further, the proposed approach retains the benefits of fixed effect approaches such as the use of readily available data from syndicated data sources (scanner data, product attribute information, etc.), and explicitly accounting for the impact of category characteristics and, especially, marketing mix actions (product, price, promotion and distribution decisions) on sales. The latter is in contrast to the simple revenue differences approach. Thus, this potential bias in the brand equity measure is reduced.

Several implications for both marketing practitioners and academics emerge. First, a comparison of the brand equity revenue multiplier measure BEM across brands provides a direct measure of how impactful a brand name itself is to consumer choice 
relative to the impacts of its competitors' brand names. A comparison of the secondary brand equity measure, Revenue Dollar Premium, across brands allows the relative financial impact of the brand to be assessed since this premium depends not only on the BEM but also on the inherent appeal of the product, price, promotion and distribution associated with the brand (i.e., the brand's unbranded equivalent). Further, tracking a brand's BEM or Revenue Dollar Premium over time provides a simple running diagnostic of a brand's "health" and the success of its branding program.

Second, more robust and accurate BE measurement allows product demand to be more accurately specified and the influences of its non-brand determinants (marketing mix and category factors) to be more accurately measured. For instance, the expected return on marketing mix investments (Rust, Lemon and Zeithaml 2004) such as product design changes and distribution expansion will be more accurately forecasted if the influences of these factors are better understood.

Third, the dollar-metric Revenue Dollar Premium measure derived from the BEM measure yields reasonable brand valuations. Correspondingly, these easily estimated premiums have a direct application to situations that require financial valuations of equity at the brand level. This is propitious since standard financial, stock market and accounting data are typically at the firm level and, thus, not fully appropriate. Hence, the methodology is appropriate for brand valuations which are central to mergers and acquisitions and, more broadly, to organizational arrangements that require a limited transfer of rights to a brand name for a period of time or in particular geographic area, such as franchising contracts and brand alliances. 
Fourth, the revenue multiplier methodology is applicable to brand structures more general than the one assessed in this paper. For example, questions can be addressed concerning ingredient branding (e.g., how much does "Intel Inside" contribute to the premium earned by a Dell computer?), co-branding (e.g., what are the contributions of Citibank and Southwest to a co-branded credit card?), and endorsement valuation (e.g., how much does Marriott contribute to the equity of "Holiday Inn by Marriott"?). Similarly, one could investigate the contributions of different levels in a brand hierarchy (i.e., corporate, family, brand, variant; Aaker, 1996). Such a hierarchical study also may lead to a better understanding of umbrella branding (Erdem, 1998). A related methodological opportunity is the use of more general parametric forms that would allow correlations between the BEMs in a set of brands and result in brand maps along the lines of Chintagunta (1994).

In sum, the proposed BEM methodology to assess brand equity is an intuitive, useful and precise tool appropriate for both managers and researchers. Its results exhibit face validity and agree with brand values computed from alternative financial data sources. The brand equity revenue multiplier holds well against the Marketing Science Institute's ideal characteristics for a BE measure, but, more importantly, is (i) easy to implement and (ii) provides a more accurate measure of brand equity because non-brand influences such as the marketing mix factors that typically confound equity measures are explicitly accounted for. Further, this measure and methodology are extendable to assess brand equity issues in a variety of organizational arrangements (e.g., franchising, brand alliances and Private Labels) and branding structures (e.g., corporate, variant, ingredient and umbrella branding). 


\section{Chapter 4}

\section{The Brand Equity of Private Labels}

\subsection{Motivating the Study}

This chapter presents the body of Essay 2. Parts of Chapters 1 and 2 address the Introduction and literature survey for the general research problem of Essay 2. I now motivate the three main objectives of this study.

First, I ask whether Private Labels are 'brands' at all. BE measurement methods under the fixed effects approach require normalizing the BE of any one brand a priori to a fixed value, typically zero. Since Private Labels are typically value products with no advertising and little promotional support, most studies have normalized Private Label BE to zero, essentially assuming that Private Labels are generic products with no BE. In this essay, I revisit this question by jointly estimating the BEs of both Private Labels and National Brands under the proposed random effects approach, and thereafter assessing whether Private Labels have BE.

Second, since my dataset is multi-retailer in nature and in order to do cross-retailer comparisons of Private Label BE, I control for differences in the characteristics of the retailers and of the consumers who shop there. Despite these controls, there is a possibility that the response to marketing mix actions varies across retailers. To account

for this potential heterogeneity, I incorporate a random coefficients specification into the conceptual model. 
Third, the literature posits that Private Labels and National Brands differ in the nature of the appeal they make to consumers. In particular, National Brands emphasize superior consumption experience whereas Private Labels stress price in the value propositions they offer. In this vein, I investigate whether the average price of Private Labels and National Brands is related to BE, and if so how.

Finally, I discuss the insights and implications that emerge from the results. The data, the variables used in the analysis, the estimated model and the results are detailed in subsequent sections.

\subsection{Empirical Investigation}

\subsubsection{Data and Variables}

The dataset contains scanner data at the SKU level from AC Nielsen on eighteen brands, including five Private Labels, of Carbonated Soft Drinks (henceforth, CSD) sold in five mid-size U.S. grocery retail chains, collected at four-week intervals over a period of two years (2005-06). Adhering to non-disclosure terms in the use of the dataset, I identify the five retailers with the numbers 1 through 5 . The unit of analysis is the Retailer-SKUmonth. Guidance on which products to include in the CSD category comes from AC Nielsen product descriptors and from retailers who typically group and place CSD products on adjacent shelves along one 'soda pop' aisle in supermarkets. Product attribute data are sourced from the AC Nielsen product descriptors, retailer data from a 1998 census on U.S. supermarkets, and demographic data on CSD consumers by retailer from the Spectra Homescan database. (See Appendix A for a list of data sources).

I define 'brand' as an identifier for any group of products which share a nominal label, 'type' a subset of the category that differs from other types in the main or base 
ingredient used in the product and easily differentiated upon observation and by the use of modifiers in the label, 'flavor' as the flavor used in a carbonated soft drink within a given type, and 'SKU' any packaging and size of the product that differs from other products of the same brand and flavor. For example, both Coca-Cola and Sprite are brands from the Coca-Cola company but Coca-Cola is of the 'Cola' type whereas Sprite is of the 'Lemon Base' type. Within Coca-Cola, 'Coke with Cherry' is a different flavor from 'Coke with Lime' or from Classic Coca-Cola. The 16 oz Coca-Cola classic nonrefillable glass bottle is a different SKU from a 16 oz Coca-Cola Classic non-refillable plastic bottle.

Brands and SKUs that are launched or discontinued such that they are not present in the sample for at least half the sample duration or not available to at least $10 \%$ of the purchasing power in dollars that shops at the concerned retailer, are removed from the analysis. The cleaned dataset contains 6 CSD types, 18 brands including 5 Private Labels, and 424 SKUs in 24,260 observations that account for over $95 \%$ of the CSD category sales in these retail chains.

Table 7 defines and summarizes the analysis variables. A comparison with Table 1 shows that many of the variables used in Essay 2 - Promotion, Distribution and Category Drivers - have the same definitions and interpretations as those used in Essay 1 , but carry an additional $r$ subscript because they apply within retailer $r$. In the interest of brevity, I do not repeat these variable descriptions. In this essay, I use the \$Million ACV measure in both distribution and merchandizing because it, unlike the $\% \mathrm{ACV}$ measure, provides for an explicit size comparison across retailers. Thus, $\mathbf{M n A C V}$ 
Distribution and \$MnACV Merchandizing measure the purchasing power a SKU is able to access with its distributional reach and merchandizing intensity, respectively.

Among observable Product attributes, there are six mutually exclusive 'CSD 'Type' dummy variables - Cola, Ginger Ale, Citrus, Cream Soda, Fruit Based, and Root Beer, six mutually exclusive 'flavor' dummy variables - Lemon, Berries (such as raspberry and blueberries), Cherry, Orange, Vanilla, and Pepper, , and three dummies for other observable attributes viz. Diet for low- or zero calorie CSDs, Red for CSDs that are artificially colored red and Caffeine Free for caffeine free CSDs. Among packaging attributes, there are three dummies for container material viz. aluminum Can, Plastic and Glass, two for packaging type viz. Multi-Unit Pack if multiple containers are packaged into one purchase unit (e.g., the 12 pack 12 oz SKU) and Single-Unit Pack otherwise, three dummies for packaging size viz. Small Pack if total volume is less than two liters (67.2 oz), Two Liter bottles, Dozen Pack if the SKU comes in multiples of a dozen containers (e.g., a twelve pack, a 24 pack, etc.), and Other SKU Size if the pack size doesn't fit any of the above descriptions. Both revenue and volume per observation have standard deviations exceeding their means indicating that there exists a lot of variation in outcomes across SKUs and time periods. Diet CSDs account for $42 \%$ of the total revenues in the category.

In addition to the Revenue Components in Essay 1, I now bring in two additional groups of variables - Retailer Characteristics and Consumer Characteristicsand include them in the Category Drivers Revenue Component. This is because these variable groups control for differences in store and shopper profiles that impact the level of sales in the CSD category at large, and whose omission might confound BE. In 
Retailer Characteristics, I include five retailer dummies that capture any sales effect particular to a retailer. In Consumer Characteristics, MeanINC and StdevINC denote respectively the mean and standard deviation of the annual income distribution of CSD consumers shopping at a retailer $r$ for each of the two years in the data. Table 8 summarizes characteristics by retailer.

\subsubsection{Estimated Model}

I adapt the general conceptual model in equation (1.5) in two ways. One, I add the two new groups of variables introduced in the previous section - Retailer Characteristics and Consumer Characteristics - in the Category Drivers Revenue Component. Two, I relax the assumption of homogenous parameters for a select set of variables. Since this study pools together data from different retailers, estimating a homogenous parameters model on the lines of that in Essay 1 implies ascribing the same set of response parameters to all the retailers. This might be an overly strong assumption. In order to allow response heterogeneity across retailers while maintaining model simplicity and parsimony, I model the response to the Promotion mix elements - Ln AdSpend, Competition and Ln \$MnACV Merchandizing - as random coefficients ${ }^{12}$. This is both because these promotion elements show a lot of variation and are likely to significantly impact sales, and because both retailers and manufacturers retain some measure of discretion and relatively short term control over promotional activity. The model is more general than that used in Essay 1 in that it nests the latter. If the parameters are indeed homogenous, then the variance of the random coefficient distribution would be very small.

\footnotetext{
12 To compare, I applied the random coefficient specification (using PROC MIXED in SAS) also on the other variables in the Distribution and Product Revenue Components to compare their response heterogeneity with that in the Promotion Revenue Component. I find that Promotion variables clearly show the highest response heterogeneity and are hence included in the MCMC analysis above.
} 
Despite controlling for marketing mix elements such as Product, Promotion and Distribution variables, as well as Category Drivers such as retailer and consumer characteristics, there is a possibility that retailer-brand interactions differ systematically across brands and retailers. One reason is that historical relationships or long term contracts between the manufacturer and retailer could lead to better trade promotion terms or better shelf positions. Regional tastes and preferences among consumers for particular brands could also impact retailer-brand interactions systematically. To account for such a possibility, I estimate BE at the retailer-brand level, (i.e. with an $r b$ subscript). This is a flexible specification in that it nests the case where National Brands have the same BE irrespective of retailer.

Equation (4.1) shows the estimated model in which $r=1,2, . .5$ indexes retailer, $j=1,2, \ldots J$ indexes SKU and $t=1,2, \ldots T$ indexes time-period:

$$
\begin{aligned}
\left.\operatorname{Ln}_{\left(\text {Revenue }_{i j t}\right.}\right)=\beta_{0}+\left[\sum_{a=1}^{A} \beta_{1, a} \operatorname{Ln}\left(\text { Product }_{a, j}\right)+\xi_{r v}+\eta_{i j}\right] \\
+\sum_{c=1}^{C} \gamma_{r, c} \operatorname{Ln}\left(\text { Promotion }_{c, y j t}\right)+\sum_{d=1}^{D} \beta_{2, d} \operatorname{Ln}\left(\text { Distribution }_{d, y j t}\right) \\
+\sum_{p=1}^{P} \beta_{3, p} \operatorname{Ln}\left(\text { Category Drivers }_{p, r t}\right)+\operatorname{Ln}\left(\mathrm{BEM}_{r b(j)}\right)+u_{j t} .
\end{aligned}
$$

The random coefficients vector $\boldsymbol{\gamma}_{r}$ for Promotion variables is specified thus:

$$
\begin{aligned}
& \gamma_{r}^{A D V T} \sim N\left(\bar{\gamma}^{A D V T}, \sigma_{A D V T}^{2}\right) ; \\
& \gamma_{r}^{\text {COMPTN }} \sim N\left(\bar{\gamma}^{\text {COMPTN }}, \sigma_{\text {COMPTN }}^{2}\right) ; \\
& \gamma_{r}^{M E R C H} \sim N\left(\bar{\gamma}^{\text {MERCH }}, \sigma_{\text {MERCH }}^{2}\right) .
\end{aligned}
$$

The composed error term $\varepsilon_{r j t}$ consists of four IID variance components, at the retailerbrand, retailer-variant, retailer-SKU and retailer-SKU-time levels, thus: 


$$
\varepsilon_{r j t}=\operatorname{Ln}\left(\operatorname{BEM}_{r b(j)}\right)+\xi_{r v}+\eta_{r j}+u_{r j t} .
$$

Three of these variance components, $\left\{\xi_{r v}, \eta_{r j}, u_{r j t}\right\}$ are symmetric and assumed to be distributed IID mean-zero normal thus:

$$
\begin{aligned}
\xi_{r v} & \sim \operatorname{IID} N\left(0, \sigma_{\xi_{r}}^{2}\right) ; \\
\eta_{r j} & \sim \operatorname{IID} N\left(0, \sigma_{\eta_{r}}^{2}\right) ; \\
u_{r j t} & \sim \operatorname{IIDN} N\left(0, \sigma_{u_{r}}^{2}\right) .
\end{aligned}
$$

Here, $\xi_{r v}$ and $\eta_{r j}$ account for revenue heterogeneity due to latent factors at the retailervariant and retailer-SKU level that are not captured in the observable attributes but that could confound BE. Random shocks unrelated to any variable in the model manifest as IID measurement error $u_{r j t}$. Any systematic brand-level revenue impact in retailer $r$, unexplained by covariates as well as by $\xi_{r v}$ and $\eta_{r j}$ but common across all SKUs and variants within the brand (and hence, inherent to the branded product) is captured by $\operatorname{Ln}\left(\operatorname{BEM}_{r b(j)}\right)^{13}$. Following the discussion in Sections 1.2.2 and 3.2.2, the remaining variance component defined at the retailer-brand level, $\operatorname{Ln}\left(\operatorname{BEM}_{r b(j)}\right)$, is assumed distributed IID exponential (van den Broeck et al, 1994) with retailer-specific parameter $\lambda_{r}$ thus:

$$
\begin{aligned}
& \operatorname{Ln}\left(\operatorname{BEM}_{r b(j)}\right) \sim \operatorname{IID} \operatorname{Exp}\left(\lambda_{r}\right) ; \\
& \lambda_{r} \sim f_{\text {Gamma }}\left(\alpha_{r}, \gamma_{r}\right) .
\end{aligned}
$$

13 Goldfarb, Lu and Moorthy (2007) make the case that explicitly accounting for objective attributes underestimates $\mathrm{BE}$ by discounting experience attributes. I argue that the brand level factors that generate experience attributes (such as flavor, aftertaste, 'lightness' etc) lead to preference formation among consumers. If these preferences are correlated across large enough groups of consumers, they would be captured in the proposed BE measure. 
I assume the components of the composed error term $\left\{\operatorname{Ln}\left(\operatorname{BEM}_{r b(j)}\right), \xi_{r v}, \eta_{r j}, u_{r j t}\right\}$ are distributed independent of each other, of the explanatory variables and across time. The MCMC sampling scheme for the model is detailed in Appendix B. Again, following the rationale behind equation (3.6), I define a Revenue Dollar Premium measure for brands for any given retailer $r$ as:

$$
\operatorname{Rrevium}_{r b} \text { Premium Dollar }_{r b}=\sum_{j=1}^{T}\left\{\left[\begin{array}{l}
\text { Revenue from } \\
\text { Branded SKU } j \\
\text { at retailer } r
\end{array}\right]-\left[\begin{array}{l}
\text { Revenue from } \\
\text { Unbranded Equivalent } \\
\text { of SKU } j \text { at retailer } r
\end{array}\right]\right\} \text {. }
$$

\subsubsection{Discussion of Results}

As in Chapter 3, essentially, two sets of results emerge from the analysis - main effects for equation (4.1) and BEM estimates for every retailer-brand combination. The former is checked for intuitive signs and for consistency with similar effects in prior studies in the literature (and thereby for face validity), whereas the latter is investigated for insights into Private Label $\mathrm{BE}$ and an understanding of how retailer characteristics relate to National and Private Label BE.

\section{Revenue Component Parameter Estimates}

Table 9 lists the mean and the 95\% highest probability density (HPD) intervals of the main effects estimates of the model. For the Product Revenue Component, I find that after controlling for other factors, caffeine is a hit with CSD consumers, cans and glass containers are preferred to plastic ones, and that citrus and fruit based CSD types sell well whereas root beer, relatively, does not. Even though the smallest CSD type by revenue, cream soda, has a small number of SKUs, negligible promotion and availability 
limited to select stores, it sells relatively well at these stores and consequently has a large coefficient. Multi-unit packs sell better than do single units and small pack sizes. Berries and pepper flavors find favor with consumers, controlling for their relative marketing mix efforts. Many but not all of the main effects in the Product Revenue Component are significantly different from zero. This occurs because the latent SKU and variant factors $\eta_{r j}$ and $\xi_{r v}$ capture a lot of the variation in revenue that would otherwise be accounted for by observed product attributes ${ }^{14}$. In line with Essay 1, I find that the relative size of sum of the systematic variance components $\left(\sigma_{\xi}^{2}+\sigma_{\eta}^{2}\right)$ is greater than (almost twice in this case) that of the random error term $\sigma_{u}^{2}$ implying that the bulk of the unexplained variation in sales is attributed to systematic latent factors at the variant and SKU levels.

For the Promotion Revenue Component, I show the mean of the random coefficients of the promotion variables in Table 9. I find that on the average across retailers, advertising spend by National Brands significantly and positively impacts sales, inter-product competition negatives impacts sales, and increased merchandizing activity stimulates sales (e.g., Kumar and Leone, 1994). Table 10 displays the individual estimates for each $\gamma_{r}$ by retailer, obtained directly from the MCMC routine. The estimates in Table 10 clearly show that (i) there exists heterogeneity in the response parameters to the promotion variables across retailers, (ii) the revenue elasticity by retailer of merchandizing activity as well as the response sensitivity by retailer to advertising are all significant and of the expected positive sign, and (iii) the effects of Competition are

\footnotetext{
14 Again, a simple hedonic OLS regression without $\eta_{r j}$ and $\xi_{r v}$ confirms this. Most of the Product variables are significant when latent SKU and variant specific factors are removed from the model.
} 
negative and significant for all retailers except Retailer 5 for which it is statistically insignificant.

In the Distribution Revenue Component, I find that increased access to buying power boosts sales as does increased shelf-space. The revenue elasticity of distributional reach is close to one (at 1.193) indicating that a $1 \%$ increase in access to buying power raises sales by a little over $1 \%$. This is comparable to the result in Essay 1 .

In the Category Drivers Revenue Component, I find that seasonality is important as CSD sales rise with outdoor temperatures. Sales in summer are significantly above those in spring which in turn are significantly above those in the fall. The five retailers in the sample sold more CSD in 2006 (\$263 million and 61.8 million cases) than in 2005 (\$222 million and 56.5 million cases). Hence, the negative sign on Year2005. CSD sales

rise significantly with a rise in the mean household income of shoppers (Dhar and Hoch, 1997) and drop significantly with increasing income heterogeneity. Thus, these consumer characteristics main effects bear expected signs. Among retailer characteristics, the reference retailer (Retailer 2) has the lowest category revenue and hence, expectedly, the lowest retailer fixed effect.

In sum, the main effects, including individual promotion response estimates by retailer, appear intuitive in sign and reasonable in magnitude. This lends face validity to the results.

\section{BEM Discussion}

Columns (2) to (6) in Table 11 list the mean BEM estimate for each retailerbrand combination and the 95\% Highest Probability Density (HPD) interval for each estimate. The mean BEM estimates range between 5.36 for Sprite in Retailer 1 to 1.04 
for Canada Dry in Retailer 4, and indicate that on the average, CSD brands earn 1.63 times more in revenue than their unbranded equivalents do. This translates into an average $38.7 \%$ brand contribution to revenue ${ }^{15}$.

Column (7) in Table 11 lists the grand mean and standard deviation of the crossretailer mean BEMs for each brand. Clear heterogeneity can be discerned in BE across brands and retailers. Even the large National Brands are strong in some retail chains but weak in others. Indeed, apart from Sprite, no National Brand scores a statistically significantly high BEM in all five retailers. Further, the variation of BEM across retailers has a distinct regional flavor. The brands of PepsiCo Inc. (Pepsi, Mug Root beer, Sierra Mist, and Mountain Dew) are stronger at Retailers 3, 4 and 5 which are located largely in the Northeastern U.S., where PepsiCo Inc. was founded and has been historically strong. Alternately, Coca-Cola brands (Coca-Cola, Fresca, Sprite and Fanta) are relatively stronger at Retailers 1 and 2 which are located largely in the Southern U.S., where CocaCola has historically been the dominant player.

The main result of the study relates to Private Label BEs. I find that two Private Labels, those from Retailers 3 and 4, have BEM significantly greater than one in that their $2.5 \%$ HPD interval is above $1.05^{16}$. Hence, these Private Labels are "brands" in their own right. Extant BE measurement methods that would have normalized these

\footnotetext{
${ }^{15}$ This figure (38.7\%) is higher than the average for national beer brands (21\%) suggesting that brand contributions vary by category. Comparing the categories, CSD appears more concentrated because $95 \%$ of category sales in CSD come from 14 brands whereas $90 \%$ of category sales in beer come from 25 brands to cover. Higher concentration implies greater average market share, market power and possibly, higher average BE for brands in CSD than in beer. Another explanation is that for beer, both sales and advertising data were national data whereas in CSD, sales are local whereas advertising data are national. Thus, the lack of local advertising data could impact the explanatory power of the model and thereby the magnitude of the BE estimates.

${ }^{16}$ At this level, the Monte Carlo error in the simulations is comfortably below the lower limit for all retailer-brand combinations and hence, the concerned BEM value can be considered as significantly different from 1.00 .
} 
brands to zero equity would be biased. In fact, the mean BEMs of the Private Labels of Retailers 3 and 4 are higher than that of some National Brands these retailers carry.

The question then arises, 'What is it about Retailers 3 and 4 that makes their Private Label BEs significant and relatively high'? To address this, I compare the retailer profiles in Table 8. This table clearly shows that the Private Labels of Retailers 3 and 4 have the highest Private Label penetrations (i.e. ratio of Private Label revenues to total category revenues), the highest sales in revenue and volume terms and the lowest average price among the sampled Private Labels. Evidence in the literature suggests that such summary measures strengthen Private Labels (see, e.g., Raju et al, 1995; Hoch et al, 1995). In particular, I focus attention on the relation between the price and the BEM of Private Labels.

Price is often seen as a proxy for quality in vertically differentiated productmarkets (Frank, Massy, and Wind, 1972). Private Labels attempt to position themselves in a price-quality sweet spot (from a consumer perspective) of high quality at relatively lower prices. This raises the question of how price affects Private Label BE vis-à-vis National Brand BE. Price appears to play a contrasting role in National Brands and in Private Labels. To visualize this, I plot the cross-sectional average of BEM against price in cents per oz for all the brands in Figure 1. The solid circles are Private Labels and the solid diamonds represent the means of the National Brand BEMs. I then fit a simple LOWESS $^{17}$ curve to depict the trend non-parametrically. The figure makes clear that price relates negatively to Private Label BEM (the curve dips) and positively to National Brand BEM (the slope is positive). An explanation is that the value proposition of the

\footnotetext{
17 Locally weighted scatterplot smoothing using polynomial regressions, first proposed by Cleveland
} (1981). 
two groups is different. Ailawadi, Neslin and Gedenk (2001) relate Private Label associations with "economic benefits and costs" and National Brand associations with "hedonic benefits and costs". Figure 1 lends support to this conjecture that National Brands compete on 'subjective experience per dollar' (Economist, 2007) whereas Private Labels compete on 'objective quality per dollar'. Intuitively, a 'subjective experience' approach to product choice suggests an emphasis on certain psychological benefits such as salience, prestige and luxury, whereas 'objective quality' suggests a value-for-money approach to purchases. In agreement with the value proposition hypothesis, I find that higher priced Private Labels have lower BE because they violate this general value proposition of Private Labels.

Finally, I examine how BEMs in general (for both National and Private Labels) relate to retailer characteristics. To do this, I measure correlation, ex-post, between BEM, Revenue Dollar Premium, and category specific characteristics at particular retailers such as average brand prices, average brand sales and the average available shelf space to a brand.

Table 12 shows the Pearson correlation coefficients $\rho$ and the associated $\mathrm{p}$ value for a chi-square test of $|\rho|=0$. All the correlations are significant at the $95 \%$ confidence level. Overall, these findings appear intuitive and consistent with the literature. I detail five interesting points of note.

First, the BEM and Revenue Dollar Premium are significantly correlated yet relate differently to price per oz. In the case of BEM, price can be considered a proxy for quality (Frank, Massy and Wind, 1972) and BEM relates positively to price suggesting that $\mathrm{BE}$ measures some consumer perception of product quality underlying the brand. 
On the other hand, CSD as a category has its modulus of price elasticity greater than one $^{18}$ and hence, lower prices should imply greater sales and revenues. Correspondingly, Revenue Dollar Premium relates negatively to price. Together, these correlations of opposite sign imply that the BEM and Revenue Dollar Premium measures capture different aspects of the BE construct. Second, as expected, both BE measures relate positively to sales revenue, lending face validity to the BE measures. Third, BEM and Revenue Dollar Premium correlate positively and significantly with the average number of SKUs carried by a brand. This is intuitive in that brands with a larger number of SKUs are able to compete at different size points, garner relatively more shelf space and thereby increase revenues. For a given level of marketing mix support, this translates into higher BE.

\subsection{Managerial Implications and Summary}

The conceptual model of $\mathrm{BE}$ as random effects naturally lends itself to assessing whether particular Private Labels have brand equity since the BEM measure does not require a particular real world product (typically a Private Label or low share National Brand) to be normalized to a predefined equity level (usually zero). In this essay, I adapt my conceptual framework to a multi-retailer setting and incorporate the use a random coefficients specification to account for response heterogeneity across retailers. Further, I draw the BEMs of all retailer-brand combinations from independent BE distributions for each retailer. The BE estimates bear face validity in that they are of reasonable magnitude and of intuitive sign.

\footnotetext{
18 The magnitude of the price coefficient in a simple log-log regression of sales volume against price and product attributes confirms this.
} 
Some implications for managers emerge. The BE estimates promise to be of interest to both manufacturers and retailers who would like to assess whether Private Labels have brand equity, and how this equity compares to that of National Brands. The primary result of the study, as managers and researchers have long suspected, is that some Private Labels indeed have BE, and therefore, are brands.

Further, the BE estimates of Private Labels present evidence favoring an "economic benefits and costs" value proposition, in the carbonated soft drinks category. For instance, I find that the BE of Private Labels correlates negatively with the price of Private Labels whereas that of National Brands correlates positively with price. This strongly suggests that the consistent value proposition of the Private Label is an "economic benefits and costs" one, that for National Brands is a "hedonic benefits and costs" one and agrees with results in extant literature (e.g., Ailawadi, Neslin and Gedenk, 2001; Hansen et al, 2006).

The existence of response heterogeneity to promotional activity across retailers is clear. Thus, retailers differ in their ability to deploy promotional mix elements to influence sales and thereby, residual BE. The proposed model, allows managers to assess the efficacy and efficiency of different marketing plans by offering the opportunity to integrate the effects of marketing mix variables into the study of $\mathrm{BE}$, while maintaining promotional response differentials across retailers.

Another fruitful area of study implied by the model is an extension to other categories. Private Label marketing and pricing strategies are likely to vary by retailer and by category. Replicating the analysis across categories can yield insights into how product characteristics and marketing plans can be tailored to best fit a retailer's consumer base. 
While this study was conducted at the level of the retail chain, it is relatively straightforward to extend the study of BE to a lower level (that of individual stores, cities, regions) or to a higher level such as across pricing formats (Hi-Lo or EDLP) or retailer types (Food, Drug, Mass and Value). Such applications of the model could reveal interesting insights about how BE might depend on and vary across retailing arrangements. 


\section{Chapter 5}

\section{Spatial Patterns in Brand Equity}

\subsection{Motivating the Study}

This chapter presents the body of Essay 3 and is primarily concerned with the incorporation of geospatial location information into the study of BE. The introduction and literature survey for this Essay are partly covered in Chapters 1 and 2.

US metropolitan markets differ in demographic composition which implies potentially different consumer segment sizes, and these differences could influence product demand, consumption patterns and brand preferences. Thus, since U.S. metropolitan markets differ in so many ways, I inquire into whether BEs in these markets also differ, and whether they vary systematically with any market specific factors such as demographic composition or geographic location.

Further, one market's brand related outcomes could be influenced by those in nearby markets. Thus, the location, distances, and sizes of a group of markets in a region could contain information about the distribution of BEs across those markets. This brings me to the second objective of this essay - to investigate the existence and nature of any spatial patterns in BE across geographical markets.

I apply the conceptual model for BE estimation under random effects separately to each city market, thereby obtaining one set of BE estimates for each market. Spatial analysis studies typically assume a multivariate normal covariance structure. In this application, since the BE estimates are clearly non-normal, I develop a distribution-free approach to estimating spatial parameters based on a Generalized Least Squares (GLS) 
method. This constitutes this essay's methodological contribution. Lastly, I discuss the insights and the managerial implications that emerge from the analysis results.

\subsection{Data and Variables}

I use data on aggregate beer sales in each of 49 U.S. metropolitan markets at the SKUquarter level. The sample covers 2 years (2006-07). Table 13 shows a descriptive summary of the variables used. Both the data sources and the product category under analysis (beer) are the same as in Essay 1. Hence, the variable descriptions are also the same as in Essay 1, but at different levels of aggregation (particular metropolitan markets in Essay 3 as against nationwide figures in Essay 1). Correspondingly, all data in this essay carry the additional subscript $m$ denoting the particular metropolitan market in which the data point applies. A comparison between Tables 1 and 13 shows significant overlap in many of the variables used, particularly in the Product, Promotion and Distribution Revenue Components. I now detail the differences between the two sets of data and variables in a concise manner.

In the Product Revenue Component, Color is not included because information from AC Nielsen descriptors for some variants was not available. Subjective Taste is not included because it is a national level measure and is likely to vary significantly across markets. All the other variables in the Product Revenue Component are the same as those in Essay 1. For the Promotion Revenue Component, as in Essay 2, I use \$MnACV Merchandizing instead of \%ACV Merchandizing because the \$MnACV measure provides for an absolute size comparison across markets. Likewise in the Distribution Revenue Component, I use \$MnACV Distribution instead of the \%ACV 
Distribution. All the other variables in the Promotion and Distribution Revenue Components, are the same as those in Essay 1.

In the Category Drivers Revenue Component, one year dummy Year2005, and three quarter rather than season dummies Quarter 1, Quarter 2 and Quarter 3, are included in the analysis, in line with the sample period chosen. Freight PPI is not included because it is a national level measure and is likely to vary significantly by geographical market.

Table 14 shows a summary of the characteristics of the 18 brands in the sample, including the Brand Age in years to 2007. Table 15 shows market characteristics, primarily demographics, taken from the Census Bureau. These are the mean annual Income in a metropolitan market, the market's total adult Population (aged 21 and above), and the percentage of ethnic minorities (\% Minority) in a market. In addition to these market specific characteristics, I define a market-brand level variable OriginDistance, for distance in thousands of miles from a particular brand's place of U.S. origin ${ }^{19}$ to a metropolitan market.

After removing products with quarterly sales below $\$ 100$ in a U.S. metropolitan market, brands that have only one variant in a market or variants that have only one SKU in a market, I have 85,510 observations remaining comprising 649 SKUs and 73 variants for the top 18 beer brands across 49 U.S. metropolitan markets.

\footnotetext{
${ }^{19}$ For domestic brands, the place of U.S. origin is either where the brand was first brewed or the market
} where it was first launched. For imported brands, I use the location of the brewer's U.S. head office. 


\subsection{Model Development}

I propose a two-stage model. In Stage I, Brand Equity Multipliers (BEMs) are estimated following the general conceptual model in Chapter 1. In Stage II, these BEMs are related to market characteristics, and the influence of BEMs in neighboring markets.

\subsubsection{Brand Equity Estimation}

I implement the proposed random effects model separately on each market. This is because replicating the model independently for each market yields flexibility and accuracy in the values of the response parameters for both the variables and the BEM values. Further, the underlying BEM distribution is identified separately for each metropolitan market, after all observable demand effects specific to that market have been accounted for.

The estimated model equation is:

$$
\begin{aligned}
& \operatorname{Ln}\left(\text { Revenue }_{m j t}\right)=\beta_{0}^{(m)}+\left[\sum_{a=1}^{A} \beta_{1, a}^{(m)} \operatorname{Ln}\left(\text { Product }_{a, m j}\right)+\xi_{m v}+\eta_{m j}\right] \\
& +\sum_{c=1}^{C} \beta_{2, c}^{(m)} \operatorname{Ln}\left(\text { Promotion }_{c, m j t}\right)+\sum_{d=1}^{D} \beta_{3, d}^{(m)} \operatorname{Ln}\left(\text { Distribution }_{d, m j t}\right) \\
& +\sum_{p=1}^{P} \beta_{4, p}^{(m)} \operatorname{Ln}\left(\text { Category Drivers }_{p, t}\right)+\operatorname{Ln}\left(\operatorname{BEM}_{m b(j)}\right)+u_{m j t} .
\end{aligned}
$$

Here, the subscript $m$ indexes market, $j$ indexes SKU, and $t$ indexes time period. The unit of analysis for each market is SKU-quarter. Essentially, the model in (5.1) is replicated 49 times, once for each metropolitan market. Thus, the vector of demand determinants such as marketing mix variables and category characteristics in market $m$ for $\operatorname{SKU} j$ in 
period $t$, and the associated coefficient vector $\boldsymbol{\beta}^{(m)}$, are market specific. The error term $\varepsilon_{m j t}$ is composed of four IID variance components:

$$
\varepsilon_{m j t}=\operatorname{Ln}\left(\operatorname{BEM}_{m b(j)}\right)+\xi_{m v}+\eta_{m j}+u_{m j t} .
$$

The first three variance components in equation (5.2) capture revenue heterogeneity due to the systematic action of unobserved factors at the brand, variant and SKU levels, following the rationale discussed in Chapter 1. Consistent with equation (1.7), I assume the following three variance components in equation (5.2) to be distributed mean zero normal:

$$
\begin{aligned}
\xi_{m v} & \sim \operatorname{IID} N\left(0, \sigma_{m, \xi}^{2}\right) ; \\
\eta_{m j} & \sim \operatorname{IID} N\left(0, \sigma_{m, \eta}^{2}\right) ; \\
u_{m j t} & \sim \operatorname{IID} N\left(0, \sigma_{m, u}^{2}\right) .
\end{aligned}
$$

The variance component $\operatorname{Ln}\left(\operatorname{BEM}_{m b(j)}\right)$ is assumed distributed IID exponential (van den Broeck et al, 1994) with parameter $\lambda_{m}$ for each market $m . \lambda_{m}$ in turn is assumed distributed gamma with hyper-parameters $\alpha_{m}$ and $\gamma_{m}$, thus:

$$
\begin{aligned}
& \operatorname{Ln}\left(\operatorname{BEM}_{m b(j)}\right) \sim \operatorname{IID} f_{\text {Exponential }}\left(\lambda_{m}\right) \\
& \lambda_{m} \sim f_{\text {Gamma }}\left(\alpha_{m}, \gamma_{m}\right) .
\end{aligned}
$$

The outcome at this stage is a set of Brand Equity Multipliers (BEMs) for each brand in each of the markets in which it is available. These BEM estimates are used as an input to a spatial analysis of the observed BEMs. 


\subsubsection{Spatial BEM Analysis}

I posit that product-market outcomes in neighboring markets are likely to be correlated due to both demand and supply side reasons. On the demand side, geographical proximity is likely to result in such things as similar climactic conditions, a shared regional ethos (for instance, the southern U.S. is culturally distinct from the Pacific Northwest), and a greater possibility of interpersonal interaction between the people of neighboring metropolitan markets relative to those between far-away markets. All these cause consumers' tastes and preferences in one market to be influenced by those in neighboring markets. On the supply side, firms establish distribution centers to service geographical regions, large multi-product firms tend to allocate sales territories on a geographical basis, and firms cultivate channel relationships that are often regional in scope (Bronnenberg et al, 2005). Taking the two together, there is reason to believe that markets located near one another are likely to have related product-market outcomes. Evidence in the literature also points in this direction. For instance, Bronnenberg, Dhar and Dube (2005) find a strong spatial component to the growth of brands into new markets by tracking historical market shares in the coffee category. Bronnenberg and Mahajan (2001) also find significant spatial dependence in the market shares and promotions of brands.

The assumption of spatial association in brand equities across markets is easily testable. I use Moran's I and Geary's C statistics (p. 442 in Cressie, 1993) to test for the existence of spatial association. For every market in the sample, I label the markets within a certain radius as 'neighbors' and posit that the BEMs of neighbors are correlated. Anselin (1988) shows that when spatial association exists and is significant, 
then ignoring it could yield biased, inconsistent and/or inefficient model parameters. This means that in the current application, ignoring significant geospatial association between markets could yield biased and/or inefficient estimates of main effects. Further, the degree of spatial association itself is of interest. So I propose a spatial model to explicitly estimate these effects.

Both the spatial association tests and the spatial analysis model of BEM outcomes are implemented on a brand by brand basis. The reason is that since for any market, the influence of BEMs from neighboring markets could very well vary by brand, different brands could have different strengths of spatial association. Thus, performing separate analyses by brand affords more flexibility because each brand now has its own unique spatial correlation parameter, as well as more realistic brand-specific BEM determinant estimates. I next develop a spatial effects model for BEM outcomes in Stage II of the analysis. The two-stage method is simple, easy to implement and consistent with the parametric assumptions on the BEM term made in Stage I.

One of the most commonly used models in the spatial analysis of natural and social phenomena is the Spatial Autoregressive (SAR) error model, first put forward by Cliff and Ord $(1973 ; 1981)$. In the SAR model, the error terms are assumed to be spatially correlated in a particular way. In general, for a simple linear relation given by $\mathbf{Y}=\boldsymbol{\beta} \mathbf{X} \boldsymbol{\varepsilon}+$, and a spatial weights matrix $\mathbf{M}$ that expresses the spatial map as some function of inter-unit distances, the error structure implied by the SAR model can be expressed as $\boldsymbol{\varepsilon}=\phi \mathbf{M} \boldsymbol{\varepsilon}+\mathbf{u}$ where $\mathbf{u}$ is $\operatorname{IID}\left(0, \sigma_{u}^{2}\right)$. This specification leads to an autoregressive component with parameter $\phi$, thus: 


$$
\begin{aligned}
& \boldsymbol{\varepsilon}=\phi \mathbf{M} \boldsymbol{\varepsilon}+\mathbf{u} \Rightarrow \boldsymbol{\varepsilon}=(\mathbf{I}-\phi \mathbf{M})^{-1} \mathbf{u} \\
& \Rightarrow \mathbf{Y}=\boldsymbol{\beta} \mathbf{X} \quad \mathbf{I}(\mathbf{A} \boldsymbol{\phi})^{-1} \\
& \Rightarrow \mathbf{Y}=\phi \mathbf{M Y}+\boldsymbol{\beta}(\mathbf{I} \mathbf{t} \phi \mathbf{M}) \mathbf{X}+\text {. }
\end{aligned}
$$

The SAR model implies that the dependent variable $\mathbf{Y}$, after removing the effects of known determinants, is correlated with the $\mathbf{Y}$ in neighboring locations leading to spatial externalities (Anselin, 2001). The strength of these spatial associations is typically measured using a scalar $\phi$, termed the spatial antoregressive parameter. Thus, from the model in equation (5.5):

$$
\begin{aligned}
& E(\boldsymbol{\varepsilon})=0 \\
& V(\boldsymbol{\varepsilon})=\boldsymbol{\Sigma}_{\phi}=\sigma_{u}^{2}(\mathbf{I}-\phi \mathbf{M})^{-1}\left((\mathbf{I}-\phi \mathbf{M})^{-1}\right)^{T} .
\end{aligned}
$$

Extant literature typically assumes that $\boldsymbol{\Sigma}_{\phi} \sim M V N($.$) and proceeds with$ maximum likelihood estimation. But in the current application, the BEMs as dependent variables have a particular distributional form that is clearly non-normal. Hence a multivariate normal distribution is not appropriate. This also jeopardizes maximum likelihood approaches to the estimation problem. Consequently, I propose a distribution free approach that iterates between a method of moments (in a GLS specification) and a nonlinear search to obtain parameter estimates. I detail the approach forthwith.

I model:

$$
\text { BEM } \left.\sim \boldsymbol{\gamma} f \mathbf{\Psi} Z,{ }_{\phi}\right)
$$

where the covariance structure, denoted by $\boldsymbol{\Sigma}_{\phi}$, depends on spatial autocorrelation parameter $\phi$ and a spatial weights matrix $\mathbf{M}$ following a SAR specification, thus:

$$
\boldsymbol{\Sigma}_{\phi}=\sigma_{u}^{2}(\mathbf{I}-\phi \mathbf{M})^{-1}\left((\mathbf{I}-\phi \mathbf{M})^{-1}\right)^{T}
$$


Each element $(k, l)$ of the spatial weights matrix $\mathbf{M}$ has the form:

$$
\mathbf{M}(k, l)=\left\{\begin{array}{l}
\frac{\text { Population }_{l}}{d(k, l)} \text { if } 0<d(k, l) \leq 200 \text { miles } \\
0 \quad \text { otherwise. }
\end{array}\right.
$$

Here, Population, is the population of market $l$, and $d(k, l)$ is the distance in miles between markets $k$ and $l$. Thus, $\mathbf{M}$ implicitly defines a neighborhood structure that defines as "neighboring markets" those within a certain radius of a given market. The spatial externality comes through because every market exerts a spatial "neighborhood" effect on the BEMs of its neighbors. In the construction of $\mathbf{M}$, I tested different radii between 100 miles and 500 miles in increments of 50 miles and found the difference in results is not large between two adjacent radii. I choose a radius of 200 miles to define neighborhoods around any market, partly because it is considered a drivable distance for out-of-town visits. Thus the likelihood of people-to-people interaction between towns less than 200 miles apart is likely to be significant. Also, I note that edge effects are possible. To see this, consider as an example that Buffalo, NY, present in the data, has a large market, Toronto, within its 200 mile radius that is not present in the data. I abstract away from edge effects in this analysis and assume their net impact to be negligible. One standalone market in every sense is Honolulu which has no neighbor and which is not a neighbor to any other market in the data.

Equation (5.9) implies that the spatial effects of market $l$ on market $k$ increase with the population of market $l$ and decrease with the distance between $k$ and $l$. This formulation allows $\mathbf{M}(k, l) \neq \mathbf{M}(l, k)$, which effectively makes the spatial effect asymmetric across members of a market pair. A similar application can be seen in the 
work of Parent and LeSage (2008) who use a spatial weights matrix that weighs the relative levels of economic activity between contiguous regions to measure knowledge spillovers. Their weights matrix weighs neighboring regions asymmetrically depending on GDP levels. I further row-standardize ${ }^{20}$ the weights matrix $\mathbf{M}$ so that $|\phi|<1$ (Bannerjee, Carlin and Gelfand, 2004). In sum, $\phi_{b}$ is the autocorrelation parameter for brand $b$ and it represents the degree to which $\mathrm{BEM}_{b}$ levels in a group of neighboring markets are on the average, correlated with one another. Another interpretation, more typical of SAR in spatial statistics, is that $\phi_{b}$ represents the degree to which the $\mathrm{BEM}_{b}$ of a given market can be predicted using the average of the BEMs of the neighboring markets. A $\phi_{b}$ value of 1 or -1 indicates a perfect correlation with the neighbors' average.

I propose a three-step iterated procedure (GLS and nonlinear search in oneparameter) that does not make assumptions about any particular functional form for BEM. First, I start with any randomly drawn feasible set of initial values $\left\{\phi_{b}, \sigma_{u, b}^{2}\right\}$ and compute the GLS coefficients for main effects in this stage. Thus:

$$
\begin{aligned}
& \text { Step 1: } \quad \hat{\boldsymbol{\gamma}}_{G L S}^{(b)} \mid \phi_{b}, \sigma_{u, b}^{2}=\left(\mathbf{Z}^{T} \boldsymbol{\Sigma}_{\phi(b)}^{-1} \mathbf{Z}\right)^{-1} \mathbf{Z}^{T} \boldsymbol{\Sigma}_{\phi(b)}^{-1} \mathbf{B E} \mathbf{M}_{b} \text {, } \\
& \text { Step 2: } \quad \hat{\sigma}_{u, b}^{2} \mid \hat{\gamma}_{G L S}^{(b)}, \hat{\phi}_{b}=\operatorname{Var}\left[\left(\mathbf{I}-\hat{\phi}_{b} \mathbf{M}\right)\left(\mathbf{B} \mathbf{E} \mathbf{M}_{b}-\mathbf{Z}_{G L S}^{(b)}\right)\right] \text {, }
\end{aligned}
$$

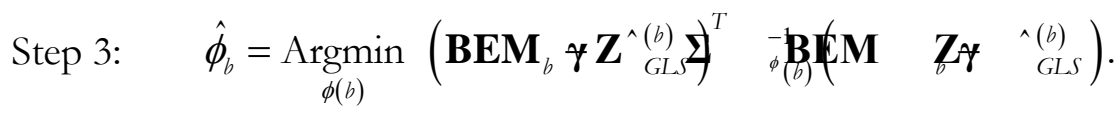

\footnotetext{
${ }^{20}$ Standardizing $\mathbf{M}$ involves normalizing each row (by dividing by the row-sum) of the un-standardized weights matrix to sum to 1 .
} 
Steps 1, 2 and 3 are iterated until the change in the estimates falls below a pre-selected relative tolerance threshold of $\left(10^{-8}\right)^{21}$. Inference can be done by using the asymptotic variance of the GLS estimator for $\hat{\boldsymbol{\gamma}}_{G L S}^{(b)}$ :

$$
\text { Asy. } \operatorname{Cov}\left(\hat{\boldsymbol{\gamma}}_{G L S}^{(b)}\right)=\left(\mathbf{Z}^{T} \mathbf{\Sigma}_{\phi(b)}^{-1} \mathbf{Z}\right)^{-1} \text {. }
$$

Performing inference on $\hat{\phi}_{b}$ and $\hat{\sigma}_{b}^{2}$, is not straightforward. Bootstrapping is ruled out because it requires independent observations whereas the model assumes spatially dependent observations. Keleijan and Prucha (1999) compare the bias and performance of moment-based estimators for a SAR model with a multivariate-normal (MVN) quasi-maximum likelihood (quasi-ML) specification and find that the former, nonlinear least squares (NLS) based estimator has properties very similar to the quasiML based one. Following their results, I specify a MVN-based quasi-ML specification for which I obtain standard errors from the Hessian matrix. I compare the estimates of the quasi-ML and the NLS estimators and see if the inference on the quasi-ML estimates can be carried over to the NLS case. To sum up, for the purpose of inference, I estimate:

$$
\mathbf{B E M}_{b} \gamma \operatorname{MVN}\left(\mathbf{Z}_{b}^{\sim}, \quad \phi(b)\right)
$$

Following Keleijan and Prucha (1999), I compare the estimates from the quasi-ML $\left(\phi_{b}^{M L}\right)$ with those from NLS $\left(\phi_{b}^{G L S}\right)$, and where the correlation is high (above 0.90), and

\footnotetext{
${ }^{21}$ There is no guarantee of convergence. Different starting points can be attempted to see if the same optimum is achieved each time. In all of my applications of the algorithm, the same optimum is achieved and the solution rapidly converges to below the specified tolerance threshold.
} 
the tests for spatial association show significant spatial dependence, I assume that the brands that show significant $\left(\phi_{b}^{M L}\right)$ also show significant $\left(\phi_{b}^{G L S}\right)$.

\section{$5.4 \quad$ Discussion of Results}

The results that emerge from the analyses comprise 49 sets of main effects parameters for the model in equation (5.1), one for each market, 49 sets of BEM estimates, one for each market, and 18 sets of spatial analyses results, one for each brand.

\section{Revenue Component Parameter Estimates}

Table 16 summarizes the main effects from all the 49 markets sampled. Figure 2 shows box-plots to depict the dispersion of these 49 sets of coefficients for the packaging variables in the Product Revenue Component. Figure 3 does likewise for variables in the Promotion and Distribution Revenue Components. These plots display the cross-sectional mean (the solid vertical line inside the shaded box) and dispersion (the length of the shaded box) in each set of 49 coefficients. The last column in Table 16 shows the number of markets where the variables are significantly different from zero. In general, I find that the main effects obtained are intuitive in sign, appear reasonable in magnitude ${ }^{22}$, and are consistent with those in Essay 1.

For the Product Revenue Component, the number of markets with significant parameter estimates indicates that whereas preferences over packaging types are sharply defined across the markets, those over beer types are not. Among packaging attributes, Cans, Cases and 12 Packs are heavily preferred controlling for other factors. This is easily

\footnotetext{
${ }^{22}$ The magnitude is reasonable in the sense that the order of the significant main effects is preserved. For example, Distribution impacts revenue more than does Merchandizing, which in turn is more impactful than Advertising, and this order is seen across markets.
} 
visualized in the box-plots of Figure 2. Many product attribute variables are not significantly different from zero partly because unobserved variant and SKU level factors explain a lot of the variation in SKU sales and these are captured in the variance components. In line with the results in the preceding two essays, I find that the variances of the latent variant and SKU factors are much larger (6.6 times) than those of the IID measurement error.

In the Promotion Revenue Component, advertising is positively and significantly related to revenue in the clear majority of metropolitan markets sampled. Panel (a) in Figure 3 brings this out. The mean of Competition is expectedly negative though the dispersion of coefficients is wide and only 17 of the 49 cases are significantly different from zero. Some estimates of the Competition coefficient spill over into positive territory, where they are not significantly different from zero (Panel (b) in Figure 3). One reason for the low significance of the coefficient for Competition is that beers similar in attributes often promote at the same time in the same market but at different stores on high consumption occasions. Since the data make no distinction regarding where in the market the product sold, in-phase promotional activity could potentially weaken the negative effect of competition. Merchandizing positively and significantly relates to revenue in every market sampled (Panel (c) in Figure 3).

For the Distribution Revenue Component, I find that revenue relates significantly positively to both the distributional reach of an item and the shelf space of it's variant. Even the smallest of the response coefficients for these variables are clearly above zero (Panels (d) and (e) in Figure 3). This is intuitive and in line with previous results. 
In the Category Drivers Revenue Component, the year 2006 had total sales for the sampled brands slightly below those of year 2005 in most cities. Accordingly, the coefficient for Year2006 is mainly negative. Quarter 3 revenues were higher than those in other quarters for almost all the markets sampled. This is intuitive because Quarter 3 includes the warm months of July and August and records the highest average outdoor temperature in most of the sampled markets compared to the average temperature of other quarters.

\section{BEMs Discussion}

Tables 17 and 18 display the summaries of the BEM estimates by brand and by market, respectively. Comparing Column (2) of Table 5 with Column (3) of Table 17, I find that in general the cross-sectional average BEMs estimated in this study are a bit larger than those in Essay 1. BE contribution to revenue here is 33\% as opposed to $20 \%$ from nationwide data. This could be partly because explanatory variables such as Subjective Taste and beer Color are not included in this study (the reasons are discussed in Section 5.2.1). Hence, despite the inclusion of variant level random effects, BE possibly captures some of the explanatory power that would otherwise go to these variables. Another difference is that these 49 metropolitan markets concentrate demand (they account for $40.1 \%$ of national sales in the grocery channel) and thereby, potentially, $\mathrm{BE}$ as well. There are also slight differences in sample composition (the top 25 brands in Essay 1 against the top 18 brands in this study) that may affect the average BEM figures.

Looking at Tables 17 and 18, it becomes clear that there is substantial heterogeneity in BEM levels across both brands and markets. This heterogeneity in BEM suggests the presence of underlying heterogeneity in consumer preferences and 
consumption patterns. Another implication of heterogeneity is that opportunities to segment the market and target consumer groups are likely to obtain. I next explore the BEM heterogeneity in brands and in markets.

First, I examine cross-market variation in BEMs. Table 18 lists summaries of BEM levels for each of the 49 markets sampled. It indicates two patterns of BEM variation, one between coastal and inland markets, and the other between different U.S. regions. Coastal markets have relatively higher mean BEM levels (indicating relatively greater brand preference among consumers in these markets) and a higher dispersion in BEM values (indicating a greater difference between strong and weak brands in these markets) than do the inland markets. To illustrate, markets in the Northern and Midwestern U.S. such as Buffalo, Cincinnati, Minneapolis, Detroit and Columbus show a low mean and standard deviation in their BEM levels. This means that after accounting for marketing mix and other demand determinants, these markets show little variation in BEMs across the sampled brands. One reason could be that this general area has been facing weak economic conditions for some time and hence, consumer preferences could have been affected. In contrast, markets in the southern U.S. and in the coastal regions show high standard deviation in BEM levels indicating strong variation in preferences across brands in these markets. These regions have seen relatively more dynamic economic activity at least since the 1980s. They have attracted settlers from diverse backgrounds likely leading to greater consumer segmentation and stronger brand preferences among consumers, and hence higher BEM levels. Managers in firms looking to test new products or new marketing efforts can incorporate the mean and variance in BEM levels in those markets as an input to their selection criteria. 
Another pattern that emerges from cross-market BEM heterogeneity is that U.S. regions such as the Midwest and the South, differ substantially in their BEMs. Figure 4 displays a box-plot showing the mean and dispersion of the BEMs for six broad U.S. regions. The highest BEM levels are recorded in the South and the West Coast whereas the lowest are in the Midwest and the Northeast. Migration reports show that the Southeast and the West continue to attract new residents even as the Midwest and the Northeast continue to lose residents, a consistent trend maintained since at least the mid 1990s (United van Lines, 2006). On the one hand, the Ageing Studies Branch under the Population Division of the U.S. Census Bureau finds that people in the 20-29 age group are the ones most likely to move, with migration probability decreasing after that until retirement age 65 (He et al, 2005), whereas on the other hand, younger people constitute a big beer consumer group (Adams Beer Handbook, 2006). Taken together, these trends suggest that the regions in the U.S. with the highest BEM levels are the ones reporting the highest net inbound migration, and thereby likely to be the most economically dynamic.

To visualize BEM heterogeneity in each brand across markets, I draw box-plots for six different brands in Figure 5. These plots display the cross-sectional mean and spread of the BEMs for each brand. The box-plots clearly show that the imported brands (Corona, Heineken and Labatt in Panels (c), (d) and (e), respectively) have a relatively higher mean than do the domestic brands (in Panels (a), (b) and (f)). The crossmarket standard deviations in BEMs, which are indicative of a heavily skewed BEM profile across markets, are largest for the large imported brands - Heineken and Corona. This could reflect the fact that these imported brands in general tend to be more popular 
in the more cosmopolitan coastal markets than in the heartland ones. This would also explain their BEM skew. Another interpretation is that narrow-focus brands (with a smaller product line in terms of variants and SKUs) such as Samuel Adams and the imported brands have a relatively higher mean and dispersion than do the mainstream brands such as Budweiser and Miller. Niche brands are positioned to appeal deeply to the preferences of a narrow audience (hence the higher mean BEM than for the mainstream brands) and do well only in those markets where their target audience is concentrated (hence, the higher dispersion in BEM).

The importance of removing the influence of marketing mix can clearly be seen. The mean BEM of popular price-class beers such as Milwaukee's Best (at 1.719), Rolling Rock (at 1.554) and Old Milwaukee (at 1.569) is higher than that of even some superpremium price-class beers such as Michelob (1.364) and Samuel Adams (1.473). This is partly because the former have little or no advertising, relatively limited distribution, low promotion activity, and a more focused assortment of SKUs and variants than the latter. Thus, the relative revenue impact of marketing mix actions compared to residual $\mathrm{BE}$ is higher for Michelob and Samuel Adams than for Milwaukee's Best, Rolling Rock and Old Milwaukee. Further evidence in support of the marketing mix affecting BEM levels comes from high-BEM super-premium price-class beers Corona (2.105) and Heineken (1.886) which, similar to high BEM brands in other price-classes, also have a focused assortment of SKUs and a narrow variant line. It is likely that the large assortment of SKUs and variants as well as heavy promotion and distribution that explain a lot of the sales of the large mainstream beers such as Budweiser (1.478), Miller (1.372) and Coors 
(1.224) account for their relatively low BEM levels. These findings are consistent with those in Essay 1.

To illustrate market selection by a niche brand, I take the case of Samuel Adams. In Essay 1, Samuel Adams recorded lower levels of distribution and promotion compared to the national sample average per brand. But in this essay, the data show that Samuel Adams has distribution and promotion levels that are higher than the per-brand average for this sample, across the 49 sampled metropolitan markets. Further, whereas these 49 metropolitan markets accounted for only $40 \%$ of the national sales for all the brands, they account for $85.5 \%$ of Samuel Adams' sales clearly indicating that Samuel Adams is concentrated in the large metropolitan areas. This helps explains it's different BEM levels in this study compared to that in Essay 1.

Demographics are important market characteristics, and marketers often take them into consideration when formulating marketing plans. The question then arises "Do market demographics contain any information about market-specific BEM?" In other words, I ask if BEM relates systematically to demographic factors such as mean Income, total Population, and \%Minority. Further, brand-market factors such as the Distance of the market from the brand's origin city, and Brand Age could also affect BEMs in a market (Bronnenberg et al, 2005). I perform a simple ordinary least squares regression over the stacked BEMs of all brand-market combinations (840 in number) against the explanatory variables listed above. Table 19 displays the results. There does not appear to be much explanatory power (the adjusted $\mathrm{R}$ square is a low $10 \%$ ) and only two variables - Population and Income - are statistically significant despite there being many degrees of freedom. I argue and later show this is due to the substantial 
explanatory power in the geospatial locations of these markets vis-à-vis one another that are ignored in the OLS results of Table 19. This brings me to the discussion of the analysis results that incorporate spatial information.

\subsubsection{Spatial Effects Discussion}

First I check whether the assumption of spatial association holds at all. Table 20 displays the test results for spatial association using the Moran's I and Geary's C statistics. As discussed previously, the tests are performed separately for each brand. The significance of the parameter estimates at the 95\% level is indicated in bold font. Under Moran's I tests, 11 of the 18 brands report significant spatial association whereas under Geary's C, 13 of the 18 brands do so, with significant overlap in the two tests' results. Four brands, Michelob, Icehouse, Labatt and Rolling Rock display no spatial association in their BEM distribution after controlling for the BEM effects of Income and \% Minority ${ }^{23}$.

Having established the presence of spatial externalities in BEMs, I structure the discussion of spatial effects with the help of four questions - (a) Does the use of spatial information improve the estimates of the impact of demographic drivers of BEM? (b) Does the use of spatial information improve the understanding of the role of demographic drivers of BEM? (c) What do the spatial correlation parameters mean and what do they imply for marketers? (d) Does the spatial analysis method developed work as expected?

\footnotetext{
${ }^{23}$ As explained in section 5.3.2, the spatial weights matrix construction takes into account the neighbor's population and geographic distance. So, as explanatory variables in the spatial regression, I use only the Income and \%Minority market characteristics. This is just as well because only one brand is analyzed at a time, and so the degrees of freedom available are limited.
} 
To check whether the use of spatial analysis improves the parameter estimates of the demographic drivers of BEM, I run a series of OLS regressions of BEM against an Intercept, Income and \%Minority and compare the results with those of the GLS spatial model $^{24}$. The OLS model ignores spatial information whereas the GLS model incorporates it. Table 21 summarizes the results of the OLS regressions and Table 22 does likewise for the GLS spatial analyses. The bold font indicates significance at the 95\% confidence level. Clearly, very few of the OLS estimates of demographic drivers of BEM are significant compared to the estimates from GLS results ${ }^{25}$. Thus, I infer that the use of spatial information helps improve model estimates in the Stage II regression.

I now turn to the second question raised above. To paraphrase "Does the use of spatial information aid in the understanding of the role of demographic drivers of BEM?" To explore this, I discuss the insights and implications arising from the main effects of the GLS spatial analysis, depicted in columns (4) to (6) in Table 22. The limited degrees of freedom weaken inference on main effects rendering a majority nonsignificant at the $95 \%$ confidence level. Still, some clear trends are visible. The BEM of super-premium price-class brands such as Heineken, Michelob and Samuel Adams are significantly positively related to the mean Income in a market. Popular price-class brands such as Busch and Keystone relate significantly negatively to the mean Income in a market. This is intuitive. Non-significant results for other popular price-class beers such as Rolling Rock, Icehouse and Pabst are also in this general direction. The results and interpretation for $\%$ Minority also are largely along expected lines. I find that the

${ }^{24}$ I use Income and \%Minority as explanatory demographic variables because they are the only variables that are significant in a simple, pooled regression (Table 19). I tested the variables for significance in the spatial regression and these are the only variables significant.

${ }^{25}$ Further, I find that the OLS model has a higher mean square error, and a lower explained variance (simple R-square measure) than do the corresponding measures in the GLS spatial model. 
BEMs of popular price-class brands such as Pabst, Old Milwaukee and Keystone are significantly positively related to the $\%$ of ethnic minorities in a city market's population. At the same time, those of some other popular price-class beers targeted specifically at the working class blue-collar males such as Busch, are Rolling Rock are significantly negatively impacted indicating that these brands are relatively more popular in ethnically homogenous markets.

Overall, the BEMs of imported and niche brands - Corona, Heineken, Samuel Adams, and Labatt - appear to relate significantly to mean income and ethnic composition of the population. Ethnically heterogeneous markets are favored by the mainstream imports, and super-premium price-class offerings do well in markets with high mean incomes. The statistical significance of main effects in the BEM regression implies that Market demographics and geospatial location contain information about BEM levels of particular brands. Since geospatial location data for U.S. metropolitan markets are easily accessible to marketers, they should be incorporated into city-or region specific marketing plans.

I now proceed to the third of the questions raised at the start of this section, namely, "What do the spatial correlation parameters mean and what do they imply for marketers?" Column (2) of Table 22 lists the spatial autocorrelation parameter $\phi_{b}$ for each brand $b$ in the sample. To reiterate interpretation, a focal market's $\phi_{b}$ measures the extent to which the average $\mathrm{BEM}_{b}$ of its neighboring markets predicts its own $\mathrm{BEM}_{b}$ (see, Bronnenberg and Sismeiro, 2005). A +1 (-1) value for $\phi_{b}$ indicates perfect positive (negative) correlation for the focal market's $\mathrm{BEM}_{b}$ with the mean $\mathrm{BEM}_{b}$ of neighboring markets. The results in Table 22 show that the 7 largest mainstream National Brands by 
share - Budweiser, Miller, Coors, Natural, Corona, Busch and Heineken - have significant, positive $\phi_{b}$. These brands are old, well-established and have long-standing relationships with beer distributors in almost all U.S. regions. They also have the highest levels of marketing mix activity (merchandizing, and advertising). Among the more niche offerings, Samuel Adams, Tecate and Modelo Especial show significantly positive $\phi_{b} \mathrm{~s}$ suggesting that there could be a regional $\mathrm{BE}$ or regional preference shock for these brands in some U.S. regions.

To visualize the effect of $\phi_{b}$, I illustrate the BEMs on a spatial map. Figures 6, 7 and 8 depict the BEMs for the largest 8 and the smallest 4 brands by market share on the U.S. map. The solid circle, representing a market's location, has size directly proportional to the $\mathrm{BEM}_{b}$ level. One clear trend visible from the figures is that overall, markets in the coastal regions have higher BEM levels than do those in the interior regions, as discussed previously. $\phi_{b}$ values tend to be large and significant when regional clustering of BEMs of similar magnitude (whether large or small) is observed. To see this, I refer to Figures 6, 7 and 8 and illustrate the case of the three largest brands by sales - Budweiser, Miller and Coors.

Consider the case of Budweiser in the top left panel of Figure 6. Budweiser is the U.S. sales leader with a presence in all the markets and in most SKU sizes. The figure shows that BEM solid circles of say, a 'medium' size appear clustered along the MidAtlantic and Lower-Atlantic coasts, the lower Midwest (the Tennessee, Missouri, Indiana belt), relatively smaller BEM circles in the New England and Great Lakes regions and relatively larger ones in the Southern California-Rockies belt. The point is that BEM 
magnitudes show small intra-region and relatively larger inter-region differences and this pattern accounts for the large $\phi_{b}$ values of some brands.

Similarly, Miller shows a clustering of relatively large BEMs in only the MidAtlantic and Lower-Atlantic coasts as well as the Southern California and Rockies regions, and a clustering of relatively small BEM values in Midwest, Great Lakes and New England regions. In comparison, Coors appears to have relatively small BEM values across the country. This also ties in with the Essay 1 result wherein Coors appeared to gain most of its sales from distribution and promotions strengths rather than from its brand equity. The BEM distribution of popular price-class beer Natural follows along roughly the same lines as Budweiser and Miller.

These four brands - Budweiser, Miller, Coors and Natural - contrast well with those of the two largest imports - Corona and Heineken, depicted in Figure 7. Heineken has its highest BEMs from New York City and its high BEM regions are all coastal by location. Corona has a large NYC presence (second largest BEM in the sample at 7.82), and has higher BEM values closer to the border with Mexico. Presumably, Hispanic populations in these areas are likely to be higher closer one goes to the Mexican border, and these groups have a high preference for the Corona brand.

Finally, I ask "Does the spatial analysis method developed work as expected?" From all appearances, it does. The method converges rapidly to a solution from a number of different starting points in every case. The inter-iteration error is comfortably 
within the pre-set tolerance limits ${ }^{26}$ in every case (Column (8) in Table 22). Inference on $\phi_{b}$ is consistent between the MVN based quasi-ML results and those of the spatial association tests. Since the significance of $\phi_{b} \mathrm{~s}$ is an empirical question and since not all $\phi_{b} s$ are significant, the method appears to be able to discriminate between the spatial externality patterns of different brands. Finally, even though $\left(\phi_{b}^{M L}\right)$ and $\left(\phi_{b}^{G L S}\right)$ are highly correlated ${ }^{27}$, the two series are substantially different in their mean and standard deviation thereby validating the need for the development and use of the distributionfree GLS method

Overall, I find that the results of the spatial analysis are intuitive in the sign of the significant main effects, appear realistic in the magnitudes of the $\phi_{b}$ values, and show distinct regional patterns in BEM distribution. I also find that the spatial analysis method developed performs well.

\subsection{Managerial Implications and Summary}

This study contributes to the growing literature of the spatial analysis of marketing effects. I seek to test the conjecture made at the beginning of the essay that $\mathrm{BE}$ in one market influences and is influenced by those in neighboring markets due to both demand side and supply side factors. Consequently, in this essay, I develop and demonstrate a

${ }^{26}$ Even the largest relative error between parameter values in consecutive iterations at stoppage point, among all the parameters estimated, is of the order of $10^{-6}$. And in every case, the inter-iteration error in $\phi_{b}$ is below the pre-set threshold of $10^{-8}$.

${ }^{27}$ The correlation between the $\phi_{b}$ series of the proposed distribution-free model $\left(\phi_{b}^{G L S}\right)$ and that of the MVN based estimates $\left(\phi_{b}^{M L}\right)$ is 0.936 whereas that between the variances is 0.993 . 
method to analyze spatial patterns in BE for a set of brands across U.S. metropolitan markets that does not rely on distributional assumptions. The estimates of the model appear reasonable and in line with expectations from prior research. Some implications for managers emerge.

I find evidence of substantial BEM heterogeneity across both brands and markets. This BEM heterogeneity points to the likely presence of heterogeneity underlying consumer preferences and consumption patterns. This heterogeneity on the one hand is a challenge because it limits the ability of any single brand-product to appeal to all or even most consumers. But, on the other hand it implies an opportunity to segment the market and design marketing efforts accordingly.

As managers have long suspected and as has been shown for some outcomes such as market shares in the literature, this essay's main result is that there exists substantial spatial correlation between the brand equities of beer brands across geographical markets. The implication is that for brands that show a high degree of spatial association at the regional level, managers can leverage high BEMs in one market to influence those in neighboring markets in the same region by refocusing marketing efforts in those markets.

Further there appears to be a distinct regional pattern in the BEM distribution for different brands. This is consistent with evidence in the literature that managers differentiate between markets in terms of budgetary allocations for marketing activity and management attention (Bronnenberg et al, 2005) and also finds support in the fact that corporate organizations are often divided along geographical lines with decision making on many marketing efforts delegated to regional offices. 
I find that the degree of spatial correlation varies by brand and ranges from 0.16 to 0.94 in the beer category. The higher a brand's spatial correlation parameter, the higher the influence its BEM in one market has on its BEM in neighboring markets. Thus, on the demand side, the brand's positioning in the target consumers' perceptions is regional in scope, and on the supply side, the brand has developed a uniformly good (or poor) distribution system and promotional campaign. Unsurprisingly, while the largest mainstream brands have the highest spatial correlation scores $\left(\phi_{b}\right)$, the implications for niche brands with relatively high BEM and $\phi_{b}$ are promising in that they can examine the potential of developing new markets around existing ones using these results as an input to decision making. Brands with high $\phi_{b}$ in a region can leverage a relatively high BEM in any one of the region's markets to raise the BEMs in other markets in that region.

Further, I also show that whereas market demographics by themselves do not statistically significantly explain BEM, the incorporation of geospatial location information vastly improves the explanatory power of demographic factors. This is consistent with prior literature (Bronnenberg and Mahajan, 2001). In particular, the BEMs of imported and niche brands - Corona, Heineken, Samuel Adams, and Labatt appear to relate significantly to mean income and ethnic composition of the population. Ethnically heterogeneous markets are favored by the mainstream imports, and superpremium price-class offerings do well in markets with high mean incomes. Thus demographic factors in conjunction with geospatial information can be used as inputs in decision making situations such as for test markets for new products or new marketing programs. 
While this study was conducted at the level of the U.S. metropolitan markets, it is relatively straightforward to extend the study of $\mathrm{BE}$ to a lower level (that of individual stores within a metropolitan market) and to categories other than beer. Such applications of the model could reveal interesting insights about how BE might vary with microscopic changes in demographic and store location characteristics. 


\section{Chapter 6}

\section{Conclusion}

I propose and estimate a model of brand equity measurement based on a random effects approach that uses readily available data sources. In contrast to current methods that model brand equity as a fixed unknown constant for each brand, I posit that realized brand equity values in any market are outcomes of a complex process that is difficult to specify completely, but which can be modeled as draws from an underlying distribution of interest. The model is data-driven in that it does not explicitly specify how BE is generated from the underlying complex system. Rather, it makes identifying assumptions on the shape and domain of the unknown distribution based on the profit maximizing actions of rational economic agents. I develop the general conceptual framework for the model and adapt this framework to three different applications in the course of three essays: (1) Brand Equity as a Revenue Multiplier, an application based on a national dataset; (2) The Brand Equity of Private Labels, an application based on a multi-retailer setting; and (3) Spatial Patterns in Brand Equity, based on a multi-market dataset.

The random effects approach presents a simple, single-stage BE estimation and inference procedure that yields six distinct advantages: (i) an implicit baseline product for reference, (ii) easily interpretable results because BE is now a residual measure, (iii) useful downstream $\mathrm{BE}$ measures such as a $\mathrm{BE}$ dollar metric, which aids in assessing the financial value of brand assets, (iv) the use of a reduced form specification that does not make assumptions about the nature of the game and behavior of the players involved, (v) 
the incorporation of SKU based competitive effects modeled in product-attribute space, and all this (vi) in the presence of complex product structures and branding hierarchies.

However some caveats are also in order. First, the method cannot be applied to newly launched brands, say within the first 2-3 years of introduction, because of the paucity of market data about brand performance. Typically, firms and channel partners need time and data to assess whether to continue or withdraw the brand. Only after such a process has occurred, do the model's assumptions about the one-sided nature of the BE term come into play. Second, since the model is a reduced form specification, no structural interpretation of or counterfactuals from the results can be made. Third, even though I find that the choice of particular parametric form does not affect the results in large measure, the fact remains that a distributional assumption on $\mathrm{BE}$ needs to be made.

\subsection{Brand Equity as a Revenue Multiplier}

The first essay develops and implements the proposed random effects brand equity measurement approach on real data. The data are four years of monthly U.S. beer sales at the SKU level from grocery supermarkets nationwide and supplementary data from other sources (such as government agencies and the Internet).

I find that the proposed revenue multiplier methodology (a) in contrast to a revenue differences method, reasonably captures the influence of marketing mix (promotion, distribution and both observed and unobserved product attributes) and category factors; (b) parsimoniously accounts for inter-product competition effects, in contrast to a hedonic regression based approach; and (c) estimates residual brand effects in the presence of complex brand and product structures that would induce multicollinearity issues in traditional fixed effects methods. Further, the proposed BEM 
measure is (i) intuitive, (ii) credible, (iii) objective, (iv) grounded in theory, (v) based on readily available data, (vi) a single-number measure (which facilitates easier tracking and communication), (vii) robust and stable, (viii) reasonably complete (in that it captures facets of BE not captured by summary measures), and (ix) able to assess the potential of future brand line extensions. Thereby, BEM appears to meet 9 out of the 10 desiderata $^{28}$ for BE measures outlined by the Marketing Science Institute in 1999.

But does the BEM measure reflect market reality? To address this, I undertake a series of reality checks including testing the temporal stability of the BE measure, checking the face validity of the estimated main effects, and finally, seeking to validate the analysis results using independent, external sources. I find that the model parameters are intuitive in sign, that the $\mathrm{BE}$ estimates appear reasonable in magnitude, and find that financial valuation of the two largest beer brands - Budweiser and Miller - using estimates derived from the analysis agree quite well with those from external sources.

In sum, I present a flexible, new approach to assess brand equity from easily available data, in a variety of organizational arrangements and branding structures.

\subsection{The Brand Equity of Private Labels}

Essay 2 is an application of the conceptual framework for BE as random effects to the problem of estimating the brand equity of Private Label products. In contrast, under the traditional approaches using aggregate product-market outcomes data such as fixed effects or revenue differences, one brand in the sample is required to be normalized to zero BE to estimate the model. Typically, the Private Label is chosen as the reference brand. This study examines the premise of whether Private Labels have BE, effectively

\footnotetext{
28 The tenth desideratum is "Diagnostic ability" and BEM, like other product-market outcome based measures, meets it only to the extent of being able to flag large changes in BE levels.
} 
asking if Private Labels are 'brands' at all. The Private Labels in this study are all Private Labels and since Private Labels are restricted in availability to only certain retailers, I use a multi-retailer dataset to enable comparison across different Private Labels. I adapt the conceptual framework to a multi-retailer setting by using a random coefficients specification to account for response heterogeneity in promotion mix variables.

I find that there is considerable heterogeneity across retailers in the distribution of BEMs for National Brands. In particular, there also appears to be a regional flavor in the $\mathrm{BE}$ distribution of Coca-Cola and PepsiCo brands in that brands from these firms show higher $\mathrm{BE}$ in the Southern and Northeastern U.S. respectively, where these companies were founded and have been historically strong. I also find heterogeneity in the response sensitivities of the clientele at different retailers to promotion mix elements.

The main result of the analysis is that some Private Labels have BE and are indeed brands. Also, BE estimates of Private Labels present evidence favoring an 'economic benefits and costs' value proposition, consistent with results in the literature.

\subsection{Spatial Patterns in Brand Equity}

Essay 3 examines whether demographic characteristics of a market in conjunction with geospatial location information aid in understanding the distribution of $\mathrm{BE}$ across different markets. I posit that brand equities in a market are related to those in neighboring markets due to both demand side factors such as people-to-people interaction influencing consumer preferences, and supply side factors such as firm relationships with channel members in a region. To test the conjecture of spatial correlations in brand equities, I use a dataset of 18 beer brands from across 49 U.S. metropolitan markets. Spatial analysis studies typically assume a multivariate normal 
error structure. In this application, since the errors are clearly non-normal, I develop a distribution-free approach to estimating spatial parameters based on a Generalized least Squares (GLS) approach. This constitutes this essay's methodological contribution.

I find that the estimates of the model appear reasonable and in line with expectations from prior research. This essay's primary result is that there exists substantial spatial correlation between the brand equities of beer brands across geographical markets. This result lends support to the conjecture made at the beginning of the essay that brand equities in one market influence and are influenced by those in neighboring markets due to both demand side and supply side factors.

I find substantial heterogeneity in BEM levels across brands and markets, indicating that brands are strong in some areas and not in others. Further, there appears to be a distinct regional flavor in the BEM distribution for some brands. For instance, imported brands and niche brands are strong in the coastal markets.

The BEMs of imported and niche brands - Corona, Heineken, Samuel Adams, and Labatt in this sample - appear to relate significantly to local demographic characteristics such as mean income and ethnic composition of the population, in intuitive ways. In BEM terms, ethnically heterogeneous markets are favored by the mainstream imports. With regard to Income, the super-premium price-class offerings do well in markets with high mean incomes.

In sum, I develop and demonstrate a method to estimate brand equity and to incorporate spatial information into the deconstruction of the BEM results. I find that incorporating spatial information yields better parameter estimates of the impact of demographic drivers. 
In conclusion, the dissertation introduces the concept of brand equity as a random effect, builds a case for economic constraints on brand equity based on the profit maximization by rational agents and develops a parametric model to estimate brand equity. The proposed model integrates information from varied sources such as UPC scanners, opinion surveys, and spatial maps, is econometrically implemented on real data, and is extended to three different application contexts. The proposed brand equity measure bears face and external validity under different reality checks and the proposed model yields insights into brand equity that have managerial implications. 


\section{Bibliography}

Aaker, D. (1991), Managing Brand Equity. New York Free Press, New York.

Aaker, D. (1996), "Managing Brand Equity across Products and Markets", California Management Review, 38 (Spring), 102-120.

Aaker, D. and R. Jacobson (1994), “The Financial Information Content of Perceived Quality", Journal of Marketing Research, 31(2), 191-201.

Ailawadi, K.L., D. Lehmann, and S. Neslin (2003), "Revenue Premium as an Outcome Measure of Brand Equity", Journal of Marketing Research 67, (October), 1-17.

Ailawadi, K.L., S. Neslin, and K. Gedenk (2001), "Pursuing the Value Conscious Consumer: Private Labels versus National Brand Promotions", Journal of Marketing, 65(1), 71-89.

Adam's Beer Handbook (2002-2006), Bev-Al Communications, Norwalk, CT.

Anselin, Luc. (1988), Spatial Econometrics: Methods and Models, Dorddrecht: Kluwer Academic Publishers.

Anselin, Luc. (2001), "Spatial Econometrics," in B. Baltagi (ed.), A Companion to Theoretical Econometrics, Oxford: Basil Blackwell, 310-330.

Apelbaum, E., Gerstner, E. and P. Naik (2003), "The Effects of Expert Quality Evaluations versus Brand Names on Price Premiums?”, Journal of Product and Brand Management, 12(3), 154-165. 
Banerjee, S., Carlin, B.P. and A.E. Gelfand (2004), Hierarchical Modeling and Analysis for Spatial Data. Chapman and Hall, Boca Raton.

Bartov, E., P. Mohanram and C. Seethamraju (2002), "Valuation of Internet Stocks: An IPO Perspective", Journal of Accounting Research, 40(2),321-346.

Bell, D.R. and M. Lattin (1998), "Shopping Behavior and Consumer Preference for Store Price Format: Why Large Basket Shoppers Prefer EDLP”, Marketing Science, 17(1), 6688.

Bell, D.R., T. Ho and C. Tang (1998), “Determining Where to Shop: Fixed and Variable Costs of Shopping”, Journal of Marketing Research, 35(3), 352-369.

Bell, D.R. and S. Song. (2007), "Neighborhood Effects and Trial on the Internet: Evidence from Online Grocery Retailing," Quantitative Marketing and Economics, 5(4), $361-400$.

Besag, J. (1974), "Spatial Interaction and the Statistical Analysis of Lattice Systems," Journal of the Royal Statistical Society B 36, 192-236.

Bousch, D. Shipp, S., Loken, B., Genturck, E., Crockett, S., Kennedy, E., Minshall, B., Misurell, D., Rochford, L. and J. Strobehl (1987), “Affect Generalization to Similar and Dissimilar Brand Extensions”, Psychology and Marketing, 4(Fall), 225-237.

Bradlow, E.T., Bronnenberg, B.J, Russell G.J., Arora, N., Bell, D.R., Duvvuri, S., Ter Hofstead, F., Sismeiro, C., Thomadson, R., Yang, S., (2005), "Spatial Models in Marketing", Marketing letters, 16,3,267-278. 
Bronnenberg, B. J. (2005), "Spatial Models in Marketing Research and Practice," Applied Stochastic Models in Business and Industry, 21(4), 335-343.

Bronnenberg, B.J., and V. Mahajan (2001), "Unobserved Retailer Behavior in Multimarket Data: Joint Spatial Dependence in Market Shares and Promotion Variables," Marketing Science, 20 (Summer), 284-299.

Bronnenberg, B.J., and C. Sismeiro (2002), "Using Multimarket Data to Predict Brand Performance in Markets for Which No or Poor Data Exist," Journal of Marketing Research 39(February), 1-17.

Bronnenberg, B.J., Dhar, S. and J.P. Dube (2005), "Market Structure and the Geographic Distribution of Brand Shares in Consumer Packaged Goods Industries,” Working Paper, Anderson School of Management, UCLA.

Brown, S. (1989), "Retail Location Theory: the Legacy of Harold Hotelling", Journal of Retailing, 65 (Winter), 450-470.

Chakravarti, C., D.J. MacInnis and K. Nakamoto (1990), "Product Category Perceptions, Elaborative Processing and Brand Name Extension Strategies",Advances in Consumer Research, 17(1), 910-916.

Chakravarti, N. and R.T. Wilcox (1998),"Private Labels and the Channel Relationship: A Cross-Category Analysis", Journal of Business, 71(4), 573-600.

Chaudhari, A. and M. Holbrook (2001), “The Chain of Effects from Brand Trust and Brand Affect to Brand Performance: the Role of Brand Loyalty", Journal of Marketing, 65 (April), 81-93. 
Cleveland, W.S. (1981), “A Program for Smoothing Scatterplots by Robust Locally Weighted Regression”, American Statistician, 35, 54.

Cliff, A. and J. Ord (1973), Spatial Autocorrelation. Pion, London.

Cliff, A. and J. Ord (1973), Spatial Process: Models and Applications. Pion, London.

Corstjens, M. and R. Lal (2000), "Building store loyalty through Private Labels", Journal of Marketing Research, 37(3), 281-291.

Cotterill, R.W., Putsis, W.P. and S.K. Dhar (2000), “Assessing the Competitive Interaction Between Private Labels and National Brands", Journal of Business, 73(1), 109-137.

Cressie, Noel A. C. (1993), Statistics for Spatial Data, New York: John Wiley and Sons.

Dhar, S. and S. Hoch (1997), "Why Private Label Penetration Varies by Retailer", Marketing Science, 16(3), 208-227.

Dubin, J. (1998), “The Demand for Branded and Unbranded Products: An Econometric Method for Valuing Intangible Assets", Chapter 4 in Studies in Consumer Demand: Econometric Methods Applied to Market Data, Norwell, MA. Kluwer Academic Publishers, 77-127.

Economist, Bureau (2007), “Two Global Drinks Brands are trying to Revitalize Themselves", Economist, March 3, 382(8518), 72.

Erdem, T. (1998), “An Empirical Analysis of Umbrella Branding”, Journal of Marketing Research, 35(3), 339-351. 
Erdem, T. and J. Swait (1998), "Brand Equity as a Signaling Phenomenon”, Journal of Consumer Psychology, 7(2), 131-157.

Fader, P. and B. Hardie (1996), "Modeling Consumer Choice among SKUs", Journal of Marketing Research, 4 (November), 442-52.

Frank, R.E. and H.W. Boyd (1965), “Are Private-Brand Prone Grocery Customers Really Different?", Journal of Marketing Research, 2(4), 27-35.

Frank, R.E., W.F. Massy and Y. Wind (1972), Market Segmentation. Englewood Cliff, Prentice-Hall.

Green, P.E. and V. Srinivasan (1990), "Conjoint Analysis in Marketing: New Developments with Implications for Research and Practice, "The Journal of Marketing, 54(4), 3-19.

Guadagni, P. and J. Little (1983), "A Logit Model of Brand Choice Calibrated on Scanner Data", Marketing Science, 2, 203-238.

Hansen, K., V. Singh and P. Chintagunta (2006), "Understanding Retailer-Brand Purchase Behavior across Categories", Marketing Science, 25(1), 75-90.

He, W., M. Sengupta, V.A. Velkoff and K.A. DeBarros (2005), "65+ in the United States: 2005”, U.S. Census Bureau Current Population Reports, page 23-209.

Hoch, S., B. D. Kim, A. L. Montgomery and P. Rossi (1995), "Determinants of StoreLevel Price Elasticity", Journal of Marketing Research, 32(1), 17-29. 
Hoch, S. and L. Lodish (1998), "Private Labels and Category Management", Working paper, Wharton School, University of Pennsylvania.

Hoch, S., Kim, B., Montgomery, A. and P. Rossi (1995), "Determinants of Store-level Price Elasticity", Journal of Marketing Research, 32(1), 17-29.

Holbrook, M. (1992), "Product Quality, Attributes and Brand Name as Determinants of Price: The Case of Consumer Electronics", Marketing Letters, 3, 71-83.

Huff, D. (1964), "Defining and Estimating a Trading Area", Journal of Marketing, 28 (July), 34-38.

Interbrand BusinessWeek Brand Survey (2005), Best Global Brands 2005, URL: http://www.ourfishbowl.com/brand_val/best_brands_05/2005_rankings_dollars.pdf

Kallapur, S. and S.Y. Kwan (2004),"The Value Relevance and Reliability of Brand Assets Recognized by U.K. Firms", The Accounting Review 79 (1), 151-161.

Kamakura, W. and G. Russell (1989), “A Probabilistic Choice Model for Market Segmentation and Elasticity Structure", Journal of Marketing Research, 26(4), 379-390.

Kamakura, W. and G. Russell (1993), "Measuring Brand Value with Scanner Data", International Journal for Research in Marketing, 10(1), 9-22.

Keller, K.L. (1993), “Conceptualizing, Measuring and Managing Customer-based brand Equity", Journal of Marketing, 57(1), 1-22.

Keller, K.L. (1998), Strategic Brand Management, Prentice-Hall, New Jersey. 
Keller, K.L. and D. Lehmann (2003), “The Brand Value Chain: Optimizing Strategic and Financial Brand Performance", Marketing Management, (May/June), 26-31.

Keller, K.L. (2006), "Brands and Branding: Research Findings and Future Priorities", Marketing Science, 25(6), 740-759.

Kelejian, H.H. and I.R. Prucha (1998), “A Generalized Spatial Two-Stage Least Squares Procedure for Estimating a Spatial Autoregressive Model with Autoregressive Disturbances", Journal of Real Estate Finance and Economics, 17, 99-121.

Kumar, V. and R. Leone (1988), "Measuring the Effect of Retail Store Promotions on Brand and Store Substitution”, Journal of Marketing Research, 25(2), 178-185.

Lal, R. and R. Rao (1997), "Supermarket Competition: The Case of Everyday Low Pricing”, Marketing Science, 16(1), 60-80.

Lal, R. and V. Padmanabhan, (1995) "Competitive response and Equilibria", Marketing Science, 3(4), 267-287.

Lancaster, K.J. (1966), “A New Approach to Consumer Theory”, Journal of Political Economy, 74, 132-157.

Leuthesser, L. (1988), "Defining, Measuring and Managing Brand Equity", Working Paper 88-104, Marketing Science Institute, Cambridge, MA.

Lilien, G., P. Kotler and K.S. Moorthy (1995), Marketing Models, Prentice-Hall, New Jersey. 
Lindenberg, E.B. and S.A. Ross (1981), "Tobin's q Ratio and Industrial Organization", Journal of Business, 54(1), 1-32.

Mahajan, V., Rao, V. and R. Srivastava (1994), “An Approach to Assess the Importance of Brand Equity in Acquisition Decisions", Journal of Product Innovation Management, 11(3), 221-235.

Marketing Science Institute (1999), "Value of a Brand", Workshop at Marketing Science Institute Conference on Marketing Metrics, Washington DC (October 6-8).

Park, Chan Su, and V. Srinivasan (1994), “A Survey based Method for Measuring and Understanding Brand Equity and its Extendability", Journal of Marketing Research, 31 (May), 271-288.

Parent O. and J.P. LeSage (2008), "Using the Variance Structure of the Conditional Autoregressive Spatial Specification to Model Knowledge Spillovers”, Journal of Applied Econometrics, 23, 235-256.

Population Division, U.S. Census Bureau, Monthly Population Estimates for the United States: April 1, 2000 to October 1,2006. NA-EST-2005-01.

Raju, J., Sethuraman, R. and S. Dhar (1995),'The Introduction and Performance of Private Labels”, Management Science, 41(6), 957-978.

Rhee, H. and D. Bell (2002), "The Inter-Store Mobility of Supermarket Shoppers", Journal of Retailing, 78(2002), 225-237. 
Richardson, P., Jain, A. and A. Dick (1996), "Household Retailer-Brand Proneness: A Framework", Journal of Retailing, 72(2), 159-185.

Rossi, P., Allenby, G. and R. McCullogh (2005), Bayesian Statistics and Marketing, John Wiley and Sons, Chicago, Illinois.

Rust, R., Lemon, K. and V. Zeithaml (2000), Driving Customer Equity: How Customer Lifetime Value is Reshaping Corporate Strategy, Free Press, New York.

SABMiller (2002) Annual Report, Consolidated Financial Statements, URL: http://sabmillerstaging.framfab.co.uk/sabmiller.com/en_gb/Investors/Annual+reports Sethuraman, R. (2000), "What makes Consumers pay more for National Brands than Private Labels: Image or Quality?”, Report no. 00-110, Marketing Science Institute, Boston, MA.

Sethuraman, R. (2003), "Measuring National Brands' Equity over Private Labels", Review of Marketing Science, Vol. 1, Article 2.”

Simon, C. and M. Sullivan (1993), "The Measurement and Determinants of Brand Equity: A Financial Approach”, Marketing Science, 12, (Winter), 28-52.

Srinivasan, V. (1979), "Network Models for Estimating Brand Specific Effects in MultiAttribute Marketing Models”, Management Science, 25 (January), 11-21.

Sullivan, M. (1998), "How Brand Names Affect the Demand for Twin Automobiles", Journal of Marketing Research, 35 (May), 154-165. 
Swait, J., Erdem, T., Louviere, J. and C. Dubelaar (1993), “The Equalization Price: A Measure of Consumer Perceived Brand Equity", International Journal of Research in Marketing 10 (March), 23-45.

Train, K.R., (2003), Discrete Choice Methods with Simulation. Cambridge University Press, MA.

Tyagi, K.R. (2006), “Private Label Strength”, Review of Marketing Science, 4(2), 1-16.

United Van Lines, 2005 Migration study (2006). URL: http://www.unitedvanlines.com/ mover/united-newsroom/press-releases/2005/2005-united-migration-study-01-06.htm.

van den Broeck, J., G. Coop, J . Osiwalski and M. Steel (1994), "Stochastic Frontier Models: A Bayesian Perspective”, Journal of Econometrics, 61, p.273-303.

Villas Boas, M.J., (1993), "Predicting Pulsing Policies in an Oligopoly: A Model and an Empirical Test”, Marketing Science, 12(1), p. 88-102.

Yang, Sha and G.M. Allenby (2003), "Modeling Interdependent Consumer Preferences," Journal of Marketing Research 40, 282-294.

Yang, Sha. (2004), "Understanding the Interdependence in Consumer Preferences via Spatial Modeling," Position Paper, Session on Spatial Models in Marketing, Invitational Choice Symposium.

Yahoo Finance, Anheuser-Busch Company profile, Keys Statistics Section, Stock Beta,

URL: http:/ / finance.yahoo.com/q/ks?s=BUD 


\section{Appendix A}

\section{Data Sources}

Essay 1

1. Aggregate Data - UPC scanner data from AC Nielsen

2. Product Characteristics Data - AC Nielsen and Adams Beer Handbook

3. Beer Variant Taste Ratings - Internet. From beerpal.com, ratebeer.com

4. Brand Annual Advertising Spend - Leading National Advertisers, 2003-2006.

5. US Adult Population - U.S. Census Bureau

6. Foreign Currency Exchange Rates - U.S. Federal Reserve website

7. Freight Purchasers Price Index - Bureau of Labor Statistics

8. Stock Betas for Anheuser Busch - Yahoo! Finance

Essay 2

1. Aggregate Data - UPC Scanner data from AC Nielsen multi-retailer database

2. Consumer Characteristics - Homescan database

3. Retailer Characteristics - Retailer Websites and Supermarket Census of 1998.

Essay 3

1. Sales Data - AC Nielsen

2. Market Location Data - Internet and Google maps

3. Product Characteristics Data - AC Nielsen and Adams beer handbook

4. Foreign Currency Exchange rate - U.S. Federal Reserve website

5. Market Demographics - U.S. Census Bureau

6. Age of Brands - Internet 


\section{Appendix B}

\section{Full Conditional Likelihood Formulation and MCMC Sampling Scheme for the Random Effects BE Model}

I lay down the Gibbs sampling scheme for the MCMC routine used in the most general of the estimated models, that for Essay 2. Essay 2's Equation (4.1) reduces to Essay 1's equation (3.2) when the retailer subscript $r$, the Retailer and Consumer Characteristics variables, and the variant-specific random effect $\xi_{r v}$ is removed. Equation (4.1) also reduces to Essay 3's Equation (5.1) when retailer subscript $r$ is replaced with market superscript $(m)$, the random coefficients

vector $\boldsymbol{\gamma}_{r}$ is replaced with a homogenous parameters vector $\boldsymbol{\beta}^{\text {PROMO }}$, and the Retailer and Consumer Characteristics variables are removed.

Simplifying notation, equation (4.1) can be rewritten as:

$$
\mathbf{Y}_{r j t} \boldsymbol{\beta} \mathbf{X Z}_{r t t} \not t_{r j t} \quad r+\underbrace{\operatorname{Ln}\left(\mathrm{BEM}_{r b}\right)+\xi_{r v}+\eta_{r j}+u_{r j t}}_{\varepsilon_{r j t}}
$$

Here, $\quad \mathbf{Y}_{r j t}$ stands for $\operatorname{Ln}\left(\right.$ R evenue $\left._{r j t}\right), \quad \mathbf{Z}_{r j t}$ for the variables in $\operatorname{Ln}\left(\right.$ Promotions $\left._{r j t}\right), \mathbf{X}_{r j t}$ for the other fixed effects covariates for SKU $j$, retailer $r$ and period $t ; \boldsymbol{\beta}$ for the homogenous parameters vector and $\boldsymbol{\gamma}_{r}$ for the random coefficients vector. Further, let $\mathbf{D}=\{\mathbf{X}, \mathbf{Z}\}$ represent the data vector, $\boldsymbol{\theta}=\{\boldsymbol{\beta}, \overline{\boldsymbol{\gamma}}\}$, $\boldsymbol{\theta}^{\prime}=\left\{\boldsymbol{\beta}, \boldsymbol{\gamma}_{r}\right\}$ and $\delta_{r j t}=\xi_{r v}+\eta_{r j}+u_{r j t}$ represent that sum of the symmetric error 
components with $E(\boldsymbol{\delta})=\mathbf{0}, V\left(\delta_{r j t}\right)=\sigma_{\xi}^{2}+\sigma_{\eta}^{2}+\sigma_{u}^{2}$ and $V(\boldsymbol{\delta})=\boldsymbol{\Sigma}_{\delta}$. The likelihood of observing data given parameters for a single observation is shown in (B.2) and is extended to the entire dataset in (B.3).

$$
\begin{array}{r}
L\left(\boldsymbol{\theta}^{\prime}, \boldsymbol{\Sigma}_{\delta}, \operatorname{Ln}\left(\mathrm{BEM}_{r b}\right) \mid \mathbf{D}_{r j t}, \mathbf{Y}_{r j t}\right)=f\left(\varepsilon_{r j t} \mid .\right)=f_{N}\left(\mathbf{Y}_{r j t}, \operatorname{Ln}\left(\mathrm{BEM}_{r b}\right) \mid \mathbf{D}_{r j t}, \boldsymbol{\theta}^{\prime}, \delta_{r j t}, \boldsymbol{\Sigma}_{\delta}\right) \\
f_{E x p}\left(\operatorname{Ln}\left(\mathrm{BEM}_{r b}\right) \mid \lambda_{r}\right) \pi_{G}\left(\lambda_{r} \mid a_{r}, b_{r}\right) \pi_{I W}\left(\boldsymbol{\Sigma}_{\delta} \mid .\right)
\end{array}
$$

$$
\begin{aligned}
L\left(\boldsymbol{\theta}^{\prime}, \boldsymbol{\Sigma}_{\delta}, \mathbf{L n}(\mathbf{B E M}) \mid \mathbf{D}, \mathbf{Y}\right) & =f(\boldsymbol{\varepsilon} \mid .) \\
& =\prod_{t=1}^{T} \prod_{r=1}^{5} \prod_{j}\left[\begin{array}{l}
f_{N}\left(\boldsymbol{\delta} \mid \mathbf{D}, \boldsymbol{\theta}^{\prime}, \mathbf{Y}, \boldsymbol{\Sigma}_{\delta}, \mathbf{L n}(\mathbf{B E M})\right) \\
f_{E x p}(\mathbf{L n}(\mathbf{B E M}) \mid) \prod_{r} \pi_{G}\left(\lambda_{r} \mid a_{r}, b_{r}\right) \\
\pi_{I W}\left(\boldsymbol{\Sigma}_{\delta} \mid .\right)
\end{array}\right]
\end{aligned}
$$

Here, the distribution subscripts $N, G$ and $I W$ denote Normal, Gamma and Inverted Wishart. I describe below the process by which the Gibbs sampler draws parameter values for the $(\mathrm{h}+1)^{\text {th }}$ iteration from values for the $\mathrm{h}^{\text {th }}$ iteration. (B.4) - (B.6) generate coefficient vector $\boldsymbol{\beta}$ from a multivariate normal distribution $M V N($.$) as$

$\boldsymbol{\beta}^{(h+1)} \sim \operatorname{MVN}\left(\overline{\boldsymbol{\beta}}^{(h+1)}, \boldsymbol{\Sigma}_{\beta}^{(h+1)}\right)$

Where $\overline{\boldsymbol{\beta}}^{(h+1)}$ and $\boldsymbol{\Sigma}_{\beta}{ }^{(h+1)}$ are computed as: 
$\boldsymbol{\Sigma}_{\beta}{ }^{(h+1)_{-1}}=\left(\boldsymbol{\Sigma}_{\beta}^{(h)_{-1}}+\sigma_{u}^{2} \mathbf{X}^{\prime} \mathbf{X}\right)=\left(\boldsymbol{\Sigma}_{\beta}^{(h)_{-1}}+\sigma_{u}^{2} \sum_{j=1}^{J} \sum_{r=1}^{R} \sum_{t=1}^{T} \mathbf{X}_{r j t} \mathbf{X}_{r j t}\right)$

$\overline{\boldsymbol{\beta}}^{(h+1)}=\left(\boldsymbol{\Sigma}_{\beta}^{(h+1)}\right)^{-1}\left(\left(\boldsymbol{\Sigma}_{\beta}^{(h)}\right)^{-1} \overline{\boldsymbol{\beta}}^{(h)}+\sigma_{u}^{2} \sum_{j=1}^{J} \sum_{r=1}^{R} \sum_{t=1}^{T} \mathbf{X}_{r j t}\left(Y_{r j t}-\operatorname{Ln}\left(\mathrm{BEM}_{r b}\right)-\xi_{r v}-\eta_{r j}\right)\right)$

(B.7)-(B.9) generates precision $\tau_{u}=\frac{1}{\sigma_{u}^{2}}$ from a Gamma distribution $G($.$) as$

follows:

$\tau_{u}^{(h+1)} \sim G\left(a_{\tau u}^{(h+1)}, b_{\tau u}^{(h+1)}\right)$

$a \tau^{(h+1)}=\left({ }_{u}^{(h)}+\frac{1}{2} \sum_{j=1}^{J} \sum_{r=1}^{R} \sum_{t=1}^{T}\left({ }_{r j t}-\operatorname{Ln}\left(\mathrm{BEM}_{r b}^{(h)}\right)-\xi_{r v}-\eta_{r j}\right)^{2}\right)$

$b_{\tau u}{ }^{(h+1)}=\frac{J R T}{2}+b_{\tau u}{ }^{(h)}$

Let the random coefficient vector be denoted by $\gamma_{r, i}$ for $r=1,2, \ldots R$ and $i=$ \{Competition, Ln Merchandizing, Ln AdSpend\}. For every i, first draw from $\gamma_{r}$ from the full conditional expressed as:

$$
\begin{aligned}
& f\left(\gamma_{r, i} \mid \bar{\gamma}_{i}, \sigma_{\gamma i}^{2}, Y_{r j t}, \mathbf{D}_{r j t}, \operatorname{Ln}\left(\mathrm{BEM}_{r b}\right), .\right) \propto \frac{\exp \left(\frac{-1\left(\gamma_{r, i}-\bar{\gamma}_{r, i}\right)^{2}}{2 \sigma_{\gamma i}^{2}}\right)}{\sqrt{2 \pi \sigma_{\gamma i}^{2}}} \\
& \prod_{t=1}^{T} \prod_{j} p\left(Y_{r j t}, \operatorname{Ln}\left(\mathrm{BEM}_{r b}\right), . \mid \gamma_{r, i}\right)
\end{aligned}
$$


Where $p($.$) is the joint likelihood of observing data and parameters. Let \gamma_{r}^{(h)}$ be the $h^{\text {th }}$ draw from this density. Then the $(h+1)^{\text {th }}$ draw is given by:

$\gamma_{r}^{(h+1)}=\gamma_{r}^{(h)}+\Delta \gamma_{r}$

Where $\Delta \gamma$ is a draw from a candidate generating density (typically normal with very low variance) such that the probability $\alpha\left(\gamma_{r, i}^{(h)}, \gamma_{r, i}^{(h+1)}\right)$ that the sampler accepts the $(h+1)^{\text {th }}$ draw given the values of the $h^{\text {th }}$ draw is given by:

$\alpha\left(\gamma_{r, i}^{(h)}, \gamma_{r, i}^{(h+1)}\right)=\min \left[\frac{\sigma_{\gamma i}^{(h+1)} \exp \left(\left(\gamma_{r, i}^{(h)}-\bar{\gamma}_{i}^{(h-1)}\right)^{2}\right) \prod_{t=1}^{T} \prod_{j} p_{h}\left(Y_{r j t}, \operatorname{Ln}\left(\mathrm{BEM}_{r b}\right), . \mid \gamma_{r, i}^{(h)}\right)}{\sigma_{\gamma i}^{(h)} \exp \left(\left(\gamma_{r, i}^{(h+1)}-\bar{\gamma}_{i}^{(h)}\right)^{2}\right) \prod_{t=1}^{T} \prod_{j} p_{h+1}\left(Y_{r j t}, \operatorname{Ln}\left(\mathrm{BEM}_{r b}\right), . \mid \gamma_{r, i}^{(h+1)}\right)}, 1\right]$

If the new draw is accepted than $\gamma_{r, i}^{(h)}=\gamma_{r, i}^{(h+1)}$ and a new $\gamma_{r, i}^{(h+1)}$ is drawn. The hyper-parameters $\bar{\gamma}_{i}$ and $\sigma_{\gamma i}^{2}$ are then computes as:

$\left(\frac{1}{\sigma_{\gamma i}^{2}}\right)^{(h+1)} \sim G\left(\left(\frac{1}{\sigma_{\gamma i}^{2}}\right)^{(h)}+\frac{1}{2} \sum_{r=1}^{R}\left(\gamma_{r}^{(h)}-\bar{\gamma}_{r}^{(h)}\right)^{2}, b_{\tau}^{(h+1)}\right)$

Where $\quad b_{\tau}^{(h+1)}=\frac{R}{2}+b_{\tau}^{(h)}$

$f\left(\bar{\gamma}_{i} \mid\left\{\gamma_{r, i}\right\}, \sigma_{\gamma i}^{2}\right) \sim N\left(\frac{\sum_{r=1}^{R} \gamma_{r, i}}{R}, \frac{\sigma_{\gamma i}^{2}}{R}\right)$ 
Equations (B.16) -(B.19) generate and update the individual estimates of the variance components $\left\{\operatorname{Ln}\left(\mathrm{BEM}_{r b}\right), \xi_{r v}, \eta_{r j}\right\} . \operatorname{Ln}\left(\mathrm{BEM}_{r b}\right)$ for $r=1,2 . . R$ and $b=1,2 . . B$ is drawn from its full conditional as:

$$
f_{\operatorname{Exp}}\left(\operatorname{Ln}\left(\mathrm{BEM}_{r b}\right) \mid \lambda_{r}, .\right) \propto \frac{\exp \left(-\operatorname{Ln}\left(\mathrm{BEM}_{r b}\right) / \lambda_{r}\right)}{\lambda_{r}} \prod_{t=1}^{T} \prod_{j \in b} p\left(Y_{r j(b) t}, . \mid \operatorname{Ln}\left(\mathrm{BEM}_{r b}\right)\right)
$$

Let the $h^{\text {th }}$ draw be $\operatorname{LnBEM}_{r b}^{(h)}$. A candidate generating density, (typically normal with very small variance) is used to draw the next $(h+1)^{\text {th }}$ draw $\operatorname{LnBEM}_{r b}^{(h+1)}$. The probability alpha with which the sampler accepts $\operatorname{LnBEM}_{r b}^{(h+1)}$ given $\operatorname{LnBEM}_{r b}^{(h)}$ can be expressed as:

$$
\begin{aligned}
& \alpha\left(\begin{array}{c}
\operatorname{Ln}\left(\mathrm{BEM}_{r b}^{(h)}\right), \\
\operatorname{Ln}\left(\mathrm{BEM}_{r b}^{(h+1)}\right)
\end{array}\right) \\
& \quad=\min \left[\frac{\lambda_{r}^{(h+1)} \exp \left(-\operatorname{Ln}\left(\mathrm{BEM}_{r b}^{(h)}\right) / \lambda_{r}^{(h)}\right) \prod_{t=1}^{T} \prod_{j \in b} p\left(Y_{r j(b) t} . \mid \operatorname{Ln}\left(\mathrm{BEM}_{r b}^{(h)}\right)\right)}{\lambda_{r}^{(h)} \exp \left(-\operatorname{Ln}\left(\mathrm{BEM}_{r b}^{(h+1)}\right) / \lambda_{r}^{(h+1)}\right) \prod_{t=1}^{T} \prod_{j \in b} p\left(Y_{r j(b) t} . \mid \operatorname{Ln}\left(\mathrm{BEM}_{r b}^{(h+1)}\right)\right)}, 1\right]
\end{aligned}
$$

The hyper-parameter $\lambda_{r}$ that describes the underlying BE distribution of retailer $r$ having $b_{r}=1,2 \ldots B_{r}$ brands, is generated and updated from a gamma distribution as:

$$
\lambda_{r}^{(h+1)} \sim G\left(\lambda_{r}^{(h)}+\frac{1}{2} \sum_{b_{r}=1}^{B_{r}}\left(\operatorname{Ln}\left(\mathrm{BEM}_{r b}\right)\right)^{2}, b_{\lambda r}^{(h+1)}\right)
$$


Where $b_{\tau}^{(h+1)}=\frac{B_{r}}{2}+b_{\lambda r}^{(h)}$

The mean zero normal symmetric variance components $\left\{\xi_{r v}, \eta_{r j}\right\}$ are generated and updated as shown below. For retailer $r$ with $v_{r}=1,2 \ldots V_{r}$ variants, draw $V_{r}$ instances of $\left\{\xi_{r v}\right\}$ from:

$$
f\left(\xi_{r v} \mid \boldsymbol{\theta}, \sigma_{\xi r}^{2}, Y_{r j t}, \mathbf{D}_{r j t}, .\right) \propto \frac{\exp \left(\frac{-\left(\xi_{r v}\right)^{2}}{2 \sigma_{\xi r}^{2}}\right)}{\sqrt{2 \pi \sigma_{\xi r}^{2}}} \prod_{t=1}^{T} \prod_{j \in v} p\left(Y_{r j t}, \operatorname{Ln}\left(\mathrm{BEM}_{r b}\right), . \mid \sigma_{\xi r}^{2}\right)
$$

The $\xi_{r v}^{(h+1)}$ given $\xi_{r v}^{(h)}$ is drawn using a candidate generation density (normal with very low variance) as:

$$
\xi_{r v}^{(h+1)}=\xi_{r v}^{(h)}+\Delta \xi_{r v}
$$

Following the procedure in equations (B.12) - (B.14), an M-H draw is made for $\xi_{r v}^{(h+1)}$. The same procedure also applies to the $\left\{\eta_{r j}\right\}$ and $\sigma_{\eta r}^{2}$ 


\section{Appendix C: On Model Identification}

This note aims to discuss issues with Brand Equity (BE) identification in models using aggregate data, and is structured thus: Section I discusses extant solution approaches, Section II discusses the identification of the proposed Brand Equity Multiplier (BEM) model, Section III demonstrates the proposed model on simulated data, and Section IV compares model performance across different distributional assumptions.

\section{I. $\quad$ BE Identification using Aggregate Data}

The basic form of a brand equity (BE) estimation model using aggregate data can be written as

$$
\begin{aligned}
& Y_{j(b) t}=\beta_{0}+\sum_{a=1}^{A} X_{j(b) t} \beta_{a}+z_{b}+\varepsilon_{j(b) t} \\
& \varepsilon_{j(b) t} \sim N\left(0, \sigma^{2}\right)
\end{aligned}
$$

Here, $j, b$ and $t$ index SKU, brand and time period respectively. $Y_{j(b) t}$ is the marketing outcome of interest, $\mathbf{X}$ and $\boldsymbol{\beta}$ are vectors of explanatory variables and coefficients respectively, $\tau_{b}$ is the brand specific $\mathrm{BE}$ term to be estimated and $\varepsilon_{j(b) t}$ is the mean zero random error.

Fixed and Random effects

One approach to estimating $z_{b}$ is to model it as fixed effects using a $(0,1)$ matrix $\mathbf{Z}$. But then, the $z_{b}$ of only (B-1) brands can be identified because with $B$ dummies, the matrix $[\mathbf{X}, \mathbf{Z}]$ would be singular and would not invert. Another approach could be to model $z_{\mathrm{b}}$ 
as random effects on a symmetric distribution. But again, some normalization would be required because $\beta_{0}$ and $\mathrm{E}\left(\mathrm{z}_{\mathrm{b}}\right)$ would not be separately identified.

One of the innovations in this dissertation is the use of economic restrictions on the value of BEM as an econometric identification aid.

- I argue that the incremental product value added by the brand name for mature brands in established categories cannot be negative and show that the BEM is constrained to be $>=1$. The $\mathrm{BE}$ term in the above model is thus asymmetric. This implies that the stochastic error term is non-spherical.

- I also assume that in mature markets with unrestricted entry and exit of brands (e.g., in the Consumer Packaged Goods industry), a higher BEM is less probable than a lower BEM for a given set of product characteristics. This is based on the economic rationale that a concentration of brands in the high BEM space would invite entry into the market, increase competition, and fill-up less profitable niches. I argue that this would re-arrange the BEM distribution such that the probability density of BEM falls as the BEM value increases. The practical implication of this assumption is that there must exist in every market, brands with low (even if strictly >1) BEM. As a corollary, if all brands in a market had BEM much greater than 1, then a large part of the additional bump to market outcome would be attributable to category drivers rather to a brand specific effect.

One ready approach to estimating a non-symmetric BE term using aggregate data would be to variously constrain the $\mathrm{BE}$ terms ex post. In the literature on stochastic frontier 
estimation, two methods under this approach have been labeled Corrected Ordinary least squares (COLS) and Modified ordinary least squares (MOLS) respectively. I discuss these briefly below and then move to maximum likelihood estimation around the nonspherical disturbance.

\section{Corrected OLS}

Let $\hat{\varepsilon}_{j t}$ the estimated OLS residual. Impose the requirement that $z_{b}$ is a one-sided variable. A sufficient statistic such as the mean of all the OLS residuals of a brand $b$ could be $\hat{\varepsilon}_{b}=(\text { count of } \mathrm{j} \in \mathrm{b})^{-1} \sum_{j \in b} \hat{\varepsilon}_{j t}$ and the corrected intercept value is then $\alpha^{*}=\hat{\alpha}-\min \left\{\hat{\varepsilon}_{b}\right\}$. The problem is that all the variation in $\mathrm{Y}$ is being attributed to brand and again, the brand with $\min \left\{\hat{\varepsilon}_{b}\right\}$ is normalized to zero BE.

\section{Modified OLS}

Under MOLS, $\alpha^{*}=\hat{\alpha}-E(\hat{\varepsilon})$ and a positive error term would exist if the model assumptions and specification are true viz. $E(\hat{\varepsilon})=(J T)^{-1} \sum_{t} \sum_{j} \hat{\varepsilon}_{j t}>0$. Now the BEs of the brands are calculated as $\hat{z}_{b}=\hat{\varepsilon}_{b}-E(\hat{\varepsilon})$. Here, the BE of all B brands can in theory be calculated from the $E(\hat{\varepsilon})$. Also, note that the different levels of aggregation of $\mathrm{BE}\left(\right.$ in $\left.\varkappa_{b}\right)$ and the error term $\left(\hat{\varepsilon}_{j t}\right)$ leads to the defining of an error term $\hat{\eta}_{j t}=\hat{\varepsilon}_{j t}-\hat{\psi}_{b}$ that would account for noise in $Y_{j t}$ unrelated to brand. The problem is that there could be instances with $\hat{\psi}_{b}<0$ given sufficiently low instances of $\hat{\varepsilon}_{b}$. 


\section{Maximum Likelihood Estimator}

This brings up the Maximum Likelihood (ML) approach which requires a explicit functional form $g($.$) for z_{b}$. When combined with the one-sidedness assumption, the likelihood approach requires that the one-sided distribution $g($.$) have only a few$ parameters $\left(\right.$ say, $\left.\sigma_{z}\right)$. The results are not very sensitive to which one-sided distribution I choose (Gamma, exponential, half-normal etc) as long as it is not too flexible ${ }^{29}$. Under ML, $z_{b}$ is modeled as an error component and must be uncorrelated with $\boldsymbol{X}_{j t}$ and with other error components for consistent estimates. The vector of parameters $\boldsymbol{\theta}=\left\{\boldsymbol{\beta}, \sigma_{\eta}{ }^{2}, \sigma_{v}{ }^{2}, \sigma_{z}\right\}$ that maximize the likelihood of observing data $\mathbf{D}$ is found by maximizing the log likelihood thus:

$$
\underset{\boldsymbol{\theta}}{\operatorname{Max}} L L(\boldsymbol{\theta} \mid \mathbf{D})=\operatorname{Max}_{\boldsymbol{\theta}} \sum_{b=1}^{B} f\left(\boldsymbol{\varepsilon}_{b} \mid \mathbf{D}, \boldsymbol{\theta}\right)
$$

The independence assumptions lead to the formulation of an expression for the likelihood of observing data given the composed error

$$
f\left(\boldsymbol{\varepsilon}_{b} \mid \mathbf{D}, \boldsymbol{\theta}\right)=g\left(z_{b}\right)\left(\prod_{j \in b} \prod_{t=1}^{T} f_{N}\left(\eta_{j t}\right)\right)\left(\prod_{j \in b} f_{N}\left(v_{j}\right)\right) .
$$

29 Taken to the limit, a very flexible distribution would essentially be non-parametric. And any distribution free approach would again require at least one brand's BE be normalized as happened with fixed effects. 
The result of the ML analysis yield an estimate of $\sigma_{z}$. All the $z_{b}$ relate to one another through $g\left(z_{b} \mid \sigma_{z}\right)$. Having obtained $\sigma_{z}$, I can now find individual $z_{b}$ for each of the B brands as the conditional expectation of the $\mathrm{BE}$ error component given $\mathbf{D}$ and $\boldsymbol{\theta}$, thus:

$$
E\left(\hat{z}_{b} \mid \hat{\boldsymbol{\varepsilon}}_{b}, \mathbf{D}, \boldsymbol{\theta}\right)=\int_{0}^{\infty} z_{b} g\left(\hat{z}_{b} \mid \hat{\boldsymbol{\varepsilon}}_{b}, \mathbf{D}, \boldsymbol{\theta}\right) d \tau_{b} .
$$

In the next section, I derive the mathematical expression in closed form for $f\left(\boldsymbol{\varepsilon}_{b} \mid \mathbf{D}, \boldsymbol{\theta}\right)$ and $E\left(\hat{z}_{b} \mid \hat{\varepsilon}_{b}\right)$.

\section{Maximum Likelihood (ML) approach to the proposed BEM model}

The general BE Multiplier (BEM) model estimated in the paper for log revenue $Y_{j(b) t}$ of SKU $j$ of brand $b$ in period $t$ is:

$$
Y_{j(b) t}=\alpha+\mathbf{X \beta}_{(b) t}+v_{j(b)}+z_{b}+\eta_{j(b) t}
$$

Where $\alpha$ is the intercept, $\mathbf{X}_{j(b) t}$ is the vector of covariates, $\boldsymbol{\beta}$ is the coefficient vector, $\eta_{j(b) t} \sim$ i.i.d. $N\left(0, \sigma_{\eta}^{2}\right)$ is random revenue shocks, $v_{j(b)} \sim$ i.i.d. $N\left(0, \sigma^{2}{ }_{v}\right)$ is the latent SKU specific shock to revenue, and $\tau_{b} \sim \operatorname{iid} f_{\text {Exp }}\left(\sigma_{z}\right)$ is the BEM.

I define vectors $\mathbf{w}_{b}=\left(\eta_{j \in b, 1}, \eta_{j \in b, 2}, \ldots \eta_{j \in b, T}\right)$ and $\mathbf{u}_{b}=\left(v_{1 \in b}, v_{2 \in b}, \ldots v_{J \in b}\right)$ for any

brand $b$ in the sample. Then $\mathbf{w}=\left(\mathbf{w}_{1}, \ldots \mathbf{w}_{B}\right)$ and $\mathbf{u}=\left(\mathbf{u}_{1}, \ldots \mathbf{u}_{B}\right)$. Because $\left(\eta_{j(b) t}, v_{j(b)}\right)$ 
are independently and identically distributed (IID) and are assumed independent of each other for all $j, b$ and $t$, the density of some vector $\mathbf{v}$ defined as $\mathbf{v}=(\mathbf{w}, \mathbf{u})$ becomes:

$$
f(\mathbf{v})=f(\mathbf{w}, \mathbf{u})=\prod_{l=1}^{L} f\left(\mathbf{w}_{l}\right) \prod_{m=1}^{M} f\left(\mathbf{u}_{m}\right)
$$

I denote $\mathrm{k}_{\mathrm{b}}=1,2, \ldots \mathrm{K}_{\mathrm{b}}$ as the index for each $j \in b, t$ of brand $b$. Then the density of $\mathbf{v}_{b}$ can be written as (since components of $\mathbf{v}_{b}$ are independent draws)

$$
f\left(\mathbf{v}_{b}\right)=\prod_{k(b)=1}^{K_{b}} f\left(v_{k_{b}}\right)=\frac{1}{(2 \pi)^{\frac{K_{b}}{2}} \sigma_{v}^{K_{b}}} \exp \left(-\frac{\sum_{k(b)=1}^{K_{b}} v_{k(b)}{ }^{2}}{2 \sigma_{v}{ }^{2}}\right) .
$$

The joint density of $z_{b}$ with $\mathbf{v}_{b}$ would then be

$$
f\left(z_{b}, \mathbf{v}_{b}\right)=\frac{1}{(2 \pi)^{\frac{K_{b}}{2}} \sigma_{v}{ }^{K_{b}} \sigma_{z}} \exp \left\{-\frac{z_{b}}{\sigma_{z}}-\frac{\sum_{k(b)=1}^{K_{b}} v_{k(b)}{ }^{2}}{2 \sigma_{v}^{2}}\right\} .
$$

I replace $\mathbf{v}_{b}$ with $\varepsilon_{j t}=v_{j t}+z_{b}=>\mathbf{v} \boldsymbol{\xi}={ }_{b}-z_{b}$, where $\boldsymbol{\varepsilon}_{b}=\left(\varepsilon_{1}, \varepsilon_{2}, \ldots \varepsilon_{K_{b}}\right)$ and the subscripts $k(b)=1,2,3, \ldots K_{b}$ as defined previously. I get: 


$$
f\left(z_{b}, \boldsymbol{\varepsilon}_{b}\right)=\frac{1}{(2 \pi)^{\frac{K_{b}}{2}} \sigma_{v}^{K_{b}} \sigma_{z}} \exp \left\{-\frac{z_{b}}{\sigma_{z}}-\frac{\sum_{k(b)=1}^{K_{b}}\left(\varepsilon_{k(b)}-z_{b}\right)^{2}}{2 \sigma_{v}{ }^{2}}\right\}
$$

To obtain the marginal distribution of $\boldsymbol{\varepsilon}_{b}$ alone, I integrate out $z_{b b}$ from the equation above as:

$$
f\left(\varepsilon_{b}\right)=\int_{0}^{\infty} f\left(z_{b}, \varepsilon_{b}\right) d z_{b}
$$

Simplifying the exponential part in the above equation yields:

$\exp \left\{-\frac{z_{b}}{\sigma_{z}}-\frac{\sum_{k(b)=1}^{K_{b}}\left(\varepsilon_{k(b)}-z_{b}\right)^{2}}{2 \sigma_{v}{ }^{2}}\right\}=\exp \left\{-\frac{2 \sigma_{v}{ }^{2} z_{b}+\sigma_{z} \sum_{k(b)=1}^{K_{b}}\left(\varepsilon_{k(b)}{ }^{2}+z_{b b}{ }^{2}-2 z_{b} \varepsilon_{k(b)}\right)}{2 \sigma_{v}{ }^{2} \sigma_{z}}\right\}$

For algebraic simplicity, I define $\sigma_{v^{*}}{ }^{2}=\frac{\sigma_{v}{ }^{2}}{K_{b}}$ and $A=\left(\frac{\sum_{k(b)} \varepsilon_{k(b)}}{K_{b}}-\frac{\sigma_{v^{*}}{ }^{2}}{\sigma_{z}}\right)$ Then the exponential in the above equation reduces to: 
$\exp \left\{-\frac{\left[z_{b}^{2}-2 z_{b} A \pm A^{2}+\frac{\sum_{k(b)} \varepsilon_{k(b)}{ }^{2}}{K_{b}}\right]}{2 \sigma_{v^{*}}^{2}}\right\}=\exp \left\{-\frac{1}{2}\left(\frac{z_{b}-A}{\sigma_{v^{*}}}\right)^{2}-\frac{1}{2}\left(\frac{\sum_{k(b)} \varepsilon_{k(b)}^{2}}{K \sigma_{v^{*}}^{2}}-\left(\frac{A}{\sigma_{v^{*}}}\right)^{2}\right)\right\}$

(C.12)

Thus I have:

$f\left(\varepsilon_{b}\right)=\int_{0}^{\infty} \frac{1}{(2 \pi)^{\frac{K_{b}}{2}} \sigma_{v}^{K_{b}} \sigma_{z}} \exp \left\{-\frac{1}{2}\left(\frac{z_{b}-A}{\sigma_{v^{*}}}\right)^{2}-\frac{1}{2}\left(\frac{\sum_{k(b)} \varepsilon_{k(b)}{ }^{2}}{K \sigma_{v^{*}}{ }^{2}}-\left(\frac{A}{\sigma_{v^{*}}}\right)^{2}\right)\right\}\left|\mathbf{J}_{v \rightarrow \varepsilon}\right| d z_{b}$

Here, $\left|\mathbf{J}_{v \rightarrow \varepsilon}\right|$ is the determinant of the Jacobian of the transformation

$\mathbf{v} \boldsymbol{\varepsilon}={ }_{b}-r_{b}$ and it is unity because the transformation is linear. I get:

$f\left(\varepsilon_{b}\right)=\frac{1}{(2 \pi)^{\frac{K_{b}-1}{2}} \sigma_{v}^{K_{b}-1} K_{b} \sigma_{z}}\left[1-\Phi\left(\frac{-A}{\sigma_{v^{*}}}\right)\right] \exp \left(-\frac{1}{2}\left(\frac{\sum_{k(b)} \varepsilon_{k(b)}{ }^{2}}{K_{b} \sigma_{v^{*}}{ }^{2}}-\left(\frac{A}{\sigma_{v^{*}}}\right)^{2}\right)\right)$

(C.14)

The equation above is the closed functional form of the composed non-normal error of the model. The log-likelihood of the model is easily derived from it. Maximum likelihood 
(ML) methods can now directly be applied to obtain coefficient vectors $\boldsymbol{\theta}=\left\{\alpha, \boldsymbol{\beta}, \sigma_{v^{*}}, \sigma_{z}\right\}$, thus:

\section{$\underset{\boldsymbol{\theta}}{\operatorname{Max}} \operatorname{LL}(\boldsymbol{\theta} \mid \mathbf{D})$}

Here, $\mathbf{D}=\left\{Y_{j(b) t}, \mathbf{X}_{j(b) t}\right\}$ is the observed data matrix. Note at this stage that (i) the intercept $\alpha$, the variance of the symmetric error $\left(\sigma_{v^{*}}\right)$ and the parameter(s) of the asymmetric $\mathrm{BE}$ distribution (in this case $\sigma_{z}$ ) are clearly identified using ML methods (ii) BE is identified only upto the $\sigma_{z}$. To further identify the moments of individual BEs of each brand $b$ given $\sigma_{z}$, I need to find the conditional $E\left(z_{b} \mid \boldsymbol{\varepsilon}_{b}\right)$ and use it as a point estimate for $z_{b}$. The conditional expectation can be found thus:

$$
E\left(z_{b} \mid \boldsymbol{\varepsilon}_{b}\right)=\int_{0}^{\infty} z_{b} f\left(z_{b} \mid \boldsymbol{\varepsilon}_{b}\right) d z_{b} .
$$

But the above requires that the conditional distribution $f\left(z_{b} \mid \boldsymbol{\varepsilon}_{b}\right)$ be found. Thus:

$$
f\left(z_{b} \mid \boldsymbol{\varepsilon}_{b}, \mathbf{D}, \boldsymbol{\theta}\right)=\frac{f\left(z_{b}, \boldsymbol{\varepsilon}_{b} \mid \mathbf{D}, \boldsymbol{\theta}\right)}{f\left(\boldsymbol{\varepsilon}_{b} \mid \mathbf{D}, \boldsymbol{\theta}\right)}=\frac{1}{\sqrt{2 \pi} \sigma_{v^{*}}}\left[1-\Phi\left(\frac{-A}{\sigma_{v^{*}}}\right)\right]^{-1} \exp \left(-\frac{1}{2}\left(\frac{z_{b}-A}{\sigma_{v^{*}}}\right)^{2}\right)
$$

The quantity in equation (3) is akin to a truncated normal distribution $N^{+}\left(A, \sigma_{v^{*}}{ }^{2}\right)$ which has the following mean: 


$$
E\left(z_{b} \mid \boldsymbol{\varepsilon}_{b}, \mathbf{D}, \boldsymbol{\theta}\right)=A+\sigma_{v^{*}}\left[\frac{\phi\left(\frac{-A}{\sigma_{v^{*}}}\right)}{1-\Phi\left(\frac{-A}{\sigma_{v^{*}}}\right)}\right] .
$$

But $\mathrm{BE}$ in my model is $B E_{b}=\exp \left(z_{b}\right)$. So I obtain an expression for $E\left(\exp \left(z_{b}\right) \mid \boldsymbol{\varepsilon}_{b}\right)$

as:

$$
E\left(\exp \left(z_{b}\right) \mid \boldsymbol{\varepsilon}_{b}, \mathbf{D}, \boldsymbol{\theta}\right)=\int_{0}^{\infty} \exp \left(z_{b}\right) f\left(z_{b} \mid \boldsymbol{\varepsilon}_{b}\right) d z_{b}=\int_{0}^{\infty} \frac{1}{\sqrt{2 \pi} \sigma_{v^{*}}}\left[1-\Phi\left(\frac{-A}{\sigma_{v^{*}}}\right)\right]^{-1} \exp \left(-\frac{1}{2}\left(\frac{z_{b}-A}{\sigma_{v^{*}}}\right)^{2}+z_{b}\right)
$$

Which simplifies to:

$$
E\left(\exp \left(z_{b}\right) \mid \boldsymbol{\varepsilon}_{b}, \mathbf{D}, \boldsymbol{\theta}\right)=\frac{\left[1-\Phi\left(\frac{-A}{\sigma_{v^{*}}}-\sigma_{v^{*}}\right)\right]}{\left[1-\Phi\left(\frac{-A}{\sigma_{v^{*}}}\right)\right]} \exp \left\{\frac{-1}{2}\left(1-\frac{2 A}{\sigma_{v^{*}}}\right)\right\}
$$

Equation (C.19) when applied to each brand $b=1,2 \ldots B$ yields the BEM of all $B$ brands in the sample.

\section{Simulation Results on Parameter Recovery}

Having constructed a mathematically closed form for the model's likelihood expression,

I can now assess the model's efficacy using simulation experiments. My simulation 
experiment investigates (i) whether the model recovers the unknown parameters, including the BEM or $\operatorname{Ln}(\mathrm{BEM})$ of all brands in the sample, (ii) how well the parameters are recovered (e.g., using the mean squared deviation of the estimated from the true values), and (iii) how variation in the characteristics of the simulated data (sample size, true distribution of the BEM values etc) affects parameter recovery. In the following section, I compare model fit across different distributional assumptions for the BEM values.

\section{Experiment 1}

In the first experiment, the true relation between $\log$ revenue for brand $b$ in time $t\left(\mathrm{Y}_{\mathrm{bt}}\right)$, explanatory variables $\mathrm{X}=\left[\mathrm{X}_{1 \mathrm{~b},}, \mathrm{X}_{2 \mathrm{~b}}\right], \mathrm{BEM}$ term $\mathrm{z}_{\mathrm{b}}$ and random shock $\varepsilon_{b t}$ as:

$$
Y_{b t}=20+2 x_{1, b t}-3 x_{3, b t}+\tau_{b}+\varepsilon_{b t}
$$

The data are generated as (i) $x_{1}$ is the $\log$ of i.i.d. draws from $N^{+}(2,2)$, truncated at 1 ,

(ii) $x_{2}$ is the $\log$ of IID draws from $N^{+}(1,3)$ truncated at 1 , (iii) $\varepsilon_{j(b) t} \sim \operatorname{IID} N(0,4)$ and (iv) $\tau_{b} \sim$ i.i.d. $\mathrm{f}_{\text {exp }}(\lambda)=\lambda \mathrm{e}^{-\lambda z}$ for $\lambda=0.2$. Table 23 displays the results of models I, II and III having number of brands 5, 10 and 20 respectively. Each model is estimated using both the ML estimator and an Markov-Chain Monte-Carlo (MCMC) routine utilizing Bayesian Updating under Gibbs Sampling (BUGS), and the results for each method is displayed. The results suggest that:

- MLE outperforms MCMC in terms of fit (lower Mean Squared Deviation or MSD) when the number of brands is large (10 or 20) but underperforms MCMC in when the number is small (5 brands). 
- Parameter recovery in main effects is excellent and expectedly, MLE proves efficient. MLE estimates are closer to the true values than are the MCMC estimates in models II and III but in small samples (model I), MCMC does better.

- The variances of the asymmetric component and of the symmetric error are separately identified.

- The hyper-parameter lambda is identified but appears to differ significantly from the true value. Here, the MCMC estimate appears to do as well as badly as the MLE one.

Experiment 2

I next investigate how model fit is affected by changing parameters in the data generation mechanism. I generate draws of $Z=\left\{z_{1}, z_{2}, \ldots z_{B}\right\}$ (the log of the BEM in the model) from a series of uniform distributions and compare the MSD with the mean and dispersion of the $Z$ draws. Table 24 displays these results (under the normal-exponential MLE model).

- The main effects all appear remarkably close to their true values. Thus I know that parameter recovery for main effects is good even when the draw of $Z$ is not exponential.

- Since I draw a different sequence of $Z$ each time for a fresh run, there is variation in the $Z$ numbers. I run 500 cycles and report the summary of the analysis as grand mean, min and max of the values obtained in Table 24 . I find that the mean square deviation (MSD) is low with a grand mean of 0.13 . Thus, the model 
recovers $Z$ parameters well in 500 different instances even when the data generation distribution is not exponential but is fairly arbitrary.

- We find that model fit (as measured by MSD) seems to worsen with rise in both the level and the dispersion of $Z$ values (as measured by rising mean and a rising standard deviation standard deviation). This is depicted as a scatter-plot in each of Figures 9 and 10 where MSD appears to have a hetero-skedastic pattern.

\section{Simulation Results on Cross-Distribution Comparison}

We compare model fit (using MSD) across different one-sided distributions using a simulation experiment. The true value of the parameters are as in the relation:

$$
\begin{aligned}
& Y_{j(b) t}=100+2 x_{1}-3 x_{2}+z_{b}+\varepsilon_{j(b) t} \\
& \varepsilon_{j(b) t} \sim \text { i.i.d. } N(0,4) \\
& z_{b} \sim \text { integers uniform }(1,10)
\end{aligned}
$$

Apart from the MLE estimation of the exponential model (Model I), I also present fixed effects (Model II) with the lowest BEM set to zero, and three common one-sided distributions viz. The truncated Normal (Model V), the Gamma (Model VIII) and the lognormal (Model VI). To test whether restrictions on the parameters of the one-sided distributions affect parameter recovery, I restrict the shape parameters of the Gamma to 2 (Model) and the mean of the lognormal to 1 (Model). The results are presented in Table 25. I summarize the salient points below:

- Recovery of main effects shows little variation regardless of the distribution used. The symmetric error variance sigma is captured well in all models. 
- The best fit (in terms of lowest MSD) is attained by the Truncated Normal, the exponential, the half normal and the restricted Gamma respectively.

- The lowest true BEM was 1 and it was captured by the restricted gamma model. Interestingly, while the MLE exponential model could only capture 0.2 , the MCMC exponential model recovered 0.6 which is closer to 1 . The restricted gamma model captured 1 perfectly. It is for this reason why I assume that the distribution of BEM is such that there is at least one brand on or close to the 'unbranded product response frontier'.

- The restricted models in general seem to do better than the more general forms (except for the truncated normal). This lends credence to my conjecture that greater flexibility would impede identification.

The question remains as to how well parameter recovery might proceed if the true distribution of $Z$ was such that the minimum $Z$ value was not close to the frontier. To test this, I draw $Z$ as integers from a uniform distribution $U(5,15)$ and use the same relation as above to generate data. The minimum $Z$ value here is 5 . Table 26 displays the recovered parameters and model fit.

- We find that since the $Z$ values' true distribution does not resemble that of an exponential, model fit suffers for the exponential in both the MLE and the MCMC methods. The model forces a fit and the excess BE common to all brands (i.e., 5) is absorbed into the intercept.

- But the more flexible distributions (truncated normal, gamma) do a much better job of parameter recovery since their modes are not restricted to be zero. The Lognormal seems to be an exception here in that it doesn't recover Zs well. 
Table 1. U.S. Beer Market Summary of Variables (Essay 1)

\begin{tabular}{|c|c|c|c|c|}
\hline $\begin{array}{l}\text { Revenue } \\
\text { Component }\end{array}$ & Variable & Description & Mean & Source \\
\hline & Ln(Revenue) & Log of revenue for SKU $j$ in period $t$ & $13.4(1.2)$ & Scanner Data \\
\hline \multirow[t]{2}{*}{ Product } & $\mathrm{Craft}_{j}$ & Craft type $=1$, otherwise $=0$ & 0.04 & \\
\hline & Dry $_{j}$ & Dry type $=1$, otherwise $=0$ & 0.01 & Scanner \\
\hline \multirow[t]{5}{*}{ Beer Type } & Ice $_{j}$ & Ice type $=1$, otherwise $=0$ & 0.12 & Data \\
\hline & Lite $_{j}$ & Lite type $=1$, otherwise $=0$ & 0.4 & (AC Nielsen) \\
\hline & Subjective Taste $_{i}$ & $\begin{array}{l}\text { Regression residual of beer ratings }(0-5 \text { scale }) \text { on } \\
\text { all objective product attributes }\end{array}$ & -0.02 & $\begin{array}{c}\text { Internet and } \\
\text { Regression Residual }\end{array}$ \\
\hline & Imported $_{j}$ & Imported brewer $=1$, otherwise $=0$ & 0.06 & Scanner Data \\
\hline & Domestic $_{j}$ & U.S. brewer $=1$, otherwise $=0$ & & Seaninter Data \\
\hline \multirow{4}{*}{ Beer Color } & Dark $_{j}$ & Dark color $=1$, otherwise $=0$ & 0.01 & \\
\hline & 6 Pack $12 \mathrm{oz}_{\mathrm{j}}$ & 6 Pack of $12 \mathrm{oz}$. Containers $=1$, else 0 & 0.24 & \\
\hline & 6 Pack Other oz & 6 Pack, Non -12 oz. Containers $=1$, else 0 & 0.07 & Scanner Data \\
\hline & 12 Pack $_{j}$ & 12 Pack $=1$, otherwise $=0$ & 0.3 & \\
\hline \multirow[t]{4}{*}{ Packaging } & Case $_{j}$ & Pack of 18 or more containers $=1$, else 0 & 0.26 & \\
\hline & SmallPack $_{j}$ & Pack with total volume $<72 \mathrm{Oz} .=1$, else 0 & 0.13 & \\
\hline & $\mathrm{Can}_{\mathrm{j}}$ & Can $=1$, otherwise $=0$ & 0.47 & \\
\hline & Bottle $_{i}$ & Bottle $=1$, otherwise $=0$ & 0.53 & \\
\hline Promotion & AdSpend $_{\mathrm{vt}}$ & Annual Ad spend in \$ million & 30.61 & LNA \\
\hline \multirow[t]{12}{*}{ Drivers } & FreightPPI $_{t}$ & Long haul freight PPI & 115.43 & Labor Statistics \\
\hline & CanadaRate $_{\mathrm{t}}$ & Canadian dollar exchange rate per US dollar & 1.37 & \multirow{3}{*}{ US Federal Reserve } \\
\hline & PesoRate $_{t}$ & Mexican peso exchange rate per US dollar & 10.6 & \\
\hline & EuroRate $_{\mathrm{t}}$ & Euro exchange rate per US dollar & 1.13 & \\
\hline & Winter $_{t}$ & Winter $=1$, otherwise $=0$ & 0.24 & \multirow{8}{*}{ Scanner Data } \\
\hline & Fall $_{t}$ & Fall $=1$, otherwise $=0$ & 0.24 & \\
\hline & Spring $_{t}$ & Spring $=1$, otherwise $=0$ & 0.23 & \\
\hline & Summer $_{\mathrm{t}}$ & Summer $=1$, otherwise $=0$ & 0.29 & \\
\hline & Year $2002 \mathrm{t}$ & Year $2002=1$, otherwise $=0$ & 0.26 & \\
\hline & Year $2003_{t}$ & Year $2003=1$, otherwise $=0$ & 0.25 & \\
\hline & Year $2004_{t}$ & Year $2004=1$, otherwise $=0$ & 0.23 & \\
\hline & Year $2005_{t}$ & Year $2005=1$, otherwise $=0$ & 0.27 & \\
\hline
\end{tabular}

LNA stands for Leading National Advertisers, ACV for 'All Commodity Volume', 'PPI' for Purchasers Price Index. 
Table 2. U.S. Beer Market Summary Statistics by Brand (Essay 1)

\begin{tabular}{|c|c|c|c|c|c|c|c|}
\hline Brand $^{a}$ & Origin & $\begin{array}{c}\text { Revenue } \\
\text { Share }\end{array}$ & $\begin{array}{c}\text { Average } \\
\text { Price } \\
(\$ / o z .) \\
\end{array}$ & $\begin{array}{c}\text { Average } \\
\% A C V \\
\text { Distbn } \\
\end{array}$ & $\begin{array}{c}\text { Average } \\
\% A C V \\
\text { Merch } \\
\end{array}$ & $\begin{array}{l}\text { AdSpend } \\
\text { (\$ million } \\
\text { per year) }\end{array}$ & $\begin{array}{c}\text { Taste } \\
\text { Rating } \\
(0-5) \\
\end{array}$ \\
\hline Budweiser & USA & $29.60 \%$ & 0.06 & 56.26 & 20.68 & 267.08 & 1.31 \\
\hline Miller & USA & $14.70 \%$ & 0.05 & 49.28 & 16.95 & 192.35 & 1.55 \\
\hline Coors & USA & $9.10 \%$ & 0.06 & 53.01 & 21.56 & 147.48 & 1.42 \\
\hline Corona & Mexico & $8.60 \%$ & 0.10 & 72.10 & 35.72 & 43.10 & 1.44 \\
\hline Michelob & USA & $6.10 \%$ & 0.07 & 56.16 & 18.54 & 73.87 & 1.52 \\
\hline Busch & USA & $5.40 \%$ & 0.05 & 34.40 & 11.08 & 12.30 & 1.29 \\
\hline Natural & USA & $4.80 \%$ & 0.04 & 46.65 & 13.86 & 0.14 & 1.09 \\
\hline Heineken & Europe & $4.10 \%$ & 0.10 & 68.15 & 32.32 & 50.38 & 2.68 \\
\hline Milwaukee's Best & USA & $3.40 \%$ & 0.04 & 38.22 & 7.00 & 0.00 & 1.22 \\
\hline Keystone & USA & $1.50 \%$ & 0.04 & 24.59 & 7.08 & 2.40 & 1.37 \\
\hline Samuel Adams & USA & $1.30 \%$ & 0.10 & 47.52 & 17.96 & 29.25 & 3.03 \\
\hline Tecate & Mexico & $1.30 \%$ & 0.07 & 21.36 & 10.06 & 2.72 & 1.87 \\
\hline Icehouse & USA & $1.10 \%$ & 0.05 & 19.63 & 6.17 & 1.82 & 1.83 \\
\hline Labatt & Canada & $1.10 \%$ & 0.06 & 18.28 & 5.91 & 12.75 & 2.21 \\
\hline Becks & Europe & $1.00 \%$ & 0.09 & 44.08 & 18.24 & 9.11 & 2.45 \\
\hline Old Milwaukee & USA & $1.00 \%$ & 0.04 & 20.40 & 3.00 & 0.12 & 1.41 \\
\hline Amstel & Europe & $0.80 \%$ & 0.10 & 52.88 & 25.61 & 21.06 & 2.03 \\
\hline Rolling Rock & USA & $0.80 \%$ & 0.07 & 61.14 & 20.10 & 5.29 & 2.07 \\
\hline Pabst & USA & $0.70 \%$ & 0.04 & 25.74 & 5.71 & 0.34 & 1.79 \\
\hline Fosters & Australia & $0.70 \%$ & 0.08 & 53.01 & 14.39 & 5.91 & 2.14 \\
\hline Molson & Canada & $0.70 \%$ & 0.06 & 18.30 & 4.43 & 3.56 & 2.16 \\
\hline Dos Equis & Mexico & $0.50 \%$ & 0.09 & 37.28 & 11.62 & 4.69 & 2.40 \\
\hline George Killian's & USA & $0.50 \%$ & 0.08 & 55.76 & 20.96 & 0.00 & 2.76 \\
\hline Modelo Especial & Mexico & $0.50 \%$ & 0.09 & 23.08 & 5.66 & 1.65 & 2.05 \\
\hline Pacifico Clara & Mexico & $0.50 \%$ & 0.09 & 27.50 & 8.96 & 1.68 & 2.16 \\
\hline Mean & & $4.00 \%$ & 0.068 & 40.9 & 14.5 & 35.56 & 1.89 \\
\hline Std Dev & & $6.40 \%$ & 0.065 & 16.70 & 8.70 & 5.29 & 0.53 \\
\hline
\end{tabular}

a Sorted in descending order by revenue share.

b Revenue weighted average over the brand's SKUs over te entire sample period.

c Average yearly advertising spend 
Table 3. Main Effects of the Revenue Regression (Essay 1)

\begin{tabular}{|c|c|c|c|c|}
\hline $\begin{array}{l}\text { Revenue } \\
\text { Component }\end{array}$ & Variable & Mean & $\begin{array}{l}2.5 \% \\
\text { HPD }\end{array}$ & $\begin{array}{l}97.5 \% \\
\text { HPD }\end{array}$ \\
\hline & Intercept & -8.68 & -13.64 & -3.81 \\
\hline Product & Craft & 0.44 & 0.00 & 0.84 \\
\hline Beer Type & Dry & -0.12 & -1.16 & 0.89 \\
\hline & Ice & 0.19 & -0.08 & 0.39 \\
\hline & Lite & 0.37 & 0.29 & 0.44 \\
\hline & Regular & \multicolumn{3}{|c|}{ Reference Attribute } \\
\hline & Subjective Taste & -0.50 & -0.70 & -0.31 \\
\hline & Imported & 0.12 & -0.14 & 0.37 \\
\hline & Domestic & \multicolumn{3}{|c|}{ Reference Attribute } \\
\hline & Amber & 0.24 & -0.42 & 0.94 \\
\hline \multirow{6}{*}{ Beer Color } & Golden & 0.39 & -0.07 & 1.05 \\
\hline & Light & 0.49 & 0.01 & 1.17 \\
\hline & Dark & \multicolumn{3}{|c|}{ Reference Attribute } \\
\hline & 6Pack $12 \mathrm{oz}$ & 0.04 & -0.09 & 0.16 \\
\hline & 6Pack Other oz & 0.20 & -0.05 & 0.39 \\
\hline & 12 Pack & 0.63 & 0.49 & 0.79 \\
\hline \multirow{5}{*}{ Packaging } & Case & 1.11 & 0.92 & 1.30 \\
\hline & SmallPack & \multicolumn{3}{|c|}{ Reference Attribute } \\
\hline & Can & 0.25 & 0.13 & 0.38 \\
\hline & Bottle & \multicolumn{3}{|c|}{ Reference Attribute } \\
\hline & Latent Brand Factors $\lambda$ & 0.22 & 0.12 & 0.34 \\
\hline Variance & Latent Variant Factors $\xi$ & 0.02 & 0.01 & 0.03 \\
\hline \multirow[t]{2}{*}{ Components } & Latent SKU Factors $\eta$ & 0.20 & 0.18 & 0.26 \\
\hline & Measurement Error u & 0.02 & 0.02 & 0.02 \\
\hline \multirow[t]{3}{*}{ Promotion } & Ln AdSpend & 0.02 & 0.02 & 0.03 \\
\hline & Competition & -0.73 & -0.91 & -0.55 \\
\hline & Ln \%ACV Merchandizing & 0.17 & 0.15 & 0.18 \\
\hline \multirow[t]{2}{*}{ Distribution } & Ln \%ACV Distribution & 0.96 & 0.94 & 0.97 \\
\hline & Ln Vt SKUNUM & 0.13 & 0.10 & 0.16 \\
\hline \multirow{10}{*}{$\begin{array}{l}\text { Category } \\
\text { Drivers }\end{array}$} & AdultPop & 3.07 & 2.14 & 3.95 \\
\hline & ExchgRate & 0.07 & 0.02 & 0.11 \\
\hline & Winter & -0.16 & -0.16 & -0.15 \\
\hline & Fall & -0.15 & -0.16 & -0.15 \\
\hline & Spring & -0.13 & -0.13 & -0.12 \\
\hline & Summer & \multicolumn{3}{|c|}{ Reference Season } \\
\hline & Year2002 & 0.26 & 0.23 & 0.30 \\
\hline & Year2003 & 0.15 & 0.13 & 0.17 \\
\hline & Year2004 & 0.08 & 0.07 & 0.09 \\
\hline & Year2005 & \multicolumn{3}{|c|}{ Reference Year } \\
\hline Fit & Log Marginal Density & \multicolumn{3}{|c|}{7986.11} \\
\hline
\end{tabular}

Bold font indicates parameter is significantly different from 0 at the $95 \%$ HPD interval level. 
Table 4. An Illustration of Competition Effects (Essay 1)

\begin{tabular}{|c|c|c|c|c|c|c|c|c|c|}
\hline Column & & (1) & (2) & (3) & (4) & (5) & (6) & (7) & (8) \\
\hline Row & & $\begin{array}{l}\text { Budweiser } \\
6 \mathrm{Pk} 12 \mathrm{oz} \\
\text { Can }\end{array}$ & $\begin{array}{l}\text { Bud Ice } \\
6 \mathrm{Pk} 12 \mathrm{oz} \\
\text { Bottle }\end{array}$ & $\begin{array}{l}\text { Bud Light } \\
12 \mathrm{Pk} 12 \mathrm{oz} \\
\text { Bottle }\end{array}$ & $\begin{array}{l}\text { Miller } \\
6 \mathrm{Pk} 12 \mathrm{oz} \\
\text { Bottle }\end{array}$ & $\begin{array}{l}\text { Coors Light } \\
24 \mathrm{Pk} 12 \mathrm{oz} \\
\text { Bottle }\end{array}$ & $\begin{array}{l}\text { Corona } \\
12 \mathrm{Pk} 12 \mathrm{oz} \\
\text { Bottle }\end{array}$ & $\begin{array}{c}\text { Milwaukee's Best } \\
\text { 24Pk } 12 \mathrm{oz} \\
\text { Can }\end{array}$ & $\begin{array}{c}\text { Samuel Adams } \\
\text { 12Pk } 12 \mathrm{oz} \\
\text { Bottle }\end{array}$ \\
\hline 1 & $\begin{array}{l}\text { Budweiser } \\
6 \mathrm{Pk} 12 \mathrm{oz} \text { Can }\end{array}$ & $\begin{array}{c}0 \\
(15)\end{array}$ & $\begin{array}{c}-39.18 \\
(10)\end{array}$ & $\begin{array}{c}-37.13 \\
(7)\end{array}$ & $\begin{array}{l}-60.3 \\
(12)\end{array}$ & $\begin{array}{c}-34.62 \\
(9)\end{array}$ & $\begin{array}{c}-115.88 \\
(9)\end{array}$ & $\begin{array}{c}-15.81 \\
(11)\end{array}$ & $\begin{array}{c}-61.4 \\
(8)\end{array}$ \\
\hline 2 & $\begin{array}{l}\text { Bud Ice } \\
6 \mathrm{Pk} 12 \mathrm{oz} \text { Bottle }\end{array}$ & $\begin{array}{c}-43.69 \\
(10)\end{array}$ & $\begin{array}{c}0 \\
(15)\end{array}$ & $\begin{array}{c}-58.35 \\
(11)\end{array}$ & $\begin{array}{c}-50.25 \\
(10)\end{array}$ & $\begin{array}{c}-26.92 \\
(7)\end{array}$ & $\begin{array}{c}-90.13 \\
(7)\end{array}$ & $\begin{array}{c}-10.06 \\
(7)\end{array}$ & $\begin{array}{c}-61.4 \\
(8)\end{array}$ \\
\hline 3 & $\begin{array}{l}\text { Bud Light } \\
\text { 12Pk 12oz Bottle }\end{array}$ & $\begin{array}{c}-30.58 \\
(7)\end{array}$ & $\begin{array}{c}-43.09 \\
(11)\end{array}$ & $\begin{array}{c}0 \\
(15)\end{array}$ & $\begin{array}{c}-35.17 \\
(7)\end{array}$ & $\begin{array}{c}-30.77 \\
(8)\end{array}$ & $\begin{array}{c}-103 \\
(8)\end{array}$ & $\begin{array}{c}-8.62 \\
(6)\end{array}$ & $\begin{array}{c}-69.07 \\
(9)\end{array}$ \\
\hline 4 & $\begin{array}{l}\text { Miller } \\
6 \mathrm{Pk} 12 \mathrm{oz} \text { Bottle }\end{array}$ & $\begin{array}{c}-52.43 \\
(12)\end{array}$ & $\begin{array}{c}-39.18 \\
(10)\end{array}$ & $\begin{array}{c}-37.13 \\
(7)\end{array}$ & $\begin{array}{c}0 \\
(15)\end{array}$ & $\begin{array}{c}-38.46 \\
(10)\end{array}$ & $\begin{array}{c}-128.75 \\
(10)\end{array}$ & $\begin{array}{c}-14.37 \\
(10)\end{array}$ & $\begin{array}{c}-53.72 \\
(7)\end{array}$ \\
\hline 5 & $\begin{array}{l}\text { Coors Light } \\
\text { 24Pk 12oz Bottle }\end{array}$ & $\begin{array}{c}-39.32 \\
(9)\end{array}$ & $\begin{array}{c}-27.42 \\
(7)\end{array}$ & $\begin{array}{c}-42.44 \\
(8)\end{array}$ & $\begin{array}{c}-50.25 \\
(10)\end{array}$ & $\begin{array}{c}0 \\
(15)\end{array}$ & $\begin{array}{c}-115.88 \\
(9)\end{array}$ & $\begin{array}{c}-15.81 \\
(11)\end{array}$ & $\begin{array}{c}-46.05 \\
(6)\end{array}$ \\
\hline 6 & $\begin{array}{l}\text { Corona } \\
\text { 12Pk 12oz Bottle }\end{array}$ & $\begin{array}{c}-39.32 \\
(9)\end{array}$ & $\begin{array}{c}-27.42 \\
(7)\end{array}$ & $\begin{array}{c}-42.44 \\
(8)\end{array}$ & $\begin{array}{c}-50.25 \\
(10)\end{array}$ & $\begin{array}{c}-34.62 \\
(9)\end{array}$ & $\begin{array}{c}0 \\
(15)\end{array}$ & $\begin{array}{c}-12.93 \\
(9)\end{array}$ & $\begin{array}{c}-76.75 \\
(10)\end{array}$ \\
\hline 7 & $\begin{array}{l}\text { Milwaukee's Best } \\
24 \mathrm{Pk} 12 \mathrm{oz} \text { Can }\end{array}$ & $\begin{array}{c}-48.06 \\
(11)\end{array}$ & $\begin{array}{c}-27.42 \\
(7)\end{array}$ & $\begin{array}{c}-31.83 \\
(6)\end{array}$ & $\begin{array}{c}-50.25 \\
(10)\end{array}$ & $\begin{array}{c}-42.31 \\
(11)\end{array}$ & $\begin{array}{c}-115.88 \\
(9)\end{array}$ & $\begin{array}{c}0 \\
(15)\end{array}$ & $\begin{array}{c}-61.4 \\
(8)\end{array}$ \\
\hline 8 & $\begin{array}{l}\text { Samuel Adams } \\
\text { 12Pk 12oz Bottle }\end{array}$ & $\begin{array}{c}-34.95 \\
(8)\end{array}$ & $\begin{array}{c}-31.34 \\
(8)\end{array}$ & $\begin{array}{c}-47.74 \\
(9)\end{array}$ & $\begin{array}{c}-35.17 \\
(7)\end{array}$ & $\begin{array}{c}-23.08 \\
(6)\end{array}$ & $\begin{array}{c}-128.75 \\
(10)\end{array}$ & $\begin{array}{c}-11.5 \\
(8)\end{array}$ & $\begin{array}{c}0 \\
(15)\end{array}$ \\
\hline
\end{tabular}

Each cell (row-column datum) in the table contains two pieces of information - (i) the competition effect on the row SKU by the column SKU, and (ii) the number of attributes shared by the two SKUs denoted by an integer in brackets. 
Table 5. BEM Estimates (Essay 1)

\begin{tabular}{|c|c|c|c|c|}
\hline (1) & $(2)$ & (3) & $(4)$ & (5) \\
\hline Brand $^{a}$ & BEM & $\begin{array}{l}\text { Revenue } \\
\text { Dollar } \\
\text { Premium } \\
\text { (\$Mn/Yr) }\end{array}$ & $\begin{array}{c}\text { Total } \\
\text { Revenue } \\
(\$ \mathbf{M n} / \mathbf{Y r})\end{array}$ & $\begin{array}{c}\text { ALN }^{\mathrm{c}} \\
\text { Revenue } \\
\text { Premium }^{\mathrm{d}} \\
(\$ \mathrm{Mn} / \mathrm{Yr})\end{array}$ \\
\hline Budweiser & 1.45 & 493.75 & 1638.74 & 1609.91 \\
\hline Miller & 1.09 & 61.00 & 814.73 & 785.89 \\
\hline Coors & 1.04 & 19.02 & 503.83 & 474.99 \\
\hline Corona & 1.85 & 203.48 & 476.63 & 447.79 \\
\hline Michelob & 1.09 & 24.13 & 339.08 & 310.25 \\
\hline Busch & 1.26 & 57.98 & 299.07 & 270.23 \\
\hline Natural & 1.30 & 59.75 & 268.55 & 239.72 \\
\hline Heineken & 2.07 & 111.75 & 229.75 & 200.92 \\
\hline Milwaukee's Best & 1.16 & 22.60 & 186.12 & 157.29 \\
\hline Keystone & 1.11 & 7.14 & 85.86 & 57.02 \\
\hline Samuel Adams & 1.42 & 18.84 & 74.01 & 45.18 \\
\hline Tecate & 1.13 & 7.29 & 69.53 & 40.69 \\
\hline Icehouse & 1.22 & 9.64 & 61.06 & 32.22 \\
\hline Labatt & 1.13 & 5.80 & 63.32 & 34.48 \\
\hline Becks & 1.13 & 5.34 & 52.97 & 24.13 \\
\hline Old Milwaukee & 1.14 & 4.96 & 56.58 & 27.74 \\
\hline Amstel & 1.16 & 4.95 & 41.81 & 12.98 \\
\hline Rolling Rock & 1.18 & 5.72 & 44.36 & 15.53 \\
\hline Pabst & 1.13 & 3.58 & 41.23 & 12.39 \\
\hline Fosters & 1.18 & 4.89 & 36.47 & 7.63 \\
\hline Molson & 1.13 & 2.60 & 38.94 & 10.10 \\
\hline Dos Equis & 1.13 & 3.24 & 29.96 & 1.12 \\
\hline George Killian's & 1.27 & 5.29 & 30.12 & 1.28 \\
\hline Modelo Especial & 1.27 & 5.55 & 29.10 & 0.27 \\
\hline Pacifico Clara & 1.51 & 8.24 & 28.83 & 0.00 \\
\hline Mean & 1.26 & 46.26 & 221.62 & 192.79 \\
\hline Std Dev & 0.24 & 103.51 & 354.11 & 354.11 \\
\hline
\end{tabular}

a Sorted in descending order by revenue share.

b Revenue weighted average over all the brand's SKUs over the entire sample period.

c Average yearly advertising spend. 
Table 6. Brand Valuation of Budweiser and Miller (Essay 1)

\begin{tabular}{|c|c|c|c|}
\hline & Miller brewing Co. & Budweiser & Source \\
\hline Brand value (\$ Bn) & 4.25 & 11.93 & SEC filings, Interbrand \\
\hline Per year revenue premium $\$ M n$ & 93.2 & 493.8 & Simple average over 4 yrs \\
\hline Remove $20 \%$ retailer margin & 74.6 & 395.0 & Cost data from one supermarket chair \\
\hline $\begin{array}{l}\text { Add } 12 \% \text { sales from other } \\
\text { channels } \$ \mathrm{Mn}\end{array}$ & 84.8 & 448.9 & AC Nielsen \\
\hline Add $50 \%$ on-premises & 169.5 & 897.7 & Adams Beer Handbook \\
\hline $\begin{array}{l}\text { Share of other brands } \\
\text { in the portfolio }\end{array}$ & 0.166 & 0.0 & $\begin{array}{l}16 \% \text { of Miller Brewing's sales } \\
\text { come from brands not in the sample }\end{array}$ \\
\hline International sales $\sim 26 \%$ & 274.66 & 1213.1 & Adams Beer Handbook \\
\hline $\begin{array}{l}\text { Discount rate } \\
\text { (for the Discounted Cash Flow or } \\
\text { DCF method) }\end{array}$ & $7.30 \%$ & $10.70 \%$ & $\begin{array}{l}\text { SEC filings for Miller; } \\
\text { For Budweiser, } 5 \% \text { risk free rate, } \\
\text { Anheuser stock beta of } 0.62 \text { and long } \\
\text { term US market premium of } 9.2 \%\end{array}$ \\
\hline Brand value in $\$ \mathrm{Mn}$ & 3762.5 & 11337.8 & Applying Discounted Cash Flow \\
\hline Est. Brand Value $\$ B n$ & 3.76 & 11.34 & Based on Intrinsic BEM \\
\hline
\end{tabular}


Table 7. Multi-Retailer CSD Data, Summary of Variables (Essay 2)

\begin{tabular}{|c|c|c|c|}
\hline $\begin{array}{l}\text { Revenue } \\
\text { Component }\end{array}$ & Variable & Description & $\begin{array}{c}\text { Mean } \\
\text { (Std Dev) }\end{array}$ \\
\hline & $\operatorname{Ln}\left(\right.$ Revenue $\left._{\mathrm{jrt}}\right)$ & Log of revenue at retailer $r$ for SKU $j$ in period $t$ & $20.0(39.8)$ \\
\hline \multirow[t]{5}{*}{ Product } & Diet $_{j}$ & Low Calorie $=1$, otherwise $=0$ & 0.415 \\
\hline & Caffeine Free $_{j}$ & Caffeine Freej $=1$, otherwise $=0$ & 0.376 \\
\hline & $\operatorname{Red}_{j}$ & Red in color $=1$, otherwise $=0$. & 0.027 \\
\hline & Cola $_{j}$ & Cola type $=1$, otherwise $=0$. & 0.484 \\
\hline & Ginger $\mathrm{Ale}_{j}$ & Ginger Ale type $=1$, otherwise $=0$. & 0.083 \\
\hline \multirow{8}{*}{ Type } & Citrus $_{j}$ & Citrus type $=1$, otherwise $=0$. & 0.244 \\
\hline & CreamSoda $_{j}$ & CreamSoda type $=1$, otherwise $=0$. & 0.016 \\
\hline & Fruit Based $_{j}$ & Fruit Based type $=1$, otherwise $=0$. & 0.084 \\
\hline & ${\text { Root } \text { Beer }_{j}}$ & Root Beer type $=1$, otherwise $=0$. & 0.089 \\
\hline & $\overline{\text { Cans }_{j}}$ & Aluminuim cans $=1$, otherwise $=0$. & 0.367 \\
\hline & Plastic $_{j}$ & Plastic containers $=1$, otherwise $=0$. & 0.596 \\
\hline & Glass $_{j}$ & Glass containers $=1$, otherwise $=0$. & 0.037 \\
\hline & Single Unit Pack $\mathrm{k}_{\mathrm{j}}$ & 1 container per sales unit $=1$, otherwise $=0$. & 0.520 \\
\hline \multirow[t]{7}{*}{ Packaging } & Multi-Unit Pack $k_{j}$ & Multiple containers per sales unit $=1$, otherwise $=0$. & 0.480 \\
\hline & Small Pack & Pack volume $<2$ liters $=1$, otherwise $=0$. & 0.378 \\
\hline & Two Liter $_{j}$ & Two liter PET container $=1$, otherwise $=0$. & 0.270 \\
\hline & Dozen Pack $_{j}$ & Pack has $=12,24$, or 30 containers $=1$, otherwise $=0$. & 0.319 \\
\hline & Other SKU Size ${ }_{j}$ & Any other SKU sizes =1, otherwise $=0$. & 0.033 \\
\hline & Lemon $_{j}$ & Lemon flavor $=1$, otherwise $=0$. & 0.208 \\
\hline & Vanilla $_{j}$ & Vanilla flavor $=1$, otherwise $=0$ & 0.046 \\
\hline \multirow{4}{*}{ Flavor } & Orange $_{j}$ & Orange flavor $=1$, otherwise $=0$. & 0.032 \\
\hline & Berries $_{j}$ & Berries flavor $=1$, otherwise $=0$. & 0.014 \\
\hline & Cherry $_{j}$ & Cherry flavor $=1$, otherwise $=0$. & 0.192 \\
\hline & Pepper $_{j}$ & Pepper flavor $=1$, otherwise $=0$. & 0.087 \\
\hline \multirow[t]{3}{*}{ Promotion } & $\$ M n$ AdSpend ${ }_{v t}$ & $\$ M n$ advertising spend p.a. per variant & $22113(30027)$ \\
\hline & Competition $_{\text {jrt }}$ & Inter-product competition intensity measure & $-5.81(4.13)$ \\
\hline & \$MnACV Merchandizing jitt & Demand promoted to in $\$ \mathrm{Mn} \mathrm{ACV}$ & $1339(262)$ \\
\hline \multirow[t]{2}{*}{ Distribution } & $\$ M n$ ACV Distribution ${ }_{j \mathrm{rt}}$ & Buying power accessed in $\$ \mathrm{Mn} \mathrm{ACV}$ & $2426(980)$ \\
\hline & VtSKUNUM $_{\mathrm{rbt}}$ & Average number SKUs per variant & $9.74(6.0)$ \\
\hline \multirow{2}{*}{$\begin{array}{l}\text { Category } \\
\text { Drivers }\end{array}$} & Winter $_{t}$ & Winter $=1$ otherwise $=0$. & 0.247 \\
\hline & Summer $_{\mathrm{t}}$ & Summer $=1$ otherwise $=0$. & 0.305 \\
\hline Time & Fall $_{t}$ & Fall $=1$ otherwise $=0$ & 0.225 \\
\hline \multirow[t]{3}{*}{ Dummies } & Spring $_{\mathrm{t}}$ & Spring $=1$ otherwise $=0$ & 0.223 \\
\hline & Year2005 & Year $2005=1$, otherwise $=0$ & 0.532 \\
\hline & Year2006 & Year $2006=1$ otherwise $=0$ & 0.468 \\
\hline Consumer & MeanINC $_{\text {st }}$ & Mean Income p.a. of shopppers in $\$^{\prime} 000$ & $63.7(5.0)$ \\
\hline Characteristics & StdevINC $_{\text {st }}$ & Std deviation of avg shoppers' income p.a. $\$ 000$ & $60.4(14.2)$ \\
\hline Retailer & Retailer $\mathrm{r}_{\mathrm{jt}} 1$ through 5 & Retailer $\mathrm{r}=1$, otherwise $=0$. & 0.200 \\
\hline
\end{tabular}


Table 8. Summary of Retailer Characteristics (Essay 2)

\begin{tabular}{|c|c|c|c|c|c|}
\hline Variables & $\begin{array}{c}\text { Retailer } \\
1 \\
\end{array}$ & $\begin{array}{c}\text { Retailer } \\
2 \\
\end{array}$ & $\begin{array}{c}\text { Retailer } \\
3 \\
\end{array}$ & $\begin{array}{c}\text { Retailer } \\
4 \\
\end{array}$ & $\begin{array}{c}\text { Retailer } \\
5 \\
\end{array}$ \\
\hline Number of Observations & 4,675 & 4,081 & 5,777 & 5,189 & 4,538 \\
\hline Number of Stores & 52 & 139 & 40 & 115 & 156 \\
\hline Retailer Revenues \$Million p.a. & 2718 & 3350 & 4016 & 3528 & 2200 \\
\hline Category Revenues \$Million & 117.01 & 71.33 & 70.79 & 123.71 & 102.8 \\
\hline Units (Million Containers) & 56.4 & 36.8 & 41 & 69.8 & 56.4 \\
\hline Volume (Million Cases) & 25.8 & 14.6 & 18.6 & 33 & 26.3 \\
\hline Mean Price in Cents/Oz & 2.43 & 2.44 & 2.02 & 2.03 & 1.95 \\
\hline Average $\mathrm{Oz}$ per Container & 90.1 & 90.1 & 92.4 & 99.1 & 86.6 \\
\hline Average Number of SKUs per Brand & 20.9 & 21.2 & 32.4 & 24.1 & 20.6 \\
\hline Store Brand Share $\%$ & 2.7 & 2.0 & 10.4 & 9.1 & 3.6 \\
\hline Store Brand Revenues \$Million & 3.16 & 1.43 & 7.36 & 11.26 & 3.70 \\
\hline Store Brand Mean Price Cents/Oz & 1.49 & 1.74 & 1.33 & 1.39 & 1.35 \\
\hline Average \$MnACV Distribution per period & 150.0 & 220.2 & 121.3 & 208.1 & 137.0 \\
\hline Average Vt SKUNUM (SKUs per variant) & 9.4 & 10.64 & 9.72 & 9.81 & 9.23 \\
\hline Average \$MnACV Merchandizing per period & 18.9 & 55.9 & 31.1 & 59.6 & 56.7 \\
\hline Average Competition Level (10e-4 units) & -3.8 & -2.08 & -12.69 & -4.45 & -3.98 \\
\hline MeanINC: Mean Consumer Income \$p.a. & 72,695 & 63,630 & 63,956 & 60,777 & 57,376 \\
\hline StdevINC: Std Dev of Consumer Income \$p.a. & 81,224 & 61,239 & 67,912 & 50,758 & 39,709 \\
\hline
\end{tabular}

Here, 'p.a.' denotes Per Annum, \$Mn denotes \$Million, and bold font indicates variable name. 
Table 9. Main Effects of the Revenue Regressions (Essay 2)

\begin{tabular}{|c|c|c|c|c|c|c|c|}
\hline $\begin{array}{l}\text { Revenue } \\
\text { Component }\end{array}$ & Variable & Mean & $\begin{array}{c}\text { [95\% HPD } \\
\text { Interval] }\end{array}$ & $\begin{array}{l}\text { Revenue } \\
\text { Component } \\
\end{array}$ & Variable & Mean & $\begin{array}{c}\text { [95\% HPD } \\
\text { Interval] }\end{array}$ \\
\hline & Intercept & -55.270 & {$[-72.55,-37.55]$} & & Mean Retailer-Brand $\lambda_{\mathrm{rb}}$ & 1.283 & {$[0.65,1.72]$} \\
\hline Product & Diet & 0.020 & {$[-0.04,0.07]$} & Variance & Retailer-Variant $\xi_{r v}$ & 0.406 & {$[2.85,2.95]$} \\
\hline \multirow[t]{4}{*}{ Other } & Caffeine Free & -0.438 & {$[-0.47,-0.41]$} & \multirow[t]{2}{*}{ Components } & Retailer -SKU $\eta_{r j}$ & 0.208 & {$[0.24,0.67]$} \\
\hline & Red & 0.157 & {$[0.07,0.24]$} & & Measurement Error $u_{\mathrm{rit}}$ & 0.345 & {$[0.17,0.26]$} \\
\hline & Cola & 0.521 & {$[0.26,0.78]$} & \multirow{3}{*}{ Promotion } & Mean Ln AdSpend & 0.033 & {$[0.03,0.04]$} \\
\hline & Ginger Ale & 0.529 & {$[0.29,0.77]$} & & Mean Competition & -0.050 & {$[-0.09,-0.01]$} \\
\hline \multirow{8}{*}{ Type } & Citrus & 0.813 & {$[0.58,1.05]$} & & Mean Ln \$MnACV Merchandizing & 0.035 & {$[0.03,0.04]$} \\
\hline & Fruit Based & 0.994 & {$[0.75,1.25]$} & \multirow{2}{*}{ Distribution } & Ln \$MnACV Distribution & 1.193 & {$[1.032,1.066]$} \\
\hline & CreamSoda & 1.181 & {$[0.94,1.44]$} & & Ln Vt SKUNUM & 0.037 & {$[0.00,0.08]$} \\
\hline & Root Beer & \multicolumn{2}{|c|}{ Reference Type } & Category & Winter & -0.005 & {$[-0.03,0.02]$} \\
\hline & Cans & 0.047 & {$[-0.01,0.1]$} & Drivers & Summer & 0.043 & {$[0.02,0.06]$} \\
\hline & Plastic & -0.160 & {$[-0.21,-0.11]$} & & Fall & -0.040 & {$[-0.06,-0.02]$} \\
\hline & Glass & Refer & nce Container & & Spring & $\operatorname{Ref}$ & ce Season \\
\hline & Single-Unit Pack & -0.054 & {$[-0.08,-0.02]$} & & Year2005 & -0.115 & {$[-0.13,-0.1]$} \\
\hline \multirow[t]{7}{*}{ Packaging } & Multi-Unit Pack & \multicolumn{2}{|c|}{ Reference Pack } & & Year2006 & \multicolumn{2}{|c|}{ Reference Year } \\
\hline & Small Pack & -0.386 & {$[-0.45,-0.33]$} & Consumer & Ln MeanINC & 7.068 & {$[4.9,9.2]$} \\
\hline & Two Liter & -0.164 & {$[-0.23,-0.1]$} & Characteristics & Ln StdevINC & -2.188 & {$[-2.79,-1.59]$} \\
\hline & Dozen Pack & -0.156 & {$[-0.397,0.093]$} & & Retailer 1 & 0.904 & {$[0.42,1.3]$} \\
\hline & Other SKU Size & \multicolumn{2}{|c|}{ Reference Packsize } & Retailer & Retailer 2 & \multicolumn{2}{|c|}{ Reference Store } \\
\hline & Lemon & -1.016 & {$[-1.06,-0.97]$} & Characteristics & Retailer 3 & 0.269 & {$[-0.39,0.79]$} \\
\hline & Vanilla & -1.315 & {$[-1.37,-1.26]$} & & Retailer 4 & 1.203 & {$[0.77,1.57]$} \\
\hline \multirow{4}{*}{ Flavor } & Orange & -0.390 & {$[-0.5,-0.28]$} & & Retailer 5 & 0.498 & {$[0.04,0.95]$} \\
\hline & Berries & Refe & rence Flavor & Fit & Log Marginal Density & \multicolumn{2}{|c|}{-21530.0} \\
\hline & Cherry & -1.081 & {$[-1.13,-1.04]$} & & & & \\
\hline & Pepper & 0.361 & {$[0.25,0.48]$} & & & & \\
\hline
\end{tabular}

Parameters with their 95\% Highest Probability Density (HPD) interval not touching zero are in bold font. Variable subscripts are as in Table 7. 
Table 10. Random Coefficients in Main Effects (Essay 2)

\begin{tabular}{|c|c|c|c|}
\hline Retailer & $\begin{array}{c}\gamma_{\mathrm{r}} \text { of } \\
\text { Ln Ad-Spend } \\
\text { [95\% HPD } \\
\text { Interval] }\end{array}$ & $\begin{array}{c}\gamma_{\mathrm{r}} \text { of } \\
\text { Competition } \\
{[95 \% \text { HPD }} \\
\text { Interval] }\end{array}$ & $\begin{array}{c}\gamma_{\mathrm{r}} \text { of } \\
\text { Ln \$ MnACV } \\
\text { Merchandizing } \\
\text { [95\% HPD } \\
\text { Interval] }\end{array}$ \\
\hline 1 & $\begin{array}{c}0.026 \\
{[0.02,0.03]}\end{array}$ & $\begin{array}{c}-0.214 \\
{[-0.32,-0.10]}\end{array}$ & $\begin{array}{c}0.035 \\
{[0.03,0.04]}\end{array}$ \\
\hline 2 & $\begin{array}{c}0.035 \\
{[0.03,0.04]}\end{array}$ & $\begin{array}{c}-0.203 \\
{[-0.31,-0.11]}\end{array}$ & $\begin{array}{c}0.032 \\
{[0.03,0.04]}\end{array}$ \\
\hline 3 & $\begin{array}{c}0.027 \\
{[0.02,0.03]}\end{array}$ & $\begin{array}{c}-0.033 \\
{[-0.10,0.03]}\end{array}$ & $\begin{array}{c}0.033 \\
{[0.03,0.04]}\end{array}$ \\
\hline 4 & $\begin{array}{c}0.034 \\
{[0.03,0.04]}\end{array}$ & $\begin{array}{c}-0.154 \\
{[-0.23,-0.08]}\end{array}$ & $\begin{array}{c}0.045 \\
{[0.04,0.05]}\end{array}$ \\
\hline 5 & $\begin{array}{c}0.038 \\
{[0.03,0.04]}\end{array}$ & $\begin{array}{c}0.185 \\
{[-0.12,0.49]}\end{array}$ & $\begin{array}{c}0.054 \\
{[0.05,0.06]}\end{array}$ \\
\hline Mean & $\begin{array}{c}0.033 \\
{[0.03,0.04]}\end{array}$ & $\begin{array}{c}-0.050 \\
{[-0.09,-0.01]}\end{array}$ & $\begin{array}{c}0.035 \\
{[0.03,0.04]}\end{array}$ \\
\hline
\end{tabular}

Bold font indicates estimate is significantly different from zero. 
Table 11. BEM Estimates and 95\% HPD Interval by Retailer (Essay 2)

\begin{tabular}{|c|c|c|c|c|c|c|}
\hline (1) & $(2)$ & (3) & (4) & (5) & (6) & (7) \\
\hline \multirow[b]{2}{*}{ Brand } & \multicolumn{5}{|c|}{$\begin{array}{c}\text { BE Multiplier Values } \\
{[95 \% \text { Highest Probability Density Interval] }}\end{array}$} & \multirow{2}{*}{$\begin{array}{l}\text { Average } \\
\text { (Stdev) }\end{array}$} \\
\hline & Retailer 1 & Retailer 2 & Retailer 3 & Retailer 4 & Retailer 5 & \\
\hline Seven Up & $\begin{array}{c}1.52 \\
{[1.05,2.27]}\end{array}$ & $\begin{array}{c}3.26 \\
{[1.96,4.82]}\end{array}$ & $\begin{array}{c}1.18 \\
{[1.01,1.58]}\end{array}$ & $\begin{array}{c}1.38 \\
{[1.16,1.81]}\end{array}$ & $\begin{array}{c}1.37 \\
{[1.02,2.59]}\end{array}$ & $\begin{array}{l}1.74 \\
(0.86)\end{array}$ \\
\hline$A \& W$ & $\begin{array}{c}1.57 \\
{[1.06,2.34]}\end{array}$ & $\begin{array}{c}2.23 \\
{[1.22,3.66]}\end{array}$ & $\begin{array}{c}1.11 \\
{[1.01,1.38]}\end{array}$ & $\begin{array}{c}1.66 \\
{[1.19,2.17]}\end{array}$ & $\begin{array}{c}1.23 \\
{[1.01,1.99]}\end{array}$ & $\begin{array}{l}1.56 \\
(0.44)\end{array}$ \\
\hline Barqs & $\begin{array}{c}2.07 \\
{[1.11,4.03]}\end{array}$ & $\begin{array}{c}1.88 \\
{[1.06,4.06]}\end{array}$ & $\begin{array}{c}1.23 \\
{[1.01,1.78]}\end{array}$ & $\begin{array}{c}1.16 \\
{[1.04,1.52]}\end{array}$ & $\begin{array}{c}1.43 \\
{[1.02,2.83]}\end{array}$ & $\begin{array}{l}1.55 \\
(0.4)\end{array}$ \\
\hline Canada Dry & $\begin{array}{c}1.70 \\
{[1.19,2.71]}\end{array}$ & $\begin{array}{c}1.74 \\
{[1.06,2.75]}\end{array}$ & $\begin{array}{c}1.20 \\
{[1.01,1.53]}\end{array}$ & $\begin{array}{c}1.08 \\
{[1.01,1.42]}\end{array}$ & $\begin{array}{c}1.12 \\
{[1.01,1.48]}\end{array}$ & $\begin{array}{c}1.37 \\
(0.32)\end{array}$ \\
\hline Coke & $\begin{array}{c}2.49 \\
{[1.80,3.26]}\end{array}$ & $\begin{array}{c}1.98 \\
{[1.25,2.94]}\end{array}$ & $\begin{array}{c}1.20 \\
{[1.01,1.53]}\end{array}$ & $\begin{array}{c}1.19 \\
{[1.11,1.56]}\end{array}$ & $\begin{array}{c}1.56 \\
{[1.03,2.87]}\end{array}$ & $\begin{array}{c}1.68 \\
(0.55)\end{array}$ \\
\hline Dr Pepper & $\begin{array}{c}3.38 \\
{[2.23,4.94]}\end{array}$ & $\begin{array}{c}3.37 \\
{[1.99,5.42]}\end{array}$ & $\begin{array}{c}1.24 \\
{[1.01,1.72]}\end{array}$ & $\begin{array}{c}1.49 \\
{[1.17,1.96]}\end{array}$ & $\begin{array}{c}1.88 \\
{[1.04,3.59]}\end{array}$ & $\begin{array}{c}2.27 \\
(1.03)\end{array}$ \\
\hline Fanta & $\begin{array}{c}1.16 \\
{[1.01,1.52]}\end{array}$ & $\begin{array}{c}1.28 \\
{[1.02,2.04]}\end{array}$ & $\begin{array}{c}1.14 \\
{[1.01,1.48]}\end{array}$ & $\begin{array}{c}1.20 \\
{[1.11,1.58]}\end{array}$ & $\begin{array}{c}1.15 \\
{[1.01,1.67]}\end{array}$ & $\begin{array}{l}1.15 \\
(0.08)\end{array}$ \\
\hline Fresca & $\begin{array}{c}4.60 \\
{[1.54,10.58]}\end{array}$ & $\begin{array}{c}1.77 \\
{[1.05,4.77]}\end{array}$ & $\begin{array}{c}1.43 \\
{[1.02,2.7]}\end{array}$ & $\begin{array}{c}1.70 \\
{[1.20,2.23]}\end{array}$ & $\begin{array}{c}1.31 \\
{[1.01,2.47]}\end{array}$ & $\begin{array}{l}2.16 \\
(1.38)\end{array}$ \\
\hline $\begin{array}{l}\text { Mountain } \\
\text { Dew }\end{array}$ & $\begin{array}{c}1.48 \\
{[1.07,2.12]}\end{array}$ & $\begin{array}{c}1.09 \\
{[1.01,1.30]}\end{array}$ & $\begin{array}{c}1.09 \\
{[1.01,1.30]}\end{array}$ & $\begin{array}{c}1.26 \\
{[1.11,1.65]}\end{array}$ & $\begin{array}{c}1.26 \\
{[1.01,1.89]}\end{array}$ & $\begin{array}{l}1.23 \\
(0.16)\end{array}$ \\
\hline Mug & N.A. & $\begin{array}{c}1.37 \\
{[1.02,2.19]}\end{array}$ & $\begin{array}{c}1.20 \\
{[1.01,1.75]}\end{array}$ & $\begin{array}{c}1.09 \\
{[1.01,1.44]}\end{array}$ & $\begin{array}{c}1.82 \\
{[1.05,3.87]}\end{array}$ & $\begin{array}{l}1.15 \\
(0.09)\end{array}$ \\
\hline Pepsi & $\begin{array}{c}1.25 \\
{[1.02,1.68]}\end{array}$ & $\begin{array}{c}1.70 \\
{[1.15,2.55]}\end{array}$ & $\begin{array}{c}1.25 \\
{[1.02,1.72]}\end{array}$ & $\begin{array}{c}\mathbf{1 . 3 6} \\
{[1.21,1.79]}\end{array}$ & $\begin{array}{c}1.74 \\
{[1.04,3.14]}\end{array}$ & $\begin{array}{l}1.43 \\
(0.27)\end{array}$ \\
\hline Sprite & $\begin{array}{c}\mathbf{5 . 3 6} \\
{[2.93,9.00]}\end{array}$ & $\begin{array}{c}2.53 \\
{[1.37,3.74]}\end{array}$ & $\begin{array}{c}1.64 \\
{[1.06,2.92]}\end{array}$ & $\begin{array}{c}1.57 \\
{[1.24,2.06]}\end{array}$ & $\begin{array}{c}2.32 \\
{[1.06,5.03]}\end{array}$ & $\begin{array}{l}2.21 \\
(1.76)\end{array}$ \\
\hline Sierra Mist & $\begin{array}{c}1.51 \\
{[1.07,2.2]}\end{array}$ & $\begin{array}{c}1.68 \\
{[1.06,2.71]}\end{array}$ & $\begin{array}{c}1.25 \\
{[1.02,1.75]}\end{array}$ & $\begin{array}{c}1.52 \\
{[1.18,1.99]}\end{array}$ & $\begin{array}{c}1.59 \\
{[1.03,2.91]}\end{array}$ & $\begin{array}{l}1.59 \\
(0.56)\end{array}$ \\
\hline Store brand & $\begin{array}{c}1.10 \\
{[1,01,1.31]} \\
\end{array}$ & $\begin{array}{c}1.31 \\
{[1.02,2.03]}\end{array}$ & $\begin{array}{c}2.26 \\
{[1.64,2.95]}\end{array}$ & $\begin{array}{c}1.52 \\
{[1.18,1.99]}\end{array}$ & $\begin{array}{c}1.47 \\
{[1.02,2.31]} \\
\end{array}$ & $\begin{array}{c}1.65 \\
(0.37) \\
\end{array}$ \\
\hline Mean & 2.33 & 1.80 & 1.25 & 1.38 & 1.64 & 1.62 \\
\hline Std Dev & 1.34 & 0.73 & 0.30 & 0.23 & 1.09 & $(0.59)$ \\
\hline
\end{tabular}

BEMs in bold font indicate estimate is significantly different from 1.04. 
Table 12. Ex-Post Variable Correlations (Essay 2)

\begin{tabular}{lccc}
\hline Variables & BEM & $\begin{array}{c}\text { Revenue } \\
\text { Dollar } \\
\text { Premium }\end{array}$ & Revenue \\
\hline BEM & & & \\
(P-value) & 1.00 & $\mathbf{0 . 3 5}$ & $\mathbf{0 . 1 4}$ \\
& & $(<.0001)$ & $(<.0001)$ \\
$\begin{array}{l}\text { Revenue Dollar Premium } \\
\text { P-value) }\end{array}$ & $\mathbf{0 . 3 5}$ & 1.00 & $\mathbf{0 . 8 6}$ \\
& $(<.0001)$ & & $(<.0001)$ \\
$\begin{array}{l}\text { Revenue } \\
\text { (P-value) }\end{array}$ & $\mathbf{0 . 1 4}$ & $\mathbf{0 . 8 6}$ & 1.00 \\
& $(<.0001)$ & $(<.0001)$ & \\
$\begin{array}{l}\text { Price in \$/Oz } \\
\text { (P-value) }\end{array}$ & $\mathbf{0 . 0 1}$ & $\mathbf{- 0 . 0 7}$ & $\mathbf{- 0 . 1 0}$ \\
& 0.03 & $(<.0001)$ & $(<.0001)$ \\
$\begin{array}{l}\text { Avg \# SKUs by Retailer-Brand } \\
\text { (P-value) }\end{array}$ & $\mathbf{0 . 2 1}$ & $\mathbf{0 . 0 9}$ & $\mathbf{0 . 0 9}$ \\
\hline
\end{tabular}

The p-value is for a chi-square test of the Null: Correlation Coefficient $\varrho=0$. Variable names are indicated in bold font. 
Table 13. Summary of Analysis Variables (Essay 3)

\begin{tabular}{|c|c|c|c|}
\hline $\begin{array}{l}\text { Revenue } \\
\text { Component }\end{array}$ & Variable & Description & $\begin{array}{c}\text { Mean } \\
\text { (StDev) }\end{array}$ \\
\hline \multirow{3}{*}{ Product } & $\operatorname{Ln}\left(\right.$ Revenue $\left._{\text {mit }}\right)$ & Ln Revenue & $10.02(1.90)$ \\
\hline & Craft $_{j}$ & Craft type $=1$, otherwise $=0$. & 0.103 \\
\hline & $\operatorname{Dry}_{j}$ & Dry type $=1$, otherwise $=0$. & 0.003 \\
\hline \multirow{5}{*}{ Beer Type } & Ice $_{j}$ & Ice type $=1$, otherwise $=0$. & 0.032 \\
\hline & Light $_{j}$ & Light type $=1$, otherwise $=0$. & 0.359 \\
\hline & Regular $_{j}$ & Regular type $=1$, otherwise $=0$. & 0.503 \\
\hline & Imported $_{j}$ & Imported brewer $=1$, otherwise $=0$. & 0.145 \\
\hline & Domestic $_{j}$ & Domestic brewer $=1$, otherwise $=0$. & 0.855 \\
\hline \multirow{7}{*}{ Packaging } & Bottle $_{j}$ & Bottle $=1$, otherwise $=0$ & 0.505 \\
\hline & $\mathrm{Can}_{\mathrm{j}}$ & Can $=1$, otherwise $=0$ & 0.495 \\
\hline & SmallPack $_{j}$ & Packs with less than 6 containers & 0.164 \\
\hline & 6 Pack $12 \mathrm{oz}_{\mathrm{j}}$ & 6 Pack $12 \mathrm{Oz}=1$, otherwise $=0$. & 0.210 \\
\hline & 6 Pack Other $0 z_{j}$ & 6 Pack Other sizes $=1$, otherwise $=0$ & 0.076 \\
\hline & 12 Pack $_{\mathrm{j}}$ & 12 Pack $=1$, otherwise $=0$ & 0.257 \\
\hline & Case $_{j}$ & Case $(18,24,30+$ pack sizes $)=1$, else $=0$. & 0.263 \\
\hline \multirow{3}{*}{ Promotion } & AdSpend $_{\text {mvt }}$ & Log annual Ad spend in \$million. & $4.68(5.25)$ \\
\hline & Competition $_{\text {mit }}$ & Inter-product competition levels. & $2.47(0.46)$ \\
\hline & $\$ M n A C V$ Merchandizing ${ }_{\text {mit }}$ & $\$ M n$ ACV that promoted the SKU. & $2.66(2.12)$ \\
\hline \multirow{2}{*}{ Distribution } & $\$ M_{n A C V}$ Distribution ${ }_{\text {mjt }}$ & $\$ M n$ ACV that carried the SKU. & $4.56(1.32)$ \\
\hline & Vt SKUNUM ${ }_{\text {mvt }}$ & Average number of SKUs in the variant. & $1.89(0.71)$ \\
\hline \multirow{6}{*}{$\begin{array}{l}\text { Category } \\
\text { Drivers }\end{array}$} & Quarter1 $1_{t}$ & Quarter1 $=1$, otherwise $=0$. & 0.244 \\
\hline & Quarter2 $2_{\mathrm{t}}$ & Quarter $2=1$, otherwise $=0$ & 0.249 \\
\hline & Quarter3 $3_{t}$ & Quarter3 $=1$, otherwise $=0$ & 0.251 \\
\hline & Quarter $4_{t}$ & Quarter $4=1$, otherwise $=0$. & 0.256 \\
\hline & Year2005 & Year $2005=1$, otherwise $=0$ & 0.507 \\
\hline & Year2006 & Year $2006=1$, otherwise $=0$ & 0.493 \\
\hline
\end{tabular}


Table 14. U.S. Multi-Market Data, Brand Characteristics (Essay 3)

\begin{tabular}{|c|c|c|c|c|c|c|c|c|c|c|}
\hline Brand & $\begin{array}{l}\text { Revenues } \\
\text { (\$ Mn) }\end{array}$ & $\begin{array}{l}\text { Volume } \\
\text { sold } \\
\text { (Mn oz) }\end{array}$ & $\begin{array}{l}\text { Mean } \\
\text { Price } \\
(\$ / o z)\end{array}$ & $\begin{array}{l}\text { National } \\
\text { Advertising } \\
\text { Spend } \\
\text { (\$Mn p.a.) }\end{array}$ & $\begin{array}{c}\text { \$MnACV } \\
\text { Distribution } \\
\text { (Mean across } \\
\text { Observations) }\end{array}$ & $\begin{array}{c}\text { \$MnACV } \\
\text { Merchandizing } \\
\text { (Mean across } \\
\text { Observations) }\end{array}$ & $\begin{array}{l}\text { Number } \\
\text { of } \\
\text { Variants }\end{array}$ & $\begin{array}{c}\text { Mean } \\
\text { Number } \\
\text { of SKUs }\end{array}$ & $\begin{array}{l}\text { Number } \\
\text { of } \\
\text { Markets }\end{array}$ & $\begin{array}{c}\text { Brand } \\
\text { Age } \\
\text { (Years) }\end{array}$ \\
\hline Budweiser & $2,711.16$ & $45,595.5$ & 0.066 & 666.8 & 192.0 & 78.4 & 11 & 45.8 & 49 & 131 \\
\hline Miller & $1,404.99$ & $26,007.1$ & 0.058 & 246.9 & 191.6 & 80.3 & 8 & 38.3 & 49 & 104 \\
\hline Coors & 823.83 & $13,957.1$ & 0.063 & 296.8 & 200.5 & 90.6 & 2 & 19.2 & 49 & 133 \\
\hline Natural & 442.61 & $10,655.0$ & 0.044 & 0.0 & 154.3 & 41.5 & 2 & 13.8 & 49 & 30 \\
\hline Corona & 715.82 & $7,405.3$ & 0.102 & 36.2 & 265.2 & 137.2 & 2 & 6.7 & 49 & 82 \\
\hline Busch & 437.99 & $10,175.5$ & 0.048 & 7.8 & 138.1 & 41.5 & 3 & 16.6 & 48 & 52 \\
\hline Heineken & 502.84 & $5,171.6$ & 0.103 & 67.3 & 223.1 & 97.8 & 3 & 11.5 & 49 & 134 \\
\hline Keystone & 130.28 & $3,293.5$ & 0.042 & 0.1 & 110.9 & 38.2 & 3 & 8.5 & 47 & 18 \\
\hline Michelob & 476.43 & $6,814.9$ & 0.073 & 2.6 & 201.2 & 90.2 & 9 & 19.2 & 49 & 111 \\
\hline Milwaukee's Best & 240.98 & $6,396.8$ & 0.039 & 0.0 & 146.3 & 42.4 & 3 & 13.5 & 49 & 23 \\
\hline Icehouse & 73.56 & $1,558.6$ & 0.049 & 2.3 & 144.8 & 29.5 & 2 & 6.9 & 44 & 14 \\
\hline Modelo Especial & 85.76 & 928.0 & 0.099 & 0.0 & 174.8 & 76.5 & 2 & 6.4 & 47 & 17 \\
\hline Pabst & 62.45 & $1,452.8$ & 0.046 & 0.0 & 125.1 & 39.2 & 4 & 5.9 & 47 & 125 \\
\hline Tecate & 73.20 & $1,111.0$ & 0.077 & 4.3 & 177.0 & 77.2 & 2 & 5.6 & 41 & 52 \\
\hline Old Milwaukee & 41.95 & $1,062.8$ & 0.041 & 0.0 & 79.2 & 16.9 & 3 & 8.5 & 40 & 117 \\
\hline Labatt & 111.04 & $1,849.7$ & 0.070 & 0.0 & 173.2 & 67.3 & 6 & 15.4 & 37 & 160 \\
\hline Samuel Adams & 153.27 & $1,602.3$ & 0.098 & 0.0 & 208.4 & 118.4 & 6 & 8.0 & 48 & 147 \\
\hline Rolling Rock & 49.63 & 724.3 & 0.071 & 1.1 & 238.2 & 80.4 & 2 & 3.1 & 49 & 68 \\
\hline
\end{tabular}

Brands are sorted in the descending order of revenue share. "Mn" stands for "Million" and "p.a." for per annum. 
Table 15. U.S. Metropolitan Markets - Characteristics (Essay 3)

\begin{tabular}{|c|c|c|c|c|}
\hline Market & $\begin{array}{c}\text { \# Brands } \\
\text { in the } \\
\text { Sample }\end{array}$ & $\begin{array}{c}\text { Income } \\
\text { (\$ p.a.) }\end{array}$ & Population & $\%$ Minority \\
\hline Albany & 15 & 28,067 & 850,506 & $11 \%$ \\
\hline Atlanta & 18 & 28,380 & $5,122,275$ & $40 \%$ \\
\hline Baltimore & 13 & 31,304 & $2,660,496$ & $32 \%$ \\
\hline Birmingham & 18 & 25,500 & $1,098,834$ & $31 \%$ \\
\hline Boston & 17 & 34,563 & $4,467,781$ & $15 \%$ \\
\hline Buffallo & 17 & 24,722 & $1,134,280$ & $16 \%$ \\
\hline Charlotte & 18 & 28,004 & $1,586,202$ & $32 \%$ \\
\hline Chicago & 18 & 29,204 & $9,463,477$ & $38 \%$ \\
\hline Cincinnati & 18 & 26,510 & $2,118,212$ & $14 \%$ \\
\hline Cleveland & 18 & 25,918 & $2,106,901$ & $24 \%$ \\
\hline Columbus & 18 & 26,910 & $1,734,721$ & $18 \%$ \\
\hline Dallas & 16 & 27,042 & $5,979,240$ & $41 \%$ \\
\hline Denver & 17 & 30,549 & $2,413,844$ & $28 \%$ \\
\hline Desmoines & 17 & 28,378 & 535,598 & $10 \%$ \\
\hline Detroit & 18 & 27,343 & $4,488,815$ & $27 \%$ \\
\hline Grand Rapids & 18 & 23,750 & 772,963 & $16 \%$ \\
\hline Hartford & 15 & 32,358 & $1,185,150$ & $22 \%$ \\
\hline Houston & 17 & 28,033 & $1,276,534$ & $8 \%$ \\
\hline Indianapolis & 18 & 25,862 & $5,485,720$ & $50 \%$ \\
\hline Jacksonville & 18 & 27,365 & $1,670,070$ & $20 \%$ \\
\hline Kansas & 18 & 26,898 & $1,276,323$ & $28 \%$ \\
\hline Las Vegas & 17 & 27,425 & $1,962,412$ & $20 \%$ \\
\hline Louisville & 18 & 27,027 & $1,774,086$ & $38 \%$ \\
\hline Memphis & 17 & 24,802 & $1,220,992$ & $16 \%$ \\
\hline Miami & 17 & 23,775 & $1,269,637$ & $49 \%$ \\
\hline
\end{tabular}

\begin{tabular}{ccccc}
\hline Market & $\begin{array}{c}\text { \# Brands } \\
\text { in the } \\
\text { Sample }\end{array}$ & $\begin{array}{c}\text { Income } \\
\text { (\$ p.a.) }\end{array}$ & Population & \%Minority \\
\hline Milwaukee & 18 & 26,596 & $5,404,990$ & $21 \%$ \\
Minneapolis & 17 & 27,460 & $1,539,985$ & $25 \%$ \\
Nashville & 17 & 31,848 & $3,172,801$ & $12 \%$ \\
New Orleans & 18 & 26,821 & $1,486,442$ & $64 \%$ \\
New York City & 18 & 29,791 & $18,785,319$ & $40 \%$ \\
Honolulu & 15 & 32,772 & $1,110,265$ & $40 \%$ \\
Oklahoma City & 13 & 24,075 & $1,175,167$ & $21 \%$ \\
Omaha & 18 & 26,314 & 820,725 & $15 \%$ \\
Orland & 18 & 25,807 & $1,990,388$ & $38 \%$ \\
Phoenix & 18 & 26,132 & $4,036,744$ & $34 \%$ \\
Pittsburgh & 17 & 25,672 & $2,364,622$ & $10 \%$ \\
Portlaand & 17 & 27,999 & $2,133,931$ & $13 \%$ \\
Raleigh & 17 & 29,332 & $1,001,313$ & $29 \%$ \\
Richmond & 18 & 28,308 & $1,194,021$ & $35 \%$ \\
Sacramento & 17 & 28,304 & $2,063,900$ & $26 \%$ \\
Salt Lake City & 18 & 26,960 & $2,790,203$ & $21 \%$ \\
San Antonio & 17 & 23,988 & $1,075,530$ & $16 \%$ \\
San Diego & 17 & 22,238 & $1,936,735$ & $59 \%$ \\
San Francisco & 16 & 29,685 & $2,954,960$ & $36 \%$ \\
Seattle & 17 & 38,065 & $4,171,627$ & $30 \%$ \\
St.Louis & 18 & 32,753 & $3,259,078$ & $14 \%$ \\
Syracuse & 17 & 24,302 & 646,597 & $11 \%$ \\
Tampa & 18 & 26,518 & $2,687,027$ & $25 \%$ \\
Washington DC & 17 & 39,840 & $5,263,322$ & $39 \%$ \\
\hline Mean & 17.1 & 27,863 & $2,790,220$ & $27 \%$ \\
\hline & & & &
\end{tabular}

"\# Brands" denotes "Number of Brands". 
Table 16. Main Effects Summary (Essay 3)

\begin{tabular}{|c|c|c|c|c|c|c|}
\hline $\begin{array}{c}\text { Revenue } \\
\text { component }\end{array}$ & Variable & Mean & Std Dev & Minimum & Maximum & $\begin{array}{l}\text { \# Significant } \\
\text { at } 95 \% \mathrm{HPD}\end{array}$ \\
\hline & Intercept & 3.87 & 1.22 & -0.72 & 8.12 & 48 \\
\hline Product & Craft & 0.21 & 0.33 & -0.60 & 1.18 & 7 \\
\hline \multirow{4}{*}{ Beer Type } & Regular & -0.15 & 0.25 & -0.72 & 0.38 & 6 \\
\hline & Light & 0.03 & 0.22 & -0.45 & 0.44 & 3 \\
\hline & Ice & \multicolumn{5}{|c|}{ Reference Attribute } \\
\hline & Dry & -0.07 & 0.75 & -1.14 & 1.46 & 1 \\
\hline & $\overline{\text { Bottle }}$ & \multicolumn{5}{|c|}{ Reference Attribute } \\
\hline \multirow{6}{*}{ Packaging } & Can & 0.14 & 0.15 & -0.22 & 0.56 & 16 \\
\hline & SmallPack & 0.31 & 0.54 & -1.34 & 1.25 & 16 \\
\hline & 6 Pack 12 oz & 0.81 & 0.47 & -0.29 & 1.75 & 37 \\
\hline & 6 Pack Other oz & 0.54 & 0.59 & -0.83 & 1.67 & 26 \\
\hline & 12 Pack & 1.40 & 0.42 & 0.31 & 2.20 & 47 \\
\hline & Case & 1.80 & 0.46 & 0.66 & 2.72 & 49 \\
\hline \multirow{4}{*}{$\begin{array}{c}\text { Variance } \\
\text { Components }\end{array}$} & Brand Variance Component $\lambda_{\mathrm{m}}$ & 0.36 & 0.15 & 0.09 & 0.69 & 49 \\
\hline & Variant Variance Component $\xi_{\mathrm{mv}}$ & 0.08 & 0.06 & 0.01 & 0.24 & 49 \\
\hline & SKU Variance Component $\eta_{\mathrm{mj}}$ & 0.45 & 0.13 & 0.23 & 0.85 & 49 \\
\hline & IID Measurement Error $\mathrm{u}_{\mathrm{mjt}}$ & 0.08 & 0.03 & 0.04 & 0.16 & 49 \\
\hline \multirow{3}{*}{ Promotion } & Ln AdSpend & 0.03 & 0.02 & -0.02 & 0.08 & 34 \\
\hline & Competition & -0.06 & 0.41 & -1.34 & 1.28 & 17 \\
\hline & Ln \$MnACV Merchandizing & 0.06 & 0.03 & 0.02 & 0.16 & 49 \\
\hline \multirow{2}{*}{ Distribution } & Ln \$MnACV Distribution & 0.97 & 0.12 & 0.65 & 1.17 & 49 \\
\hline & Ln Vt SKUNUM & 0.26 & 0.12 & -0.11 & 0.47 & 38 \\
\hline \multirow{6}{*}{$\begin{array}{l}\text { Category } \\
\text { Drivers }\end{array}$} & Quarter1 $1_{t}$ & -0.36 & 0.06 & -0.47 & -0.13 & 42 \\
\hline & Quarter $2_{t}$ & -0.19 & 0.07 & -0.47 & -0.01 & 44 \\
\hline & Quarter $3_{\mathrm{t}}$ & 0.11 & 0.08 & -0.07 & 0.27 & 46 \\
\hline & Quarter $4_{t}$ & \multicolumn{5}{|c|}{ Reference Quarter } \\
\hline & Year2005t & \multicolumn{5}{|c|}{ Reference Year } \\
\hline & Year2006 & -0.02 & 0.07 & -0.29 & 0.09 & 44 \\
\hline \multirow[t]{2}{*}{ Fit } & Log Marginal Density & -388.17 & 232.63 & -1056.00 & -35.47 & 49 \\
\hline & Avg Market BEM & 1.57 & 0.33 & 1.10 & 2.49 & 49 \\
\hline
\end{tabular}

'\#' stands for 'Number of, 'HPD' for Highest probability Density Interval.. 
Table 17. BEM Summary by Brand (Essay 3)

\begin{tabular}{|c|c|c|c|c|c|c|}
\hline (1) & (2) & (3) & (4) & (5) & (6) & (7) \\
\hline Brand & $\begin{array}{l}\text { Number } \\
\text { of Markets }\end{array}$ & $\begin{array}{l}\text { Mean } \\
\text { BEM }\end{array}$ & $\begin{array}{l}\text { St Dev } \\
\text { BEM }\end{array}$ & $\begin{array}{c}\text { Min } \\
\text { BEM }\end{array}$ & $\begin{array}{c}\text { Max } \\
\text { BEM }\end{array}$ & $\begin{array}{c}\text { Revenue } \\
\text { Dollar } \\
\text { Premium } \\
\text { (\$Mn p.a.) }\end{array}$ \\
\hline Budweiser & 49 & 1.482 & 0.41 & 1.018 & 2.924 & 440.75 \\
\hline Miller & 49 & 1.377 & 0.34 & 1.014 & 2.262 & 192.33 \\
\hline Coors & 49 & 1.228 & 0.19 & 1.016 & 2.025 & 76.38 \\
\hline Natural & 49 & 1.548 & 0.46 & 1.023 & 2.674 & 78.32 \\
\hline Corona & 49 & 2.107 & 1.26 & 1.027 & 7.829 & 188.07 \\
\hline Busch & 48 & 1.424 & 0.45 & 1.020 & 3.824 & 65.18 \\
\hline Heineken & 49 & 1.900 & 1.57 & 1.026 & 11.800 & 119.07 \\
\hline Keystone & 47 & 1.385 & 0.35 & 1.021 & 2.840 & 18.1 \\
\hline Michelob & 49 & 1.321 & 0.27 & 1.017 & 2.086 & 57.9 \\
\hline Milwaukee's Best & 49 & 1.719 & 0.72 & 1.020 & 4.993 & 50.38 \\
\hline Icehouse & 44 & 1.312 & 0.33 & 1.023 & 2.768 & 8.75 \\
\hline Modelo Especial & 47 & 1.271 & 0.37 & 1.030 & 3.443 & 9.14 \\
\hline Pabst & 47 & 1.579 & 0.67 & 1.022 & 4.330 & 11.45 \\
\hline Tecate & 41 & 1.238 & 0.19 & 1.029 & 2.217 & 7.03 \\
\hline Old Milwaukee & 40 & 1.590 & 0.60 & 1.025 & 3.591 & 7.78 \\
\hline Labatt & 37 & 1.390 & 0.39 & 1.021 & 2.277 & 15.57 \\
\hline Samuel Adams & 48 & 1.529 & 0.52 & 1.025 & 3.502 & 26.53 \\
\hline Rolling Rock & 49 & 1.517 & 0.46 & 1.020 & 3.697 & 8.46 \\
\hline Mean & 46.7 & 1.495 & 0.53 & 1.02 & 3.84 & 76.73 \\
\hline
\end{tabular}

Brands sorted in descending order by revenue share. 
Table 18. BEM Summary by Market (Essay 3)

\begin{tabular}{|c|c|c|c|c|c|c|c|c|c|}
\hline \multirow{2}{*}{ Market } & \multicolumn{4}{|c|}{ BEM statistics } & \multirow{2}{*}{ Market } & \multicolumn{4}{|c|}{ BEM statistics } \\
\hline & Mean & StDev & Min & $\operatorname{Max}$ & & Mean & StDev & Min & Max \\
\hline Albany & 1.198 & 0.180 & 1.054 & 1.736 & Milwaukee & 1.156 & 0.057 & 1.048 & 1.257 \\
\hline Atlanta & 1.340 & 0.196 & 1.136 & 1.859 & Minneapolis & 1.048 & 0.018 & 1.026 & 1.100 \\
\hline Baltimore & 1.790 & 0.449 & 1.196 & 2.567 & Nashville & 1.595 & 0.416 & 1.148 & 2.920 \\
\hline Birmingham & 1.660 & 0.391 & 1.255 & 2.367 & New Orleans & 1.836 & 0.486 & 1.243 & 3.105 \\
\hline Boston & 1.330 & 0.282 & 1.095 & 2.153 & Honolulu & 1.186 & 0.216 & 1.054 & 1.985 \\
\hline Buffallo & 1.075 & 0.005 & 1.068 & 1.085 & NYC & 3.733 & 2.757 & 1.423 & 11.800 \\
\hline Charlotte & 1.738 & 0.492 & 1.184 & 3.143 & Oklahoma City & 1.817 & 0.613 & 1.293 & 3.556 \\
\hline Chicago & 1.193 & 0.109 & 1.066 & 1.461 & Omaha & 1.414 & 0.287 & 1.132 & 2.117 \\
\hline Cincinnati & 1.081 & 0.010 & 1.070 & 1.110 & Orlando & 1.587 & 0.337 & 1.228 & 2.272 \\
\hline Cleveland & 1.076 & 0.004 & 1.069 & 1.088 & Phoenix & 1.621 & 0.350 & 1.202 & 2.316 \\
\hline Columbus & 1.081 & 0.005 & 1.071 & 1.090 & Pittsburgh & 1.179 & 0.064 & 1.028 & 1.261 \\
\hline Dallas & 1.808 & 0.424 & 1.356 & 2.674 & Portland & 1.413 & 0.217 & 1.071 & 1.808 \\
\hline Denver & 1.716 & 0.656 & 1.164 & 3.502 & Raleigh & 1.835 & 0.480 & 1.198 & 3.022 \\
\hline Desmoines & 1.320 & 0.176 & 1.117 & 1.680 & Richmond & 1.913 & 0.947 & 1.168 & 5.421 \\
\hline Detroit & 1.033 & 0.006 & 1.022 & 1.041 & Sacramento & 1.832 & 0.624 & 1.228 & 3.824 \\
\hline Grand Rapids & 1.245 & 0.138 & 1.076 & 1.664 & Salt Lake City & 1.956 & 0.622 & 1.255 & 3.169 \\
\hline Hartford & 1.021 & 0.004 & 1.014 & 1.027 & San Antonio & 1.559 & 0.555 & 1.227 & 3.591 \\
\hline Houston & 1.756 & 0.503 & 1.159 & 3.061 & San Diego & 1.913 & 0.600 & 1.301 & 3.429 \\
\hline Indianapolis & 1.414 & 0.707 & 1.093 & 4.081 & San Francisco & 1.435 & 0.225 & 1.130 & 1.977 \\
\hline Jacksonville & 1.480 & 0.219 & 1.121 & 1.875 & Seattle & 1.545 & 0.346 & 1.123 & 2.335 \\
\hline Kansas & 1.278 & 0.129 & 1.077 & 1.477 & St.Louis & 1.110 & 0.050 & 1.056 & 1.215 \\
\hline Las Vegas & 1.780 & 0.461 & 1.256 & 2.784 & Syracuse & 1.254 & 0.159 & 1.087 & 1.610 \\
\hline Louisville & 1.100 & 0.042 & 1.046 & 1.208 & Tampa & 2.065 & 0.788 & 1.295 & 4.515 \\
\hline Memphis & 1.480 & 0.291 & 1.128 & 2.078 & Washington DC & 1.744 & 0.616 & 1.188 & 3.226 \\
\hline Miami & 1.567 & 0.587 & 1.132 & 3.521 & Mean & 1.516 & 0.373 & 1.146 & 2.534 \\
\hline
\end{tabular}


Table 19. OLS Analysis of Pooled BEMs (Essay 3)

\begin{tabular}{lccc}
\hline Variable & Parameter & Std Error & P-value \\
\hline Intercept & 2.144 & 0.445 & $<.0001$ \\
Brand Age & 0.002 & 0.002 & 0.375 \\
BrandAge & 0.000 & 0.000 & 0.278 \\
Income & -0.025 & 0.011 & 0.027 \\
Population & 0.080 & 0.010 & $<.0001$ \\
OriginDistance & 0.001 & 0.030 & 0.971 \\
\%Minority & 0.082 & 0.257 & 0.749 \\
\hline Adj R-square & 0.1042 & & \\
\# Observations & 840 & & \\
\hline
\end{tabular}

Variables in Bold font are significant at the 95\% confidence level. 
Table 20. Spatial Association Test Results (Essay 3)

\begin{tabular}{lcccc}
\hline \multirow{2}{*}{ Brand } & \multicolumn{2}{c}{ Moran's I } & \multicolumn{2}{c}{ Geary's C } \\
& Statistic & P-value & Statistic & P-value \\
\hline Budweiser & $\mathbf{3 . 5 5}$ & 0.0002 & $\mathbf{- 5 . 4 2}$ & 0.0000 \\
Miller & $\mathbf{3 . 7 9}$ & 0.0001 & $\mathbf{- 4 . 9 1}$ & 0.0000 \\
Coors & $\mathbf{2 . 4 6}$ & 0.0069 & $\mathbf{- 4 . 3 0}$ & 0.0000 \\
Natural & $\mathbf{2 . 3 2}$ & 0.0103 & $\mathbf{- 4 . 1 0}$ & 0.0000 \\
Corona & $\mathbf{1 . 4 3}$ & 0.0761 & $\mathbf{- 2 . 7 8}$ & 0.0027 \\
Busch & $\mathbf{1 . 5 0}$ & 0.0671 & -0.07 & 0.4709 \\
Heineken & $\mathbf{2 . 8 7}$ & 0.0020 & $\mathbf{1 . 5 2}$ & 0.9352 \\
Keystone & -0.32 & 0.6272 & $\mathbf{- 1 . 8 9}$ & 0.0291 \\
Michelob & -1.14 & 0.8726 & $\mathbf{- 0 . 5 9}$ & 0.2766 \\
Milwaukee's Best & $\mathbf{1 . 3 6}$ & 0.0880 & $\mathbf{- 1 . 3 3}$ & 0.0910 \\
Icehouse & -1.31 & 0.9048 & 1.49 & 0.9325 \\
Modelo Especial & $\mathbf{1 . 3 2}$ & 0.0973 & $\mathbf{- 3 . 0 1}$ & 0.0013 \\
Pabst & -0.97 & 0.8349 & $\mathbf{- 0 . 1 3}$ & 0.4500 \\
Tecate & $\mathbf{1 . 3 6}$ & 0.0874 & $\mathbf{- 2 . 4 6}$ & 0.0070 \\
Old Milwaukee & 0.78 & 0.2168 & $\mathbf{- 2 . 0 0}$ & 0.0226 \\
Labatt & -0.42 & 0.6637 & -0.71 & 0.2389 \\
Samuel Adams & $\mathbf{2 . 3 4}$ & 0.0097 & $\mathbf{- 3 . 2 3}$ & 0.0006 \\
Rolling Rock & -0.99 & 0.8384 & 0.40 & 0.6571 \\
\hline
\end{tabular}

Figures in bold indicate statistical significance at the $90 \%$ level. 
Table 21. BEM Simple OLS Model Results Summary (Essay 3)

The bold font denotes significance at the $95 \%$ confidence level.

\begin{tabular}{lccccc}
\hline \multicolumn{1}{c}{$(1)$} & $(2)$ & $(3)$ & $(4)$ & $(5)$ & $(6)$ \\
\hline Brand & $\begin{array}{c}\text { Mean } \\
\text { Squared } \\
\text { Error }\end{array}$ & Intercept & \%Minority & Income & $\begin{array}{c}\text { Number of } \\
\text { Observations }\end{array}$ \\
\hline Budweiser & $\mathbf{0 . 1 8 4}$ & $\mathbf{1 . 1 4}$ & 0.09 & 0.01 & 49 \\
Miller & $\mathbf{0 . 1 1 3}$ & 0.92 & 0.75 & 0.01 & 49 \\
Coors & $\mathbf{0 . 0 3 9}$ & $\mathbf{0 . 8 6}$ & 0.31 & 0.01 & 49 \\
Natural & $\mathbf{0 . 2 2 3}$ & 0.98 & 0.46 & 0.02 & 49 \\
Corona & $\mathbf{1 . 5 6 9}$ & 0.06 & 1.94 & 0.05 & 49 \\
Busch & $\mathbf{0 . 2 2 1}$ & $\mathbf{1 . 1 8}$ & -0.09 & 0.01 & 48 \\
Heineken & $\mathbf{2 . 2 6 2}$ & -2.00 & 3.42 & 0.11 & 49 \\
Keystone & $\mathbf{0 . 1 2 9}$ & 0.80 & 0.32 & 0.02 & 47 \\
Michelob & $\mathbf{0 . 0 8 1}$ & $\mathbf{1 . 0 0}$ & 0.27 & 0.01 & 49 \\
Milwaukee's Best & $\mathbf{0 . 5 3 5}$ & 0.95 & 1.07 & 0.02 & 49 \\
Icehouse & $\mathbf{0 . 1 1 5}$ & $\mathbf{1 . 3 5}$ & 0.51 & -0.01 & 47 \\
Modelo Especial & $\mathbf{0 . 1 3 4}$ & 0.34 & 0.70 & 0.03 & 47 \\
Pabst & $\mathbf{0 . 4 2 8}$ & 0.10 & 1.45 & 0.04 & 41 \\
Tecate & $\mathbf{0 . 0 4 0}$ & $\mathbf{0 . 9 0}$ & 0.21 & 0.01 & 40 \\
Old Milwaukee & $\mathbf{0 . 3 9 2}$ & 2.06 & 0.09 & -0.02 & 37 \\
Labatt & $\mathbf{0 . 1 6 3}$ & 0.59 & -0.05 & 0.03 & 48 \\
Samuel Adams & $\mathbf{0 . 2 4 8}$ & -0.12 & 0.98 & 0.05 & 49 \\
Rolling Rock & $\mathbf{0 . 2 0 7}$ & 0.66 & 0.90 & & \\
\hline
\end{tabular}


Table 22. BEM Spatial GLS Model Results Summary (Essay 3)

The notation "E-10" in column $(8)$ denotes “ $* 10^{-10}$ ”. The bold font indicates significance at the $95 \%$ confidence level.

\begin{tabular}{|c|c|c|c|c|c|c|c|}
\hline (1) & (2) & (3) & (4) & (5) & (6) & (7) & (8) \\
\hline Brand & $\begin{array}{c}\text { Spatial } \\
\text { Autocorrelation } \\
\text { Parameter } \\
\phi(200 \text { miles })\end{array}$ & $\begin{array}{c}\text { Estimated } \\
\text { Variance } \\
\sigma^{2}\end{array}$ & Intercept & \%Minority & Income & $\begin{array}{c}\text { Number of } \\
\text { Observations }\end{array}$ & $\begin{array}{l}\text { Inter- } \\
\text { Iteration } \\
\text { Error }\end{array}$ \\
\hline Budweiser & 0.71 & 0.130 & 1.133 & 0.011 & 0.187 & 49 & $6.03 \mathrm{E}-10$ \\
\hline Miller & 0.88 & 0.067 & 1.397 & 0.072 & 0.049 & 49 & $2.16 \mathrm{E}-13$ \\
\hline Coors & 0.94 & 0.028 & 1.542 & -0.106 & -0.065 & 49 & $1.04 \mathrm{E}-13$ \\
\hline Natural & 0.35 & 0.196 & 1.012 & 0.430 & 0.152 & 49 & $1.03 \mathrm{E}-13$ \\
\hline Corona & 0.51 & 1.411 & 1.271 & 0.844 & 0.316 & 49 & $2.24 \mathrm{E}-06$ \\
\hline Busch & 0.59 & 0.194 & 2.916 & -1.117 & -0.442 & 48 & $4.57 \mathrm{E}-10$ \\
\hline Heineken & 0.44 & 2.243 & 5.520 & 2.082 & 1.540 & 49 & $5.16 \mathrm{E}-12$ \\
\hline Keystone & -0.71 & 0.072 & 1.033 & 0.755 & -0.178 & 47 & 7.43E-12 \\
\hline Michelob & -0.44 & 0.097 & 0.108 & 0.580 & 0.396 & 49 & $5.24 \mathrm{E}-13$ \\
\hline Milwaukee's Best & 0.16 & 0.506 & 1.231 & -0.669 & -0.226 & 49 & $3.31 \mathrm{E}-14$ \\
\hline Icehouse & -0.24 & 0.145 & 1.492 & 0.061 & -0.059 & 44 & $5.15 \mathrm{E}-13$ \\
\hline Modelo Especial & 0.33 & 0.154 & 1.501 & 0.035 & -0.054 & 47 & $2.88 \mathrm{E}-06$ \\
\hline Pabst & -0.52 & 0.436 & 1.831 & 1.139 & -0.213 & 47 & $5.45 \mathrm{E}-08$ \\
\hline Tecate & 0.63 & 0.040 & 1.154 & -0.055 & 0.065 & 41 & $1.24 \mathrm{E}-13$ \\
\hline Old Milwaukee & 0.10 & 0.289 & 2.201 & 1.490 & -0.086 & 40 & $9.06 \mathrm{E}-12$ \\
\hline Labatt & -0.46 & 0.154 & 2.302 & 0.089 & -0.325 & 37 & $4.57 \mathrm{E}-10$ \\
\hline Samuel Adams & 0.72 & 0.181 & 0.203 & -0.997 & 0.554 & 48 & $6.22 \mathrm{E}-14$ \\
\hline Rolling Rock & -0.97 & 0.205 & 1.958 & -0.538 & -0.096 & 49 & $2.44 \mathrm{E}-13$ \\
\hline
\end{tabular}


Table 23: Results for Experiment 1

$(\mathrm{Z} \sim$ Exponential $)$

\begin{tabular}{|c|c|c|c|c|c|c|c|c|c|}
\hline \multirow[b]{2}{*}{ Variable } & \multicolumn{3}{|c|}{ Model I } & \multicolumn{3}{|c|}{ Model II } & \multicolumn{3}{|c|}{ Model III } \\
\hline & True value & $\begin{array}{c}\text { MLE } \\
\text { (Std Dev) }\end{array}$ & $\begin{array}{c}\text { MCMC } \\
\text { (95\% HPD) }\end{array}$ & True value & $\begin{array}{c}\text { MLE } \\
\text { (Std Dev) }\end{array}$ & $\begin{array}{c}\text { MCMC } \\
\text { (95\% HPD) }\end{array}$ & True value & $\begin{array}{c}\text { MLE } \\
\text { (Std Dev) }\end{array}$ & $\begin{array}{c}\text { MCMC } \\
\text { (95\% HPD) }\end{array}$ \\
\hline Intercept & 20 & $\begin{array}{c}21.17 \\
(0.386)\end{array}$ & $\begin{array}{c}20.16 \\
(13.39,21.77)\end{array}$ & 20 & $\begin{array}{l}19.589 \\
(0.331)\end{array}$ & $\begin{array}{c}19.38 \\
(18.28,20.13)\end{array}$ & 20 & $\begin{array}{l}19.866 \\
(0.288)\end{array}$ & $\begin{array}{c}19.7 \\
(18.77,20.31)\end{array}$ \\
\hline $\mathrm{x}_{1}$ & 2 & $\begin{array}{c}1.832 \\
(0.182)\end{array}$ & $\begin{array}{c}1.834 \\
(1.478,2.19)\end{array}$ & 2 & $\begin{array}{c}2.151 \\
(0.130)\end{array}$ & $\begin{array}{c}2.153 \\
(1.90,2.41)\end{array}$ & 2 & $\begin{array}{c}1.909 \\
(0.093)\end{array}$ & $\begin{array}{c}1.908 \\
(1.73,2.09)\end{array}$ \\
\hline $\mathrm{x}_{2}$ & -3 & $\begin{array}{l}-3.187 \\
(0.166)\end{array}$ & $\begin{array}{c}-3.188 \\
(-3.51,-2.85)\end{array}$ & -3 & $\begin{array}{l}-3.01 \\
(0.12)\end{array}$ & $\begin{array}{c}-3.009 \\
(-3.24,-2.77)\end{array}$ & -3 & $\begin{array}{l}-2.892 \\
(0.084)\end{array}$ & $\begin{array}{c}-2.891 \\
(-3.06,-2.73)\end{array}$ \\
\hline$\sigma$ & 4 & $\begin{array}{c}3.924 \\
(0.045)\end{array}$ & $\begin{array}{c}3.929 \\
(3.81,4.05)\end{array}$ & 4 & $\begin{array}{c}4.007 \\
(0.032)\end{array}$ & $\begin{array}{c}4.01 \\
(3.93,4.10)\end{array}$ & 4 & $\begin{array}{c}3.983 \\
(0.023)\end{array}$ & $\begin{array}{c}3.984 \\
(3.92,4.05)\end{array}$ \\
\hline$\lambda$ & 0.3 & $\begin{array}{c}0.391 \\
(0.192)\end{array}$ & $\begin{array}{c}0.3294 \\
(0.07,0.75)\end{array}$ & 0.3 & $\begin{array}{c}0.276 \\
(0.070)\end{array}$ & $\begin{array}{c}0.264 \\
(0.12,0.46)\end{array}$ & 0.2 & $\begin{array}{c}0.154 \\
(0.019)\end{array}$ & $\begin{array}{c}0.1503 \\
(0.09,0.23)\end{array}$ \\
\hline Sample size & 2000 & 2000 & 2000 & 4000 & 4000 & 4000 & 8000 & 8000 & 8000 \\
\hline Number of Zs & 5 & 5 & 5 & 10 & 10 & 10 & 20 & 20 & 20 \\
\hline Range of Z & $(0.97,5.53)$ & $(0.22,4.71)$ & $(1.23,5.72)$ & $(0.2,9.2)$ & $(0.19,9.17)$ & $(0.39,9.37)$ & $(0.02,18.9)$ & $(0.19,19.19)$ & $(0.34,19.36)$ \\
\hline Mean of Z & 3.425 & 2.560 & 3.568 & 3.389 & 3.362 & 3.825 & 6.367 & 6.511 & 6.678 \\
\hline Std dev of $Z$ & 1.706 & 1.710 & 1.71 & 2.98 & 2.975 & 2.976 & 5.509 & 5.513 & 5.513 \\
\hline MSD in Z & 0 & 0.768 & 0.034 & 0 & 0.204 & 0.249 & 0 & 0.06 & 0.136 \\
\hline
\end{tabular}


Table 24: Results for Experiment 2

$(\mathrm{Z} \sim$ Uniform integer $)$

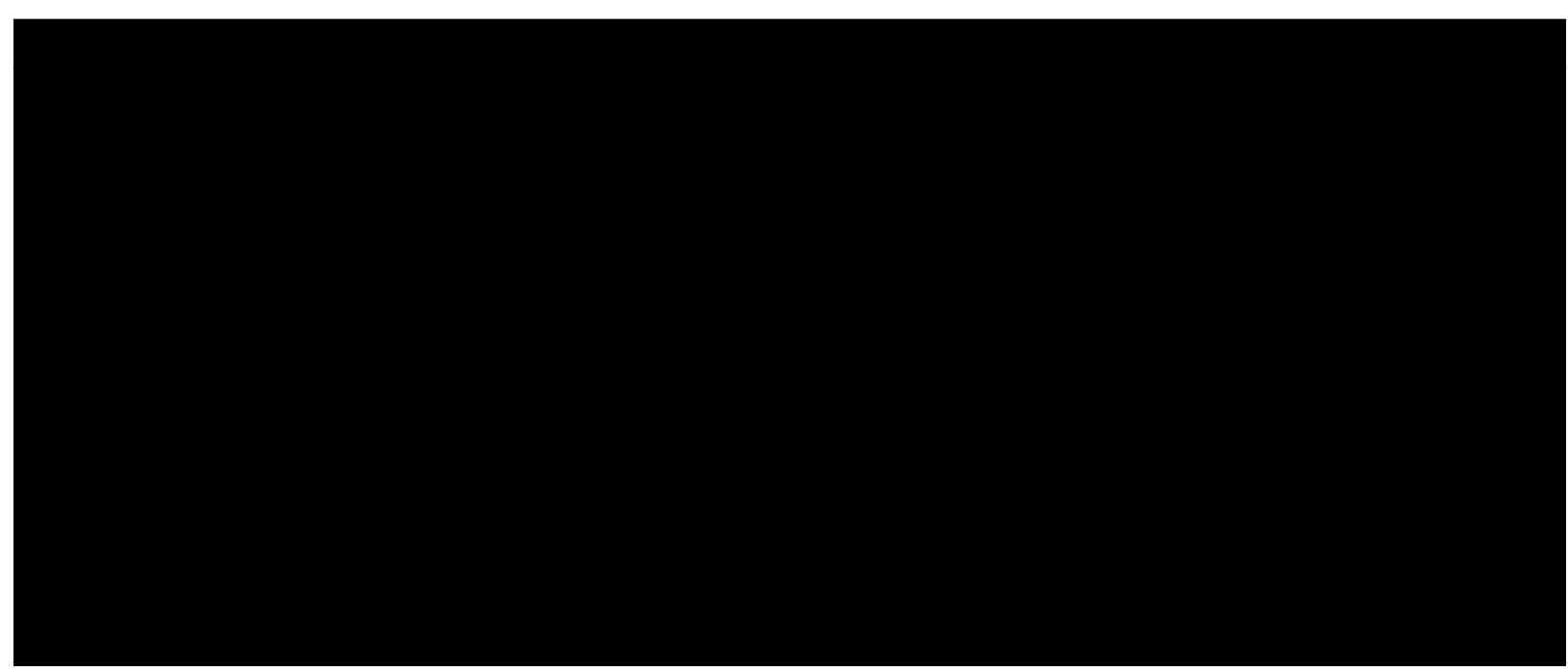


Table 25: Results for Experiment 3

$(\mathrm{Z} \sim$ Uniform integer, different distributions for estimating it) 
Table 26: Results for Experiment 4

$(Z \sim$ Uniform integer, $\operatorname{Min}(Z)=5$, different distributions for estimating it $)$ 
Figure 1. Price-BEM Relation for National and Private Labels (Essay 2)

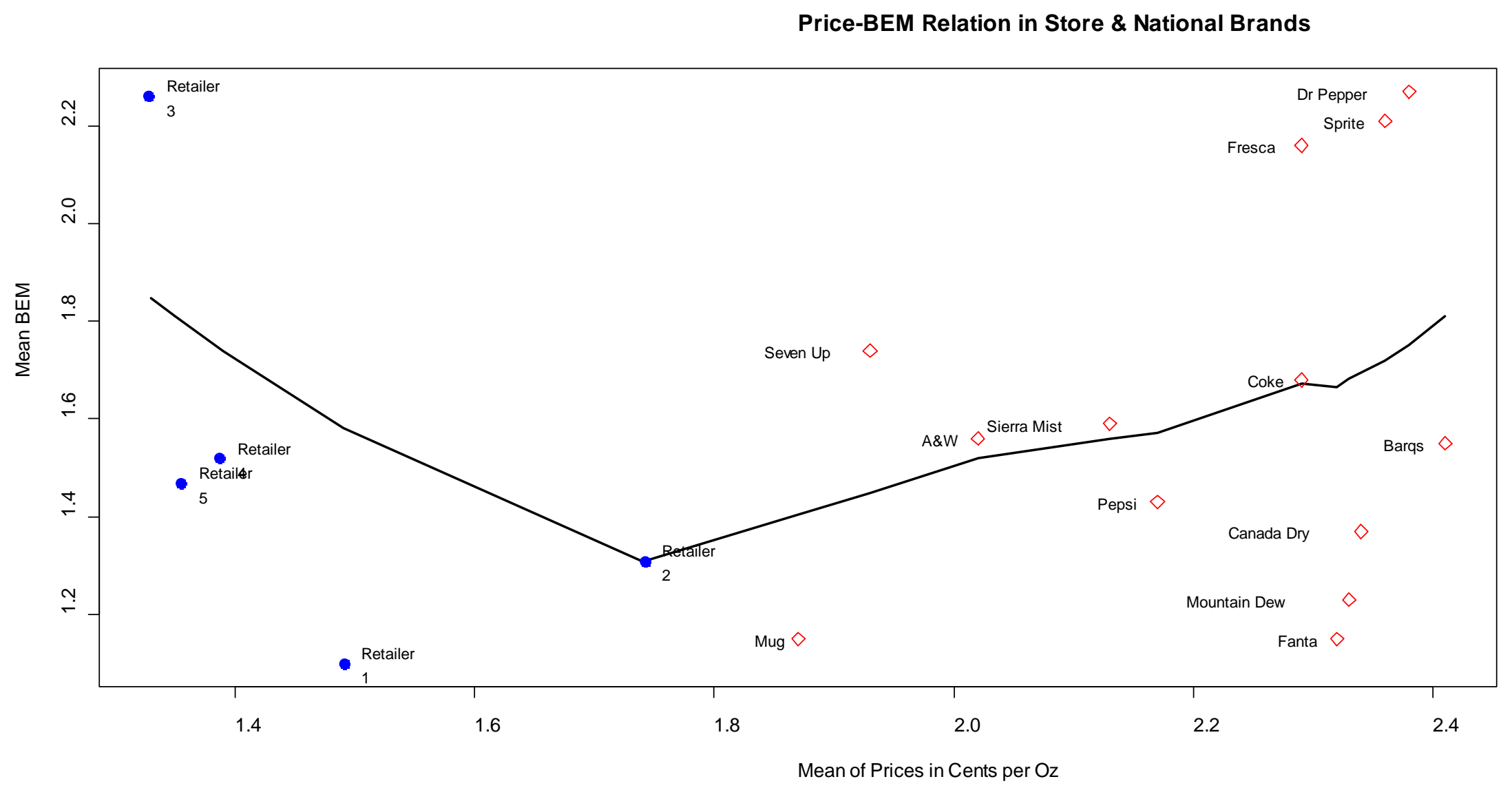


Figure 2. Box-Plots of the Coefficients of Packaging Variables (Essay 3)

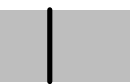


Figure 3. Box-Plots of the Coefficients of Promotion and Distribution Variables (Essay 3)

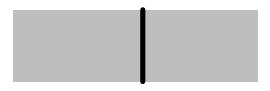


Figure 4. BEM Box-Plots for Six U.S. Regions (Essay 3)

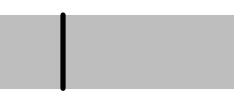


Figure 5. BEMs Box-Plots for Six Brands (Essay 3) 
Figure 6. BEM Distribution for the 4 Largest Brands by Market Share (Essay 3)
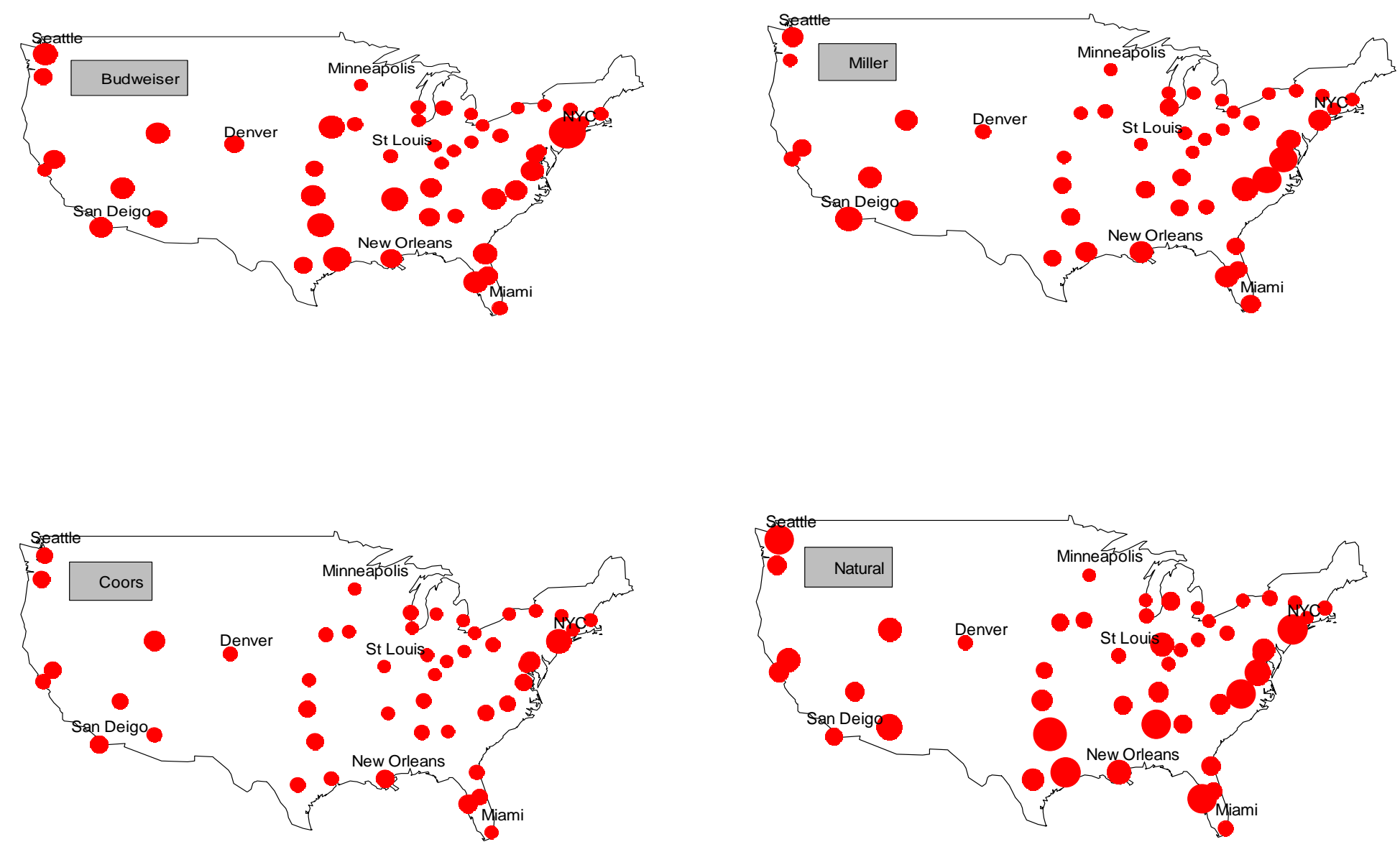
Figure 7. BEM Distribution for the Next 4 Largest Brands by Market Share (Essay 3)
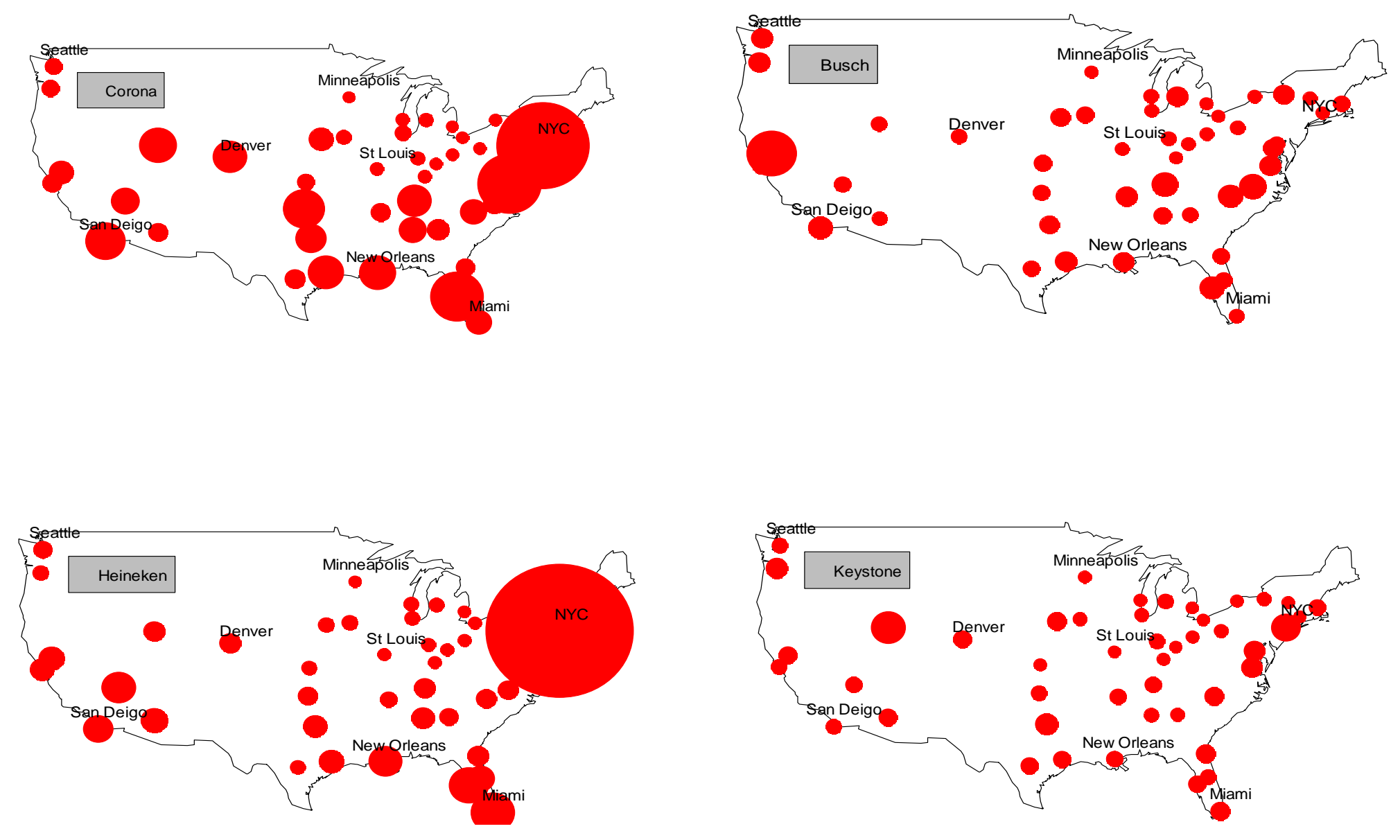
Figure 8. BEM Distribution for the 4 Smallest Brands by Market Share (Essay 3)
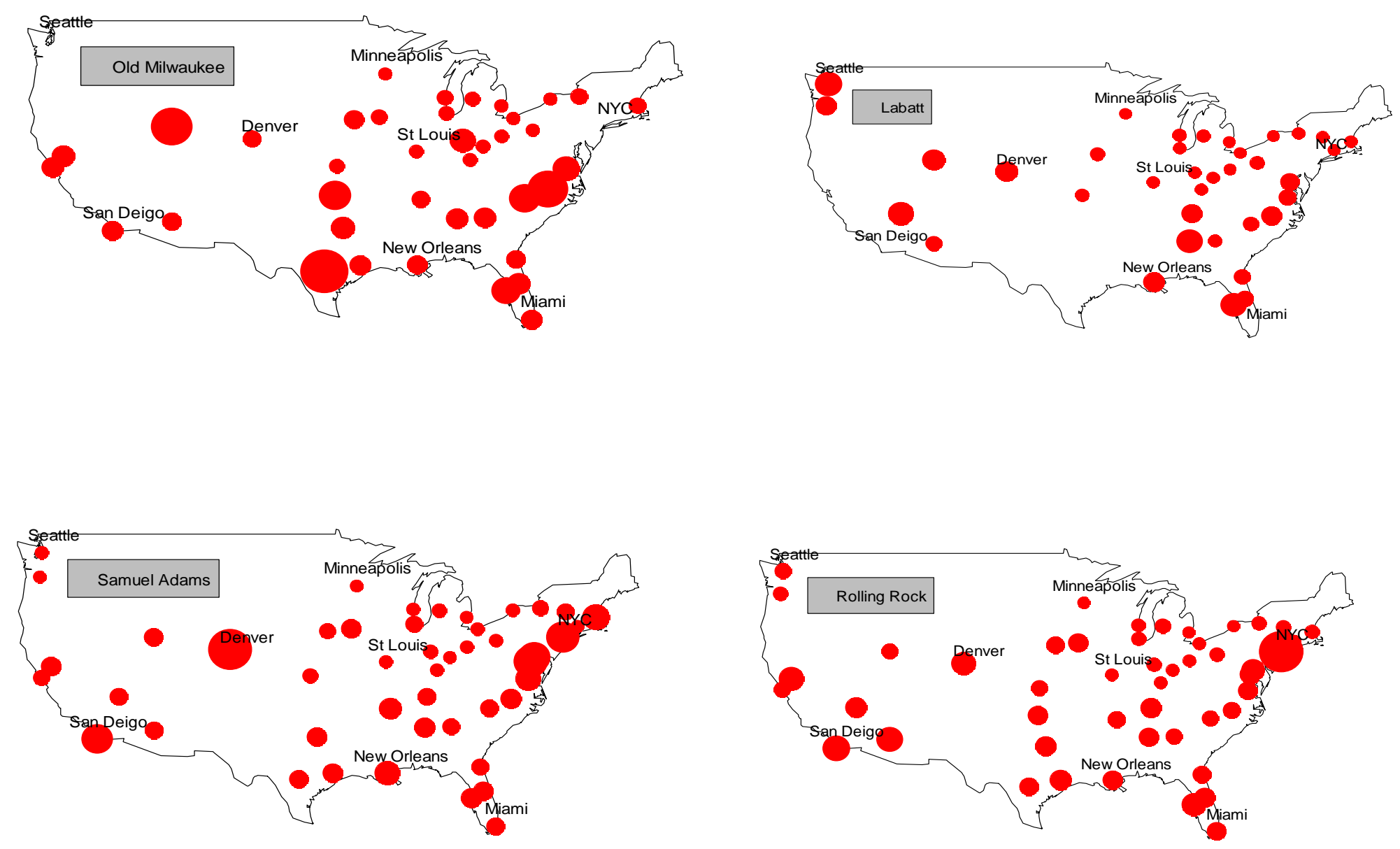
Figure 9: Variation in Model Fit against the Level of $Z$

Variation in Model fit with the Level of Z

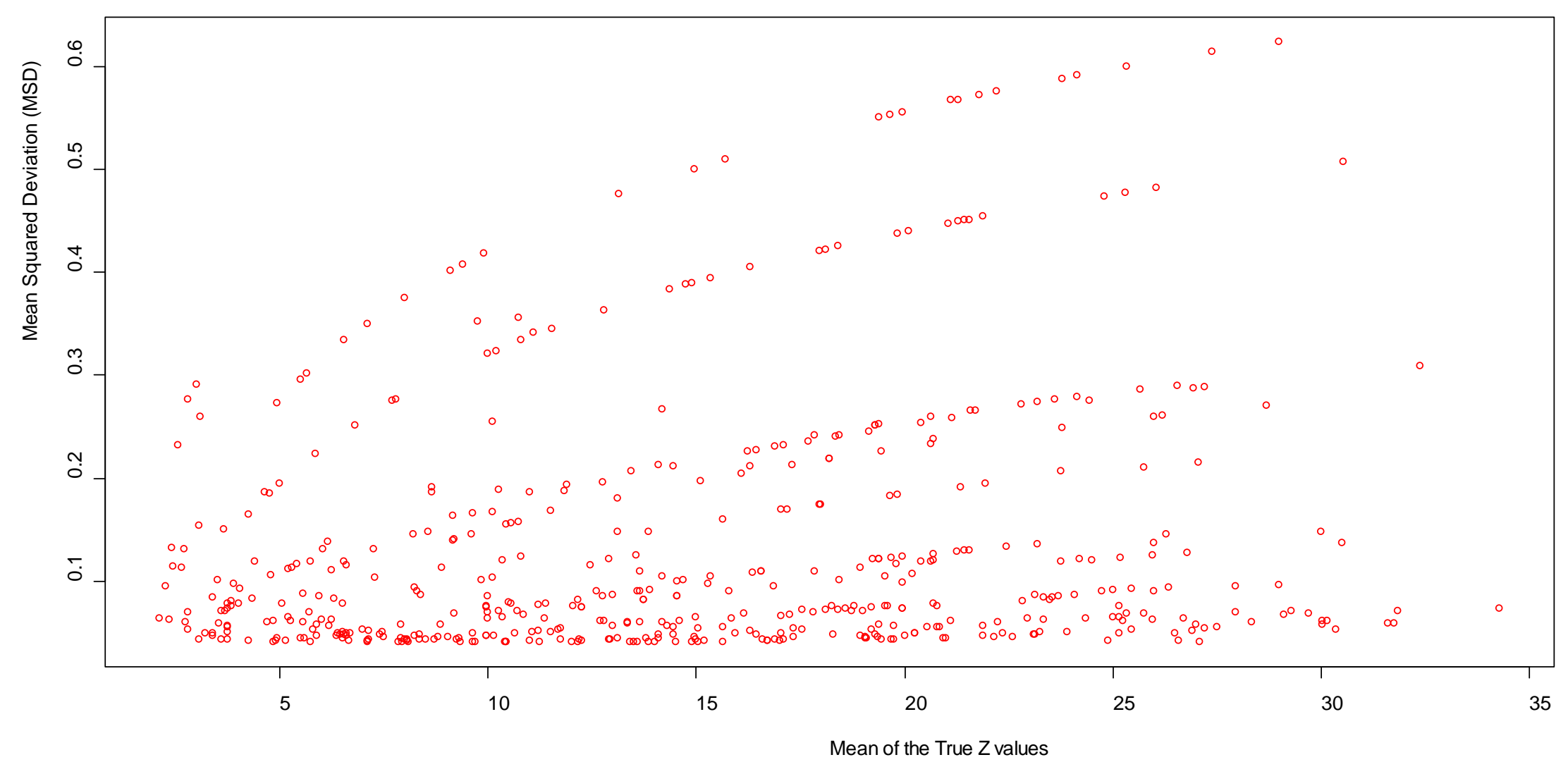


Figure 10: Variation in Model Fit against the Dispersion in $\mathrm{Z}$

Variation in Model fit with the Dispersion in Z

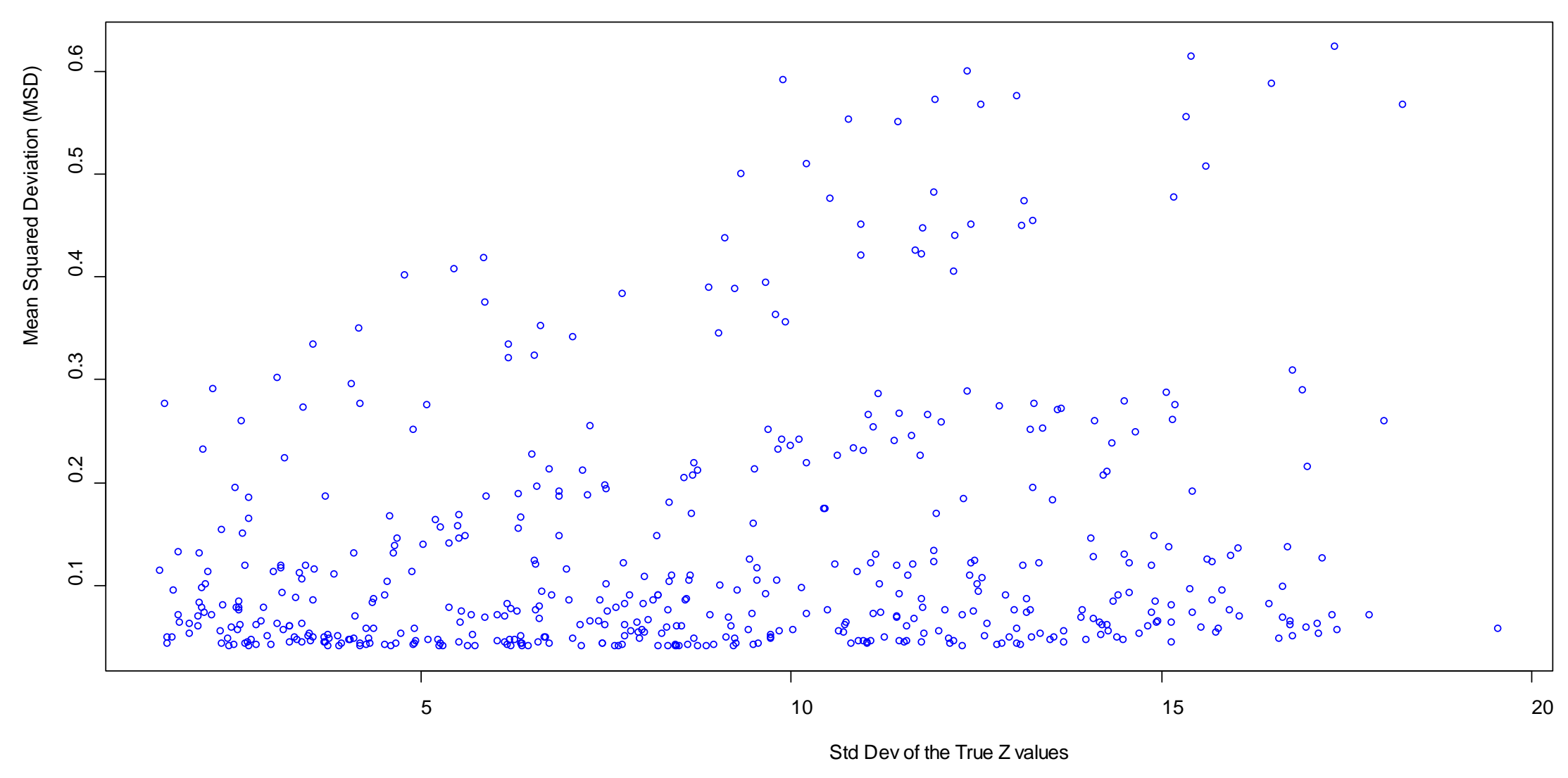


Figure 11: Recovery of Z Values under Different Distributional Assumptions

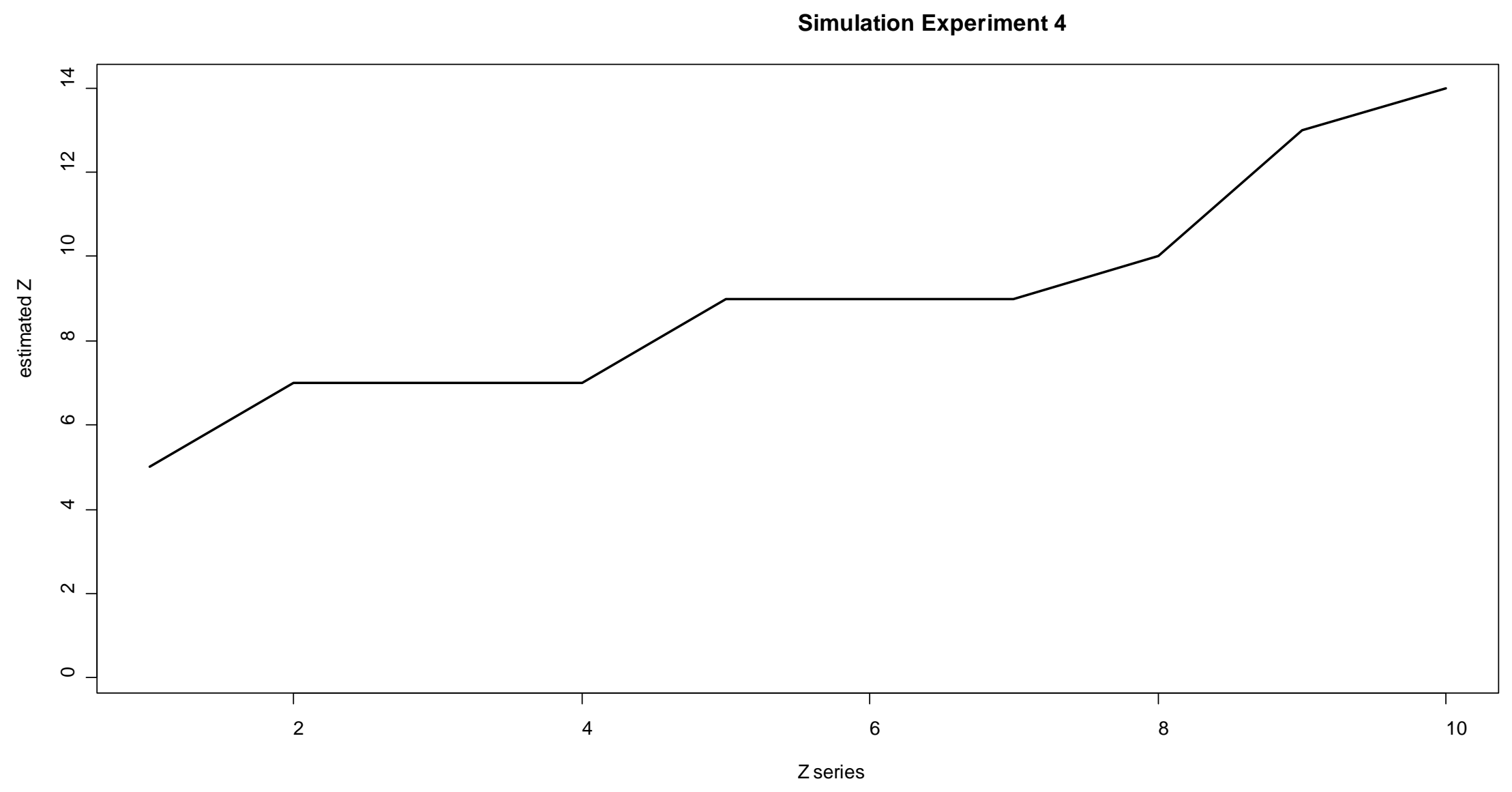

